
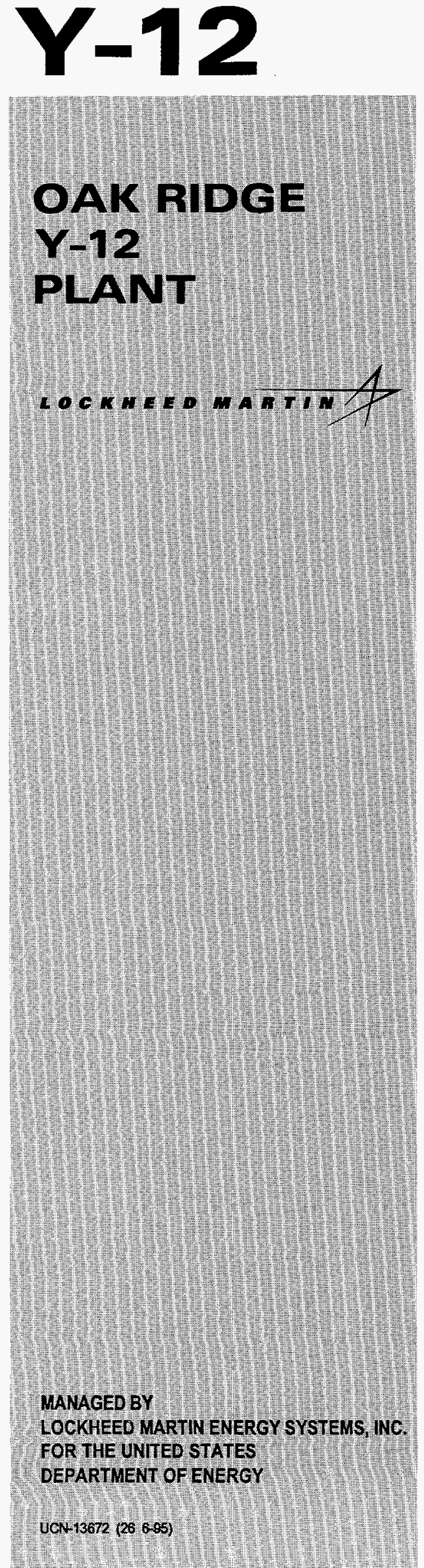

Q STI

\section{Monitoring Stresses on the PV-4 Isostatic Press from 1960 to 1997}

\author{
James A. Horak \\ Darrel C. Howard \\ Ronald E. Adamski \\ Donovan K. Kelley \\ J. Lanny Frazier
}

December 1998 


\section{DISCLAIMER}

This report was prepared as an account of work sponsored by an agency of the United States Government. Neither the United States Government nor any agency thereof, nor any of their employees, makes any warranty, express or implied, or assumes any legal liability or responsibility for the accuracy, completeness, or usefulness of any information, apparatus, product, or process disclosed, or represents that its use would not infringe privately owned rights. Reference herein to any specific commercial product, process, or service by trade name, trademark, manufacturer, or otherwise, does not necessarily constitute or imply its endorsement, recommendation, or favoring by the United States Government or any agency thereof. The views and opinions of authors expressed herein do not necessarily state or reflect those of the United States Government or any agency thereof. 


\section{DISCLAIMER}

Portions of this document may be illegible in electronic image products. Images are produced from the best available original document. 


\title{
Monitoring Stresses on the PV-4 Isostatic Press from 1960 to 1997
}

\author{
James A. Horak \\ Darrel C. Howard \\ Ronald E. Adamski \\ Donovan K. Kelley \\ J. Lanny Frazier
}

Date Published: December 1998

\author{
Prepared By \\ Y-12 Quality Services Organization \\ LOCKHEED MARTIN ENERGY SYSTEMS, INC. \\ Oak Ridge, TN 37831 \\ for the \\ U.S. DEPARTMENT OF ENERGY \\ under Contract DE-AC05-84OR21400
}





\section{CONTENTS}

LIST OF FIGURES $\ldots \ldots \ldots \ldots \ldots \ldots \ldots \ldots \ldots \ldots \ldots \ldots \ldots \ldots \ldots \ldots \ldots$

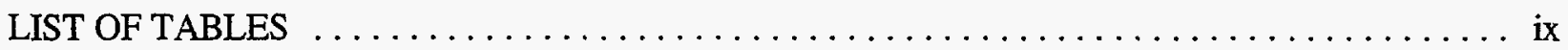

EXECUTTVE SUMMARY $\ldots \ldots \ldots \ldots \ldots \ldots \ldots \ldots \ldots \ldots \ldots \ldots \ldots \ldots \ldots \ldots \ldots \ldots$

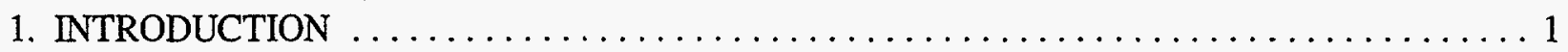

2. BACKGROUND AND STATUS $\ldots \ldots \ldots \ldots \ldots \ldots \ldots \ldots \ldots \ldots \ldots \ldots \ldots \ldots$

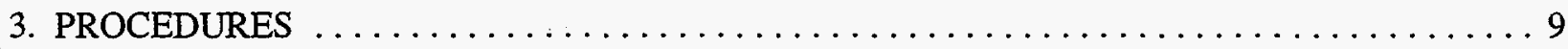

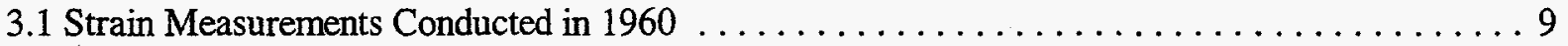

3.2 Strain Measurements Conducted from 1983 to $1998 \ldots \ldots \ldots \ldots \ldots \ldots \ldots \ldots$

4. RESULTS AND DISCUSSION . . . . . . . . . . . . . . . . . . . . . . . . 29

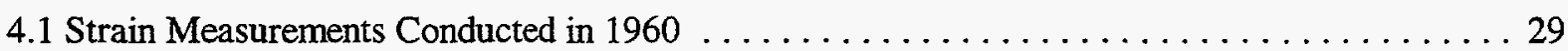

4.2 Strain Measurements Conducted from 1983 to the Present $\ldots \ldots \ldots \ldots \ldots \ldots \ldots \ldots 4$

4.3 Residual Stresses . . . . . . . . . . . . . . . . . . . . 76

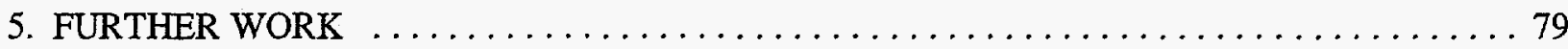

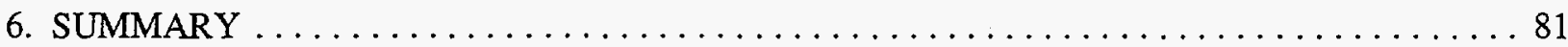

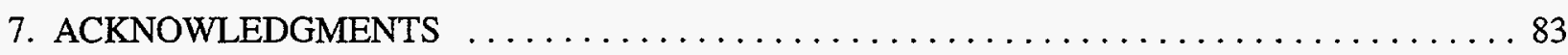

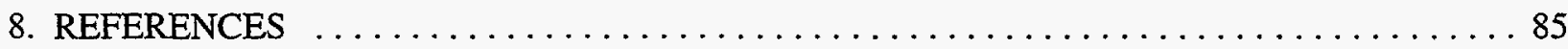

APPENDIX A PROCEDURES USED TO APPLY STRAIN GAUGE ROSETTES

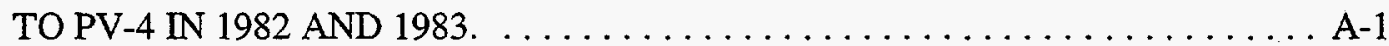

APPENDIX B STRESSES ON THE PV-4 FRAME AND PRESSURE VESSEL AT

AN INTERNAL PRESSURE OF 33 KSI ON SEPTEMBER 9, $1960 \ldots \ldots \ldots \ldots$. . . 1

APPENDIX C MANUFACTURER'S CERTIFIED CHEMICAL COMPOSITION AND

MECHANICAL PROPERTIES OF STEEL HEATS USED

IN CONSTRUCTION OF THE PV-4 ISOSTATIC PRESS $\ldots \ldots \ldots \ldots \ldots \ldots$ C-1 
APPENDIX D PLOTS OF STRAIN AS A FUNCTION OF INTERNAL PRESSURE FOR THE SEVEN STRAIN GAUGES AND LOCATIONS LISTED IN TABLE 4.2.4

AND THE COMPENSATOR GAUGES FOR MEASUREMENTS

CONDUCTED ON SEPTEMBER 8 AND 9, 1960.

D-1 


\section{LIST OF FIGURES}

2.1A Strain as a function of applied stress for a very high strength, low ductility metal

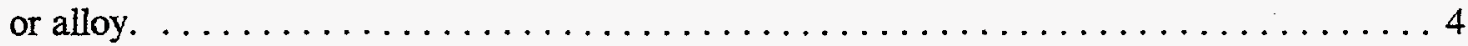

2.1B Strain as a function of applied stress for a low strength, very high ductility metal

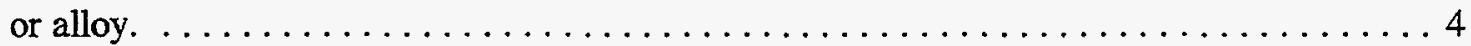

2.1C Strain as a function of applied stress for a high strength, moderately high ductility

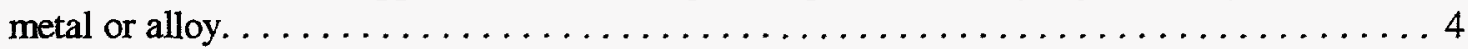

3.1.1 Locations of strain gauges on the left inside of the frame of PV-4 for tests conducted

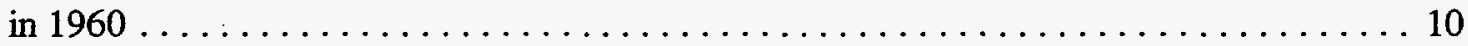

3.1.2 Locations of strain gauges on the right inside of the frame of PV-4 for tests conducted

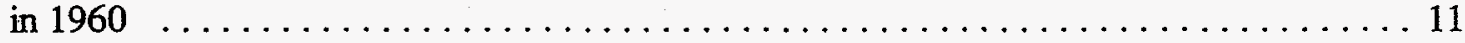

3.1.3 Location of strain gauges on the left outside and front of the frame of PV-4 for tests

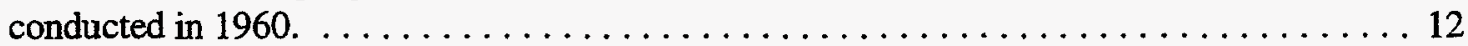

3.1.4 Locations of strain gauges on the right outside and front of the frame of PV-4 for tests

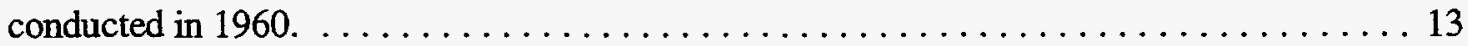

3.1.5 Locations of the strain gauges on the front of PV-4 for the tests conducted in $1960 \ldots \ldots 14$

3.1.6 Locations of the strain gauges on the back of PV-4 for the tests conducted in $1960 \ldots \ldots 15$

3.1.7 Locations of strain gauges on the outer surface of the PV-4 pressure vessel for tests

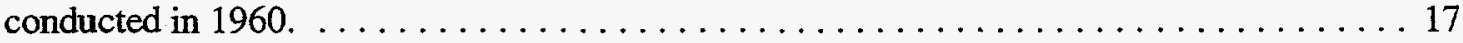

3.2.1 Schematic diagram showing locations of strain gauge rosettes applied in 1982 and 1983 on the left outside and front of the PV-4 frame. Strain gauges that were applied in 1960 that are at or near the 1982 and 1983 rosette locations are shown in parentheses.

3.2.2 Schematic diagram showing locations of strain gauge rosettes applied in 1982 and 1983 on the right outside and front of the PV-4 frame. Strain gauges that were applied in 1960 that are at or near the 1982 and 1983 rosette locations are shown

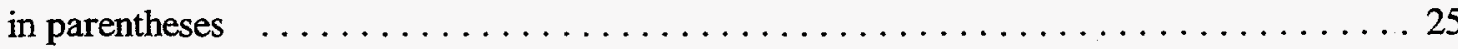

3.2.3 Schematic diagram showing locations of strain gauge rosettes applied in 1982 and 1983 on the front plate (\#1) of the PV-4 pressure vessel frame. Strain gauges that were applied in 1960 that are at or near the 1982 and 1983 rosette locations are shown in parentheses.

3.2.4 Schematic diagram showing locations of strain gauge rosettes applied in 1982 and 1983 on the back plate (\#12) of the PV-4 pressure vessel frame. Strain gauges that were applied in 1960 that are at or near the 1982 and 1983 rosette locations are shown in parentheses.

3.2.5 Schematic diagram showing locations of strain gauge rosettes applied in 1982 and 1983 on the surface of the PV-4 pressure vessel. Strain gauges that were applied in 1960 that are at or near rosette locations are shown in parentheses. Rosettes 32-35 were

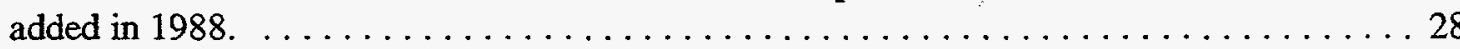

4.1.1 Stresses (ksi) on the left inside surface of the frame of PV-4 during operation at a nominal internal pressure of $30 \mathrm{ksi}$ on September 9, 1960. 
4.1.2 Stresses (ksi) on the right inside surface of the frame of PV-4 during operation at a

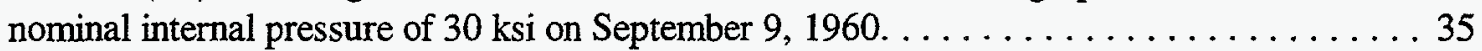

4.1.3 Average stresses (ksi) at inside faces, outside faces, and midway between these faces for PV-4 at an operating pressure of $30 \mathrm{ksi}$ on September $9,1960 . \ldots \ldots \ldots \ldots \ldots$

4.1.4 Stresses (ksi) on the front of the frame of PV-4 at a nominal internal pressure

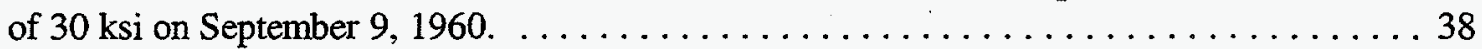

4.1.5 Stresses (ksi) on the back of the frame of PV-4 at a nominal internal pressure

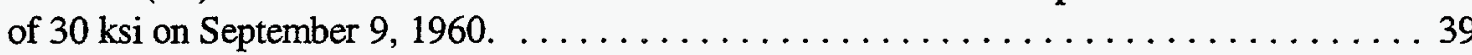

4.1.6 Stresses (ksi) measured for individual strain gauges on the outer surface of the PV-4 pressure vessel on September 9, 1960, at a nominal internal pressure of $30 \mathrm{ksi}$ in the working chamber . . . . . . . . . . . . . . . . . . . 41

4.1.7 Stresses (ksi) on the outer surface of the PV-4 pressure vessel calculated with the two-gauge rosette equations on September 9,1960, at a nominal internal pressure of $30 \mathrm{ksi}$ in the working chamber

4.2.1 Axial stresses (ksi) on the outside surfaces at the axial midplane of the front (\#1) and back (\#12) plates of PV-4 from September 9, 1960, to January 17, 1996, at a nominal internal pressure of $30 \mathrm{ksi}$. Gauges mounted in 1982 and 1983 are at the same locations as those mounted in 1960.

4.2.2 Axial stresses (ksi) on the left and right bottom of the back plate (\#12) of PV-4 near the intersection of the curved and linear portions of the frame from September 9, 1960 , to January 17,1996 , at a nominal internal pressure of $30 \mathrm{ksi}$. Gauges mounted in 1982 and 1983 are closer to the inside of the frame than those mounted in 1960.

4.2.3 Axial stresses (ksi) on the left and right bottom of the front plate (\#1) of PV-4 from September 9, 1960, to August 5, 1997, at a nominal internal pressure of $30 \mathrm{ksi}$. Gauges mounted in 1982 and 1983 are closer to the inside than those mounted in 1960 . . . 50

4.2.4 Axial stresses (ksi) on the left and right bottom of the front (\#1) and the back (\#12) plates of PV-4 near the intersection of the curved and linear portion of the frame from September 9,1960, to August 5, 1997, at a nominal internal pressure of $30 \mathrm{ksi}$. Gauges mounted in 1982 and 1983 are closer to the inside than those mounted

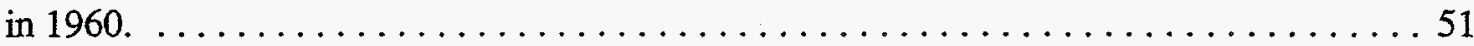

4.2.5 Axial stresses (ksi) on the left and right front (\#1) plate of PV-4 near the intersection of the curved and linear portion of the frame from September 9, 1960, to August 5, 1997, at a nominal internal pressure of $30 \mathrm{ksi}$. Gauges mounted in 1982 and 1983 are $13 \mathrm{in}$. closer to the inside than those mounted in 1960.

4.2.6 Circumferential stresses (ksi) on the surface of the PV-4 pressure vessel 4 in. from the top of the vessel from September 9, 1960, to August 5, 1997, at a nominal internal pressure of $30 \mathrm{ksi}$. (a) at $0^{\circ}$, (b) at $180^{\circ}$, and (c) at 0 and $180^{\circ}$.

4.2.7 Circumferential stresses (ksi) on the surface of the PV-4 pressure vessel $21 \mathrm{in}$. from the top of the vessel from September 9, 1960, to August 5, 1997, at a nominal internal pressure of $30 \mathrm{ksi}$. (a) at $0^{\circ}$, (b) at $180^{\circ}$, (c) at $270^{\circ}$, and (d) at $0^{\circ}, 90^{\circ}, 180^{\circ}$, and $270^{\circ}$.

4.2.8 Circumferential stresses (ksi) on the surface of the PV-4 pressure vessel 21 in. from the top of the vessel from September 9, 1960, to August 5, 1997, at a nominal internal pressure of $30 \mathrm{ksi}$. (a) at $180^{\circ}$, (b) at $315^{\circ}$, and (c) at $90^{\circ}, 180^{\circ}$, and $315^{\circ}$. 
4.2.9 Circumferential stresses (ksi) on the surface of the PV-4 pressure vessel 21 in. and 22 in. from the bottom of the vessel from September 9, 1960, to August 5, 1997, at a nominal internal pressure of $30 \mathrm{ksi}$. (a) at $0^{\circ}$ and $90^{\circ}$, (b) at $180^{\circ}$ and $270^{\circ}$, and (c) at $0^{\circ}, 90^{\circ}$,

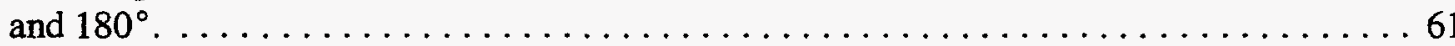

4.2.10 Average circumferential stresses (ksi) on the PV-4 pressure vessel from July 29, 1983, to August 5, 1987, at a nominal internal pressure of $30 \mathrm{ksi}$. Values in parentheses are

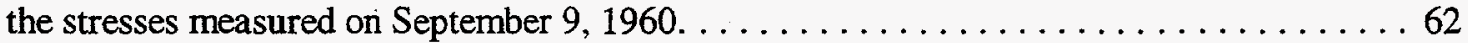

4.2.11 Strain as a function of internal pressure on December 4,1985 , for gauge \#20 located at $21 \mathrm{in}$. from the top of the PV-4 pressure vessel. . . . . . . . . . . . . . . 65

4.2.12 Strain as a function of internal pressure on June 24, 1988, for gauge \#20 located at 21 in. from the top of the PV-4 pressure vessel. . . . . . . . . . . . . . . . 66

4.2.13 Strain as a function of internal pressure on January 17, 1996, for gauge \#20 located at 21 in. from the top of the PV -4 pressure vessel. . . . . . . . . . . . . . . 67

4.2.14 Strain as a function of internal pressure for gauge 127 measured by Sturm \&

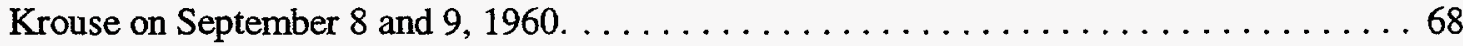

4.2.15A Plot of zero strain values $\left(10^{-6} \mathrm{in} . / \mathrm{in}\right.$.) as a function of time for gauges listed in

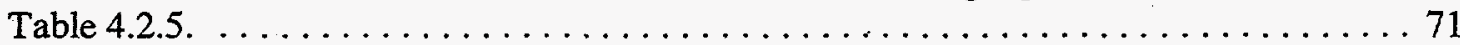

4.2.15B Plot of zero strain values $\left(10^{-6} \mathrm{in} . / \mathrm{in}\right.$.) as a function of time for gauges listed in

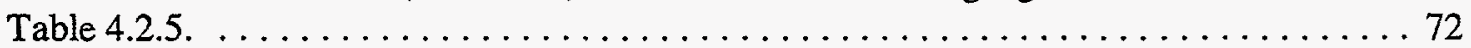

D-1 Plot of strain as a function of internal pressure for gauge 37 located on the left outside

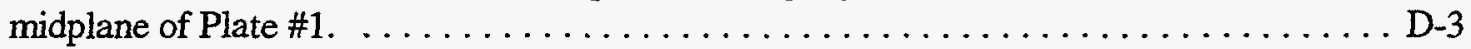

D-2 Plot of strain as a function of internal pressure for gauge 40 located on the left outside midplane of Plate \#12. . . . . . . . . . . . . . . . . . . . .

D-3 Plot of strain as a function of internal pressure for gauge 121 located on the pressure

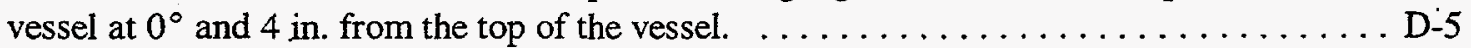

D-4 Plot of strain as a function of internal pressure for gauge 123 located on the pressure vessel at $180^{\circ}$ and $4 \mathrm{in}$. from the top of the vessel. . . . . . . . . . . .

D-5 Plot of strain as a function of internal pressure for gauge 125 located on the pressure vessel at $0^{\circ}$ and 22 in. from the top of the vessel. . . . . . . . . . .

D-6 Plot of strain as a function of internal pressure for gauge 135 located on the pressure vessel at $180^{\circ}$ and 26 in. from the bottom of the vessel $\ldots \ldots \ldots \ldots \ldots \ldots$

D-7 Plot of strain as a function of internal pressure for compensator gauge $115 \ldots . \ldots \ldots$. . . .

D-8 Plot of strain as a function of internal pressure for compensator gauge $116 \ldots \ldots \ldots$ D-10

D-9 Plot of strain as a function of internal pressure for compensator gauge $117 \ldots \ldots \ldots$ D-11 



\section{LIST OF TABLES}

3.2.1 Location and identification of strain gauge rosettes mounted on the PV-4 frame in 1982 and 1983. Gauges mounted in 1960 that are at or near the 1982 and 1983

gauge locations are shown in parentheses. . . . . . . . . . . . . . . 22

3.2.2 Location and identification of strain gauge rosettes mounted on the outer surface of the PV-4 pressure vessel in 1982 and 1983. Gauges mounted in 1960 that are at or near the 1982 and 1983 gauge locations are shown in parentheses. . . . . . . . . . 23

4.1.1 Stresses at the top of the PV-4 frame for an operating pressure of $30 \mathrm{ksi} \ldots \ldots \ldots \ldots$

4.1.2 Stresses at the middle of the PV-4 frame for an operating pressure of $30 \mathrm{ksi} \ldots \ldots \ldots 31$

4.1.3 Stresses at the bottom of the PV-4 frame for an operating pressure of $30 \mathrm{ksi} \ldots \ldots \ldots 32$

4.1.4 Stresses on the surface of the PV-4 pressure vessel on September 9, 1960, with an

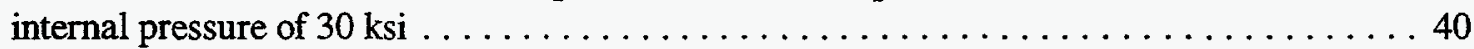

4.2.1 Times to reach nominal operating pressure of $30 \mathrm{ksi}$ and time at pressure for strain measurements conducted between December 4, 1985, and August 5, $1997 \ldots \ldots \ldots \ldots 45$

4.2.2 Measured axial stresses (ksi) on the frame of PV-4 pressure vessel at a nominal internal

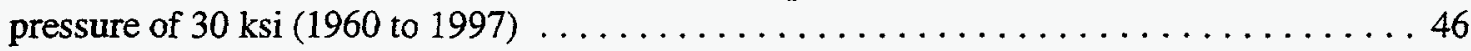

4.2.3 Two-gauge rosette calculations for circumferential stresses (ksi) on outer surface of the PV-4 pressure vessel at a nominal internal pressure of $30 \mathrm{ksi}(1960$ to 1997$) \ldots \ldots \ldots . .55$

4.2.4 Two-gauge rosette calculations for axial stresses (ksi) on outer surface of the PV-4 pressure vessel at a nominal internal pressure of $30 \mathrm{ksi}(1960$ to 1997) . . . . . . . . 56

4.2.5 Slope $\left(10^{-9} \mathrm{in} . / \mathrm{in} . / \mathrm{psi}\right)$ of strain as a function of internal pressure for PV-4 from

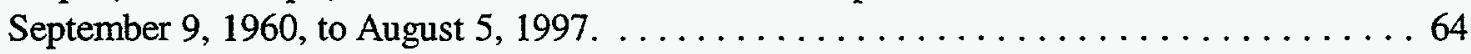

4.2.6 Zero values $\left(10^{-6}\right.$ in./in.) for strain gauges on PV-4 from December 4, 1985, to August 5,

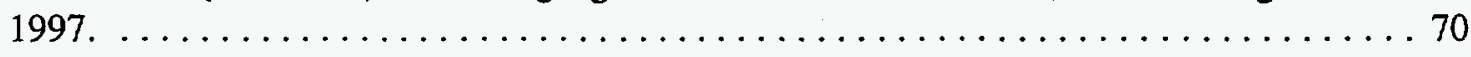

B-1 Calculated maximum stresses (ksi) for single and two-gauge rosettes on the PV-4 frame and pressure vessel at an internal pressure of $33 \mathrm{ksi}$ on September $9,1960 \ldots \ldots \ldots$. . . . 3

B.2 Calculated maximum principal stresses for three gauge rosettes on the PV-4 frame at

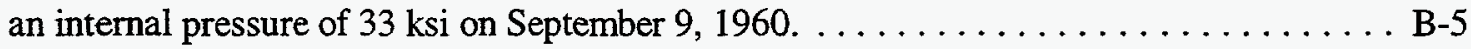

C-1 Chemical composition of the heats of T-1 steel used as the plates for the frame of the PV-4 press . . . . . . . . . . . . . . . . .

C-2 Tensile and Charpy impact properties of the heats of T-1 steel used as the plates for the frame of the PV-4 press ( 365 by 152 by 4 in.) $\ldots \ldots \ldots \ldots \ldots \ldots \ldots \ldots \ldots \ldots$

C-3 Tensile and Charpy impact properties of the heats of steel used in the pressure vessel of the PV-4 press. . . . . . . . . . . . .

C-4 Tensile and Charpy impact properties of the heats of steel used in other components of the PV-4 press. . . . . . . . . . . . . . . . . . . . . . . . . 



\section{EXECUTIVE SUMMARY}

The PV-4 isostatic press has an extremely large working volume of $98 \mathrm{ft}^{3}$ and was designed for routine operations at high internal pressure, up to $30 \mathrm{ksi}$. This combination of very large internal volume combined with high operating pressures makes PV-4 a unique and valuable component of the U.S. Department of Energy Y-12 manufacturing capability. Over 13,000 pressing operations have been conducted over the past $37+$ years. The press was designed and built in $1959 / 1960$ by the Bliss Company, a world leader in the manufacture of large, heavy-duty process and fabrication equipment for the metallurgical industry. To minimize tensile stresses on the inner surface of the pressure vessel and to assure leak before break, the vessel was fabricated using three concentric cylinders that were shrink-fitted together to form the overall pressure vessel. The vessel is contained within a large yoke or frame.

Since PV-4 was built, several new regulatory and oversight agencies (and associated regulations) have come into being; and the ASME Code has adopted new criteria and guidelines for operation and maintenance of pressure vessels. Although PV-4 is "grandfathered" as exempt from the new regulations, criteria, and guidelines, our intent is to employ the best monitoring evaluation and analysis methods to ensure maximum safety and confidence for continued operation of PV-4.

In 1960, prior to operation of the press, precision strain gauges were mounted on the pressure vessel and frame of PV-4 to confirm the calculated design pressures and operating parameters and to verify linear elastic behavior of the steels of which the vessel and frame were constructed, at pressures to $10 \%$ above the design maximum operating pressure. To provide for continuing long-term monitoring of stresses on PV-4, additional precision strain gauges were mounted on the frame and pressure vessel in 1982 and 1983. To provide a direct comparison of strains measured after 1983 with these measured in 1960, wherever possible, the new strain gauges were mounted at or close to the locations of the strain gauges used in the 1960 tests. The gauges mounted in 1982 and 1983 were also intended to provide information on the longterm integrity of the pressure vessel.

This report presents the information obtained with strain gauge measurements conducted in 1960 and from 1983 through 1997. It is the first in a series of three reports that describe the efforts to monitor the

status of and to provide analyses that assure long-term successful operation of PV-4 with maximum safety 
to personnel, facilities, and the environment. The subsequent two reports will provide stress analyses for the PV-4 pressure vessel and estimates of the fatigue life of the PV-4 pressure vessel, respectively.

Preoperational strain gauge measurements conducted in September 1960 confirmed the design stresses and operating parameters for PV-4 and verified linear elastic behavior of the pressure vessel steel at internal pressures up to $33 \mathrm{ksi}, 10 \%$ above the design maximum operating pressure which is as expected, because the manufacturer had proof tested the vessel assembly at 37.5 ksi prior to delivery (Ref. 1). Strain measurements have been conducted at 15 different times between July 1983 and August 1997. Measured strains were converted to stresses using Young's modulus and Poisson's ratio, where applicable, for steel. On the frame of PV-4, strain values and associated stresses calculated from strain values measured from July 1983 to August 1997 are in good to excellent agreement with those measured strains and stresses calculated in 1960. On the pressure vessel, the strains and associated stresses measured from July 1983 and August 1997 are in excellent agreement with those measured and calculated in 1960. Over the 37+ years of operation, there have been no significant changes in the strains, and therefore in the stresses, on the surface of the pressure vessel or in the slopes of the strain as a function of internal pressure. The excellent agreement of the stresses and slopes measured from July 1983 through August 1997 with those measured in September 1960 indicates that (1) no cracks, defects, or other flaws have developed that would affect the integrity of the pressure vessel, and (2) there has been no relaxation of the original shrink-fit pressures that were induced during fabrication of the vessel. Therefore, the original shrink-fit pressures may be used for stress analyses of the pressure vessel and for estimating the fatigue life of the vessel.

It should be noted that the strain gauges affixed to the press in 1960 and in 1982/1983 measure only operating stresses. They do not and cannot measure residual fabrication stresses-particularly those stresses in the pressure vessel resulting from the shrink-fit assembly of the three cylinders. Total residual stresses are unknown and are not evaluated in this report, but their magnitude is significant and in some locations may be additive to those measured during operation. The total stresses, operating plus residual, may exceed two-thirds of the yield strength of the pressure vessel steel and must, therefore, affect the fatigue life of the vessel. For this reason, continued monitoring of operating strains is required.

The excellent agreement of the stresses and the slopes of strain as a function of internal pressure obtained from 1983 through 1997 with those obtained in 1960 are exactly as expected for the long-term 
stability of the metallurgical structure produced during initial fabrication and heat treatment of the steels of which the press was constructed.

To ensure integrity of the pressure vessel and that there has not been relaxation of the original shrinkfit pressures, monitoring of strains with precision strain gauges should be continued. Although the press was subjected to an off-normal operation on July 9, 1996, strain gauge measurements conducted immediately after the off-normal operation and in August 1997 indicate that there has been no permanent damage to the press. However, as a result of the off-normal operation and malfunction of the data acquisition system, zero points need to be reestablished to provide direct comparison with the data obtained prior to these events. To reestablish direct comparison, a reference data base similar to that developed from December 1984 to January 1996 should be established by conducting strain gauge measurements three to four times per year for the next three to five years. 


\section{INTRODUCTION}

PV-4 is a large isostatic press that is owned and operated by the U.S. DOE Y-12 manufacturing facility to produce high density powder compacts, high strength ceramics, and certain metallic alloys. PV-4 was built by the Bliss Company (now Bliss-Salem, Inc.), and it has been operated routinely in the manufacturing facility from 1960 to the present. During this time it has performed more than 13,000 pressing operations at internal operating pressures from 5 to $30 \mathrm{ksi}$, with the majority of the operations at pressures at or near 15 and $30 \mathrm{ksi}$.

PV-4 was built with the materials technology, ASME Boiler and Pressure Vessel Code Rules, and the best design methodology in existence in the late 1950s. To minimize operating tensile stresses on the inner surface of the pressure vessel, the vessel was fabricated of three concentric right circular cylinders with the outer cylinders shrink-fitted onto the inner cylinders. The two inner cylinders are the full length of the pressure vessel. The third and outermost consists of two cylinders, each one-half the height of the vessel. Minimization of the operating tensile stresses on the inner surface results from the residual compressive stress on this surface produced by the shrink-fit process. Therefore, it is important for the long-term operations of PV-4 that there is little or no relaxation of the shrink-fit stresses that were induced in the initial fabrication of the vessel.

Installation of the press was completed in the summer of 1960. Prior to operation of the press, Sturm \& Krouse, a consulting engineering firm of Auburn, Alabama, was contracted to verify design calculations and to determine the magnitude of the shrink-fit stresses in the pressure vessel. Strain gauges were mounted on the outer circumference of the pressure vessel and on the frame that supports the vessel. Strain values were recorded at $5 \mathrm{ksi}$ increments from 0 to $30 \mathrm{ksi}$ while increasing and decreasing the working pressure between 0 and $30 \mathrm{ksi}$; strain values were also recorded while the internal pressure was 32 and $33 \mathrm{ksi}$. Stresses were then calculated for each gauge location and each pressure at which strain had been measured. The strain gauges used in 1960 were not mounted and protected for long-term operation in the environment in which PV-4 operates; and over time the gauges and their wax coating deteriorated, primarily due to the mineral oil used as the pressure medium. Therefore, beginning in 1982, to provide for long-term monitoring of the stresses on the vessel and frame, the K-25 Stress Analysis Group mounted new strain gauges on the 
pressure vessel and frame, and strains on PV-4 have been recorded periodically by this group from 1983 to the present.

In addition to measuring strains on PV-4 as a method for monitoring the long-term structural integrity of the press, this task includes additional analyses of mechanical stresses in and on the press, especially the pressure vessel. These analyses utilize the new and improved methods developed and adopted by the ASME Code after the press was built in 1960 , for calculating stresses in pressure vessels, for analyzing vessels that operate at high pressures, and for estimating fatigue lives of structures under cyclic loading conditions, which is the operational mode of isostatic presses. This report is one in a series of three reports that describes the work conducted in the three different subtasks in the overall task to monitor the status of and to provide analyses that assure long-term successful operation of PV-4 with maximum safety to personnel, facilities, and the environment. The information obtained for the three subtasks is provided in three reports (1) "Monitoring Stresses on the PV-4 Isostatic Press from 1960 to 1997," Y/QS-0006 (this report), (2) "Stress Analyses for the PV-4 Pressure Vessel," Y/QS-0007 (Ref. 2), and (3) "Estimates of the Fatigue Life of the PV-4 Pressure Vessel" Y/QS-0008 (Ref. 3).

This report presents the information obtained from the initial strain measurements conducted in 1960 and from strain measurements conducted from 1983 to 1997. The information obtained for subjects (2) and (3) is to be presented in References 2 and 3, respectively. 


\section{BACKGROUND AND STATUS}

PV-4 was built for Union Carbide Corporation Nuclear Division by Bliss Inc. to provide Y-12 with an up-to-date, state-of-the-art isostatic press which combined a very large internal working volume (98 $\left.\mathrm{ft}^{3}\right)$ with the capability of operating at high pressures, up to $30 \mathrm{ksi}$. Six important factors were combined to enable Y-12 to obtain this "high-tech" facility.

- First, Bliss has been a world leader in the design and manufacture of large complex equipment for the metal forming industry for more than 140 years. They have extensive experience in building presses with the physical size capable of handling very large primary metal forms, such as ingots and castings, combined with the strength to form these bodies into sheets, bars, billets, etc., intended for further reduction to near-finished forms by extrusion, swaging, rolling, and/or drawing with smaller metal forming equipment. They have also produced an extensive range of forming equipment for the powder metallurgy industry and presses for compacting metal and ceramic powders. Because of this long-term successful experience, Bliss was uniquely qualified to design and build PV-4.

- Second, a high-strength, low alloy steel, T-1, was chosen for construction of PV-4. This material combines both high strength and high ductility and was the structural alloy of choice in 1960 for applications such as PV-4. For thicknesses of 4 in. and greater, the minimum specified tensile yield strength for T-1 is $90 \mathrm{ksi}$, and the minimum specified ultimate tensile strength is $105 \mathrm{ksi}$ (Ref. 4). Elongation in 2 in. must be at least $15 \%$, and reduction of area must be $45 \%$ or higher (Ref. 4$)$. This combination of strength and ductility provides high toughness or resistance to fracture. Figure 2.1 shows schematic diagrams of strain as a function of applied stress for structural materials that behave in three different manners. Figure 2.1A is for a metal which is very strong, such as tungsten, molybdenum, or rhenium at room temperature, but which exhibits brittle behavior. These materials fail at very small amounts of strain energy, usually $1 \%$ or less, and the area under the stress-strain curve is very small. Figure 2.1B is for a metal, such as aluminum or copper, that is very ductile. They exhibit high strains (e.g., 50\% or more) at rupture, but they have very low strength and the area under the stress-stain curve is also rather small. Figure $2.1 \mathrm{C}$ typifies an iron base alloy such as $\mathrm{T}-1$. It 


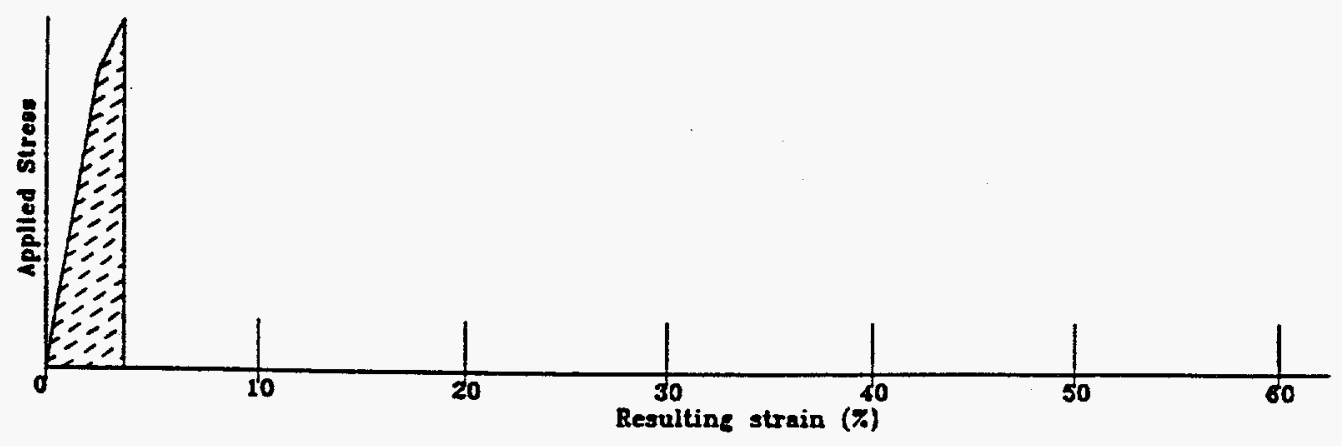

Fig. 2.1A. Strain as a function of applied stress for a very high strength, low ductility metal or alloy.

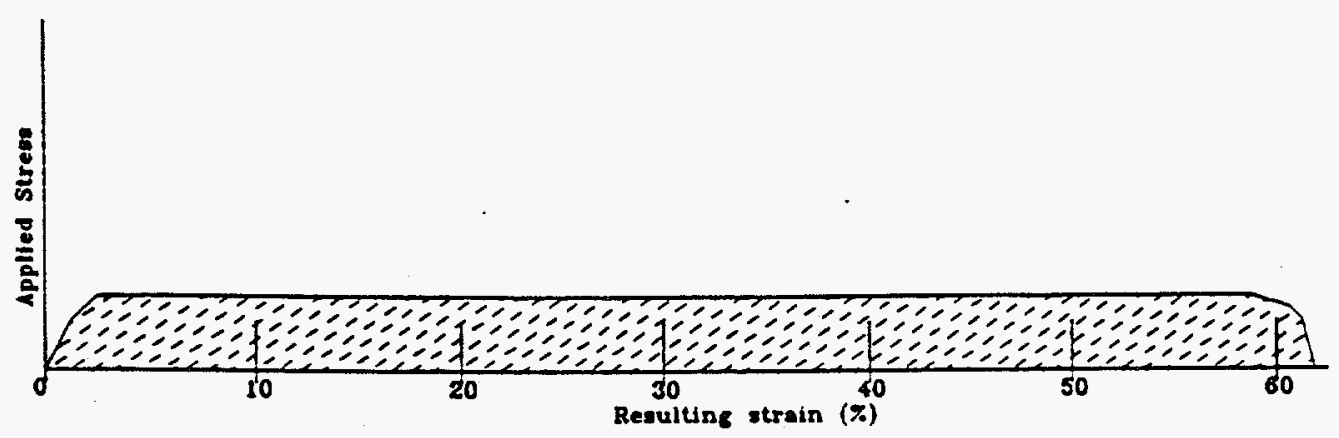

Fig. 2.1B. Strain as a function of applied stress for a low strength, very high ductility metal or alloy.

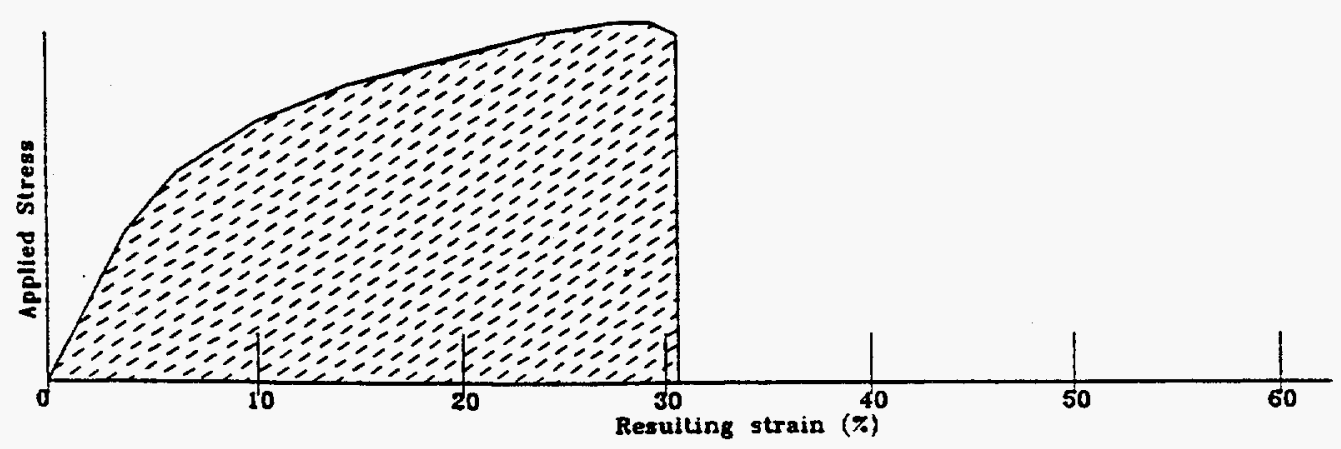

Fig. 2.1C. Strain as a function of applied stress for a high strength, moderately high ductility metal or alloy. 
requires high stresses (high strength) to produce large amounts of strain (moderately high ductility). The area under the (strain as a function of applied stress) curve is very large compared with those shown in Fig. 2.1A and 2.1B. The area under the stress-strain curve is a measure of the energy that a material can absorb before it fractures and is a measure of "toughness" (Ref. 5). At room temperature T-1 has high toughness. In materials of this type, it is difficult to initiate a crack; and if a crack is initiated, ductility is so high that the tip of the crack is immediately blunted and the crack is arrested and does not propagate.

- Third, PV-4 was built for operation at room temperature. Operation at elevated temperature is a principal cause for failure and/or short lifetimes of metallic equipment and structures; the detrimental effects of temperature are exacerbated by stresses on or within the system. PV-4 was built with a ferritic alloy, T-1, a mill-heat-treated low alloy, high-strength steel. For ferritic alloys, the ASME Boiler and Pressure Vessel Code uses constant allowable stresses for operating temperatures up to $700^{\circ} \mathrm{F}$. The Aerospace Structural Metals Handbook (Ref. 4) states that "the service range of T-1 should be restricted to $-50^{\circ} \mathrm{F}$ to $800^{\circ} \mathrm{F}$." Therefore, limiting operation of $\mathrm{PV}-4$ to room temperature provided the maximum possible conservatism for the strength properties of the steel of which it was constructed.

- To have high toughness, T-1 must be in the quenched and tempered condition and the T-1 steel of which PV-4 was constructed was given a mill heat treatment which provided maximum toughness. To maintain the uniform quenched and tempered microstructure, no welding is permitted and every engineering drawing for every component of PV-4 contains the following statement in bold, capital letters and the entire statement is underlined. NO WELDING OR ARC STRIKING WILL BE DONE ON THIS PIECE FOR ANY PURPOSE AT ANY TIME.

- Fourth, perhaps the most positive method to achieve "leak before break" in a high pressure system is to build the pressure vessel with a layered structure. In a high pressure vessel the most probable location for the initiation of a crack is at the inner surface, which is the highest stressed location in the vessel. In a layered structure, a crack that is initiated on the inner surface can, under repeated loadings, propagate through the thickness of the first layer; however, the discontinuity between the first and second layer prevents the crack from entering the second layer. The presence of the second 
layer prevents a brittle or rapid catastrophic rupture that would send shrapnel over the surrounding area. Also, the discontinuity between the first and second layers provides a leak path for the working fluid to the vessel exterior. The pressure vessel of PV-4 was fabricated with three concentric layers of forged high-strength, low alloy steel to provide redundancy and a very high degree of assurance of "leak before break."

- Fifth, in addition to being constructed with three layers, the outer two layers are shrink-fitted over the inner two layers. Shrink-fitting the second layer onto the first layer provides compressive stresses on the inner and outer walls of the first layer. These built-in compressive stresses significantly reduce the operating tensile stresses produced on the inner wall to values that are well within the safe working range. Similarly, the third layer reduces stresses in the second layer. Because the capability of PV-4 to operate at internal working pressures as high as $30 \mathrm{ksi}$ while maintaining stresses in the vessel wall well below the yield strength of the heat-treated pressure vessel steel is the result of the compressive stresses on the inner surface produced by the shrink-fit of the outer two layers, it is important to know the initial stresses on the outer surface of the pressure vessel and to monitor these stresses to assure that no changes occur in stress level or stress distribution.

- Sixth, the frame, or yoke, which supports and contains the pressure vessel is made in layers, which results in higher fatigue strength than if the frame were fabricated from a single monolithic block of metal. In the layered design, cracks that might form as a result of repeated load applications can propagate through only one layer and not through the entire frame, as could occur with a single block of metal. In addition, as stated in the third factor, no weldments are allowed on the frame of PV-4.

Immediately after construction of PV-4 was completed and prior to its use, on September 8-9, 1960, tests were conducted by Sturm \& Krouse, Inc., Research and Consulting Engineers of Auburn, Alabama, using high-resolution strain gauges to verify the design parameters of the press and to provide assurance that it could be safely operated at the design maximum operating pressure of $30 \mathrm{ksi}$ (Ref. 6.)

Several new regulatory agencies that are involved with safe operation of pressure vessels have been created since PV-4 was built and became operational in 1960 . To attempt to provide information for use by these agencies in evaluating the safety of PV-4 operation, many meetings have been held to identify methods that could be used to provide continuous, or at least periodic, assessment of the structural integrity 
of PV-4. Nondestructive diagnostic techniques such as ultrasonic measurements, $x$-ray radiography, acoustic emission, strain gauge measurements, dye penetrant examinations, and others have been considered at great length. Some of the methods or techniques that were considered are not technically feasible for PV-4, some are cost-prohibitive, and others would result in unacceptably large perturbations in the press operating schedule. The method selected as providing the most information at minimum cost and minimum interference with the PV-4 operating schedule was the use of precision strain gauges. Use of strain gauges also provides a method for continuing long-term monitoring of the structural integrity of PV-4. In addition, the preoperational strain measurements conducted by Sturm \& Krouse in September 1960 provide a reference base that is extremely valuable for evaluation, analysis, and interpretation of strain measurements conducted after 1960. At recent meetings to review methods for nondestructive inspections and/or monitoring of PV-4, the preferred method continued to be the use of precision strain gauges. Therefore, beginning in August 1982, new strain gauges were mounted on the outer surface of the pressure vessel and on the frame of the PV-4 press.

This report presents the information obtained from the strain measurements conducted on September $8-9,1960$, by Sturm \& Krouse and from July 29, 1983, to August 5, 1997, by the K-25 Stress Analysis Group. Information obtained from strain gauge measurements from 1983 through 1985 has been reported earlier by J. L. Frazier (Ref. 7). Included in the current report are analysis and interpretation of the data and implications of these observations to the operation of PV-4. Data and analysis for the strain measurements conducted by Sturm \& Krouse are included because they provide the basis for evaluation of all subsequent strain measurements and analyses. The Sturm \& Krouse report consists of a compilation of figures (133) of measured strain as a function of internal operating pressure for each strain gauge, and tables (9) for stresses at operating pressures at 20,30, and $33 \mathrm{ksi}$. Their report contains little interpretation and/or analysis of the strain measurements and their meaning to the operation of PV-4 but provides the base-line data for subsequent measurements and analyses. To be able to discern whether a flaw has been initiated, or whether a change in the integrity of the pressure vessel or a relaxation in shrink-fit pressure has occurred between 1960 and 1997, the strain data obtained in 1960 and from 1983 to 1997 must all be analyzed with the same methods and equations. 



\section{PROCEDURES}

\subsection{Strain Measurements Conducted in $\mathbf{1 9 6 0}$}

In September 1960 Sturm \& Krouse mounted a total of 136 strain gauges on the outside cylindrical surface of the pressure vessel and on the plates which form the frame of PV-4. Eighty single-element SR-4, type A-3 strain gauges were mounted to the plates which form the frame of PV-4. As shown in Figs. 3.1.1 and 3.1.2, six gauges were mounted in the axial orientation at the top and bottom inside faces on the left and right halves of the frame at the transition of the plates from semicircular to linear. These locations are subjected to the highest stresses on the frame during an isostatic pressing operation. Fewer gauges, only four on each half of the frame, were mounted at the axial midplane of the frame where stresses are calculated to be much lower than those at the top and bottom tangent locations.

As shown in Figs. 3.1.3 and 3.1.4, an additional 12 gauges were mounted in the axial orientation on each outside face of the plates which form the frame, at the same elevations as the gauges mounted on the inside faces of the plates. Because of the lower stresses expected on the outside faces of the plates, only four gauges were mounted at these locations at each elevation,

Six single-element gauges $(21,23,45,47,69$, and 71$)$ were mounted axially on the front plate (\#1) of the frame, and six additional single-element gauges $(22,24,46,48,70$, and 72$)$ were mounted axially to the back plate (\#12) of the frame at the locations shown in Figs. 3.1.5 and 3.1.6, respectively. One twogauge (one vertical and one horizontal) rosette was mounted near the top of the opening of the front plate (25 and 26) and another on the back plate ( 27 and 28), as shown in Figs. 3.1.5 and 3.1.6, respectively. Two additional two-element gauges (one vertical and one horizontal) were mounted on the front face (73 and 74) and on the back face ( 75 and 76) of the bottom of the load transfer block, which transmits the load from the pressure vessel to the frame. These gauges are shown just above the bottom opening of the frame in Figs. 3.1.5 and 3.1.6. Also shown in Figs. 3.1.5 and 3.1.6 are the location and identification of the six threegauge rosettes, each of which contained three SR-4 type AR-7 strain gauges, that were mounted to both the front and back plates of the frame. Three gauges-115, 116, and 117-were used as compensator gauges, to provide a quantitative measurement of possible changes in ambient temperature on the electrical resistivity of the wire in the strain gauges. 


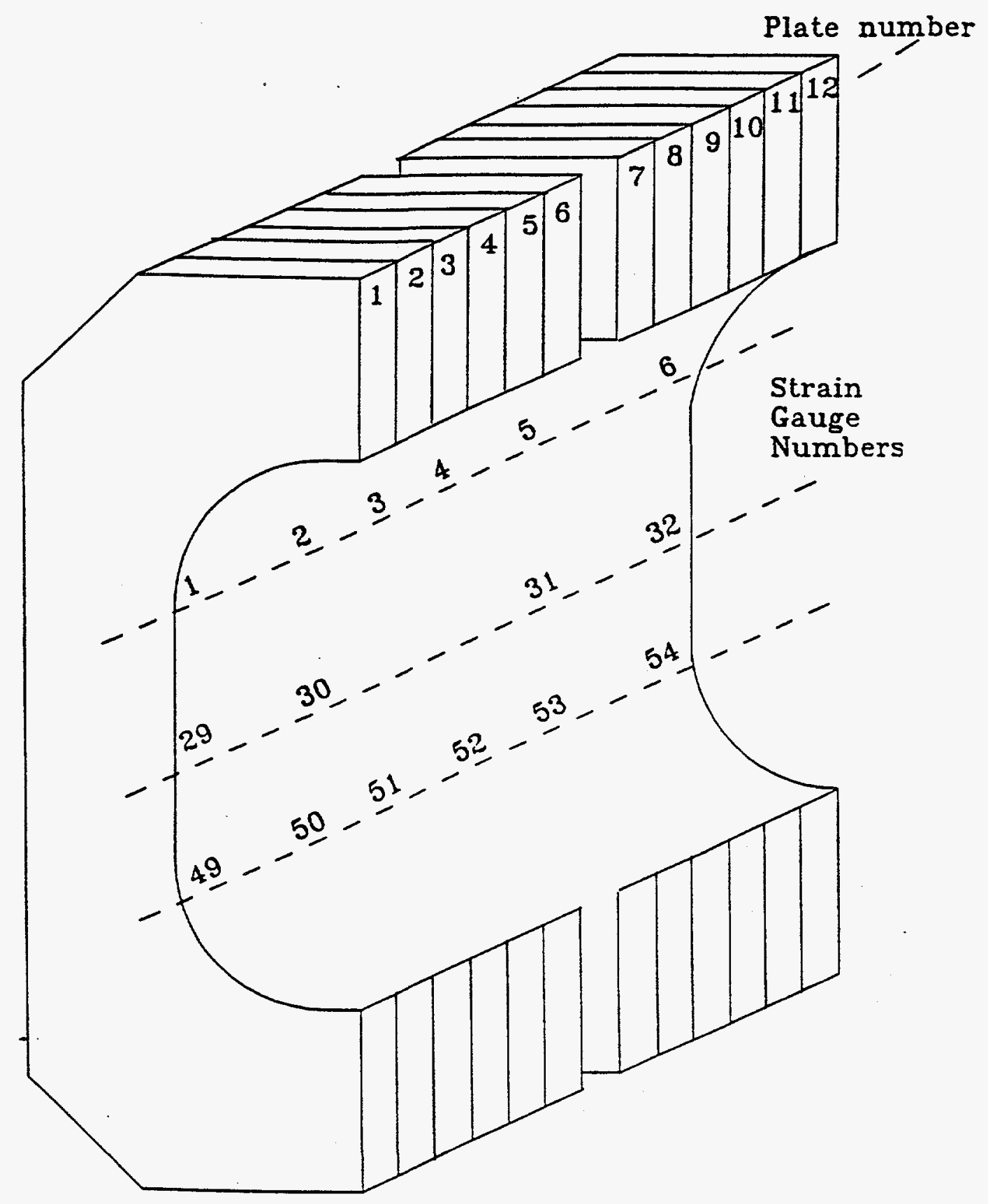

Fig. 3.1.1. Locations of strain gauges on the left inside of the frame of PV-4 for tests conducted in 1960. 


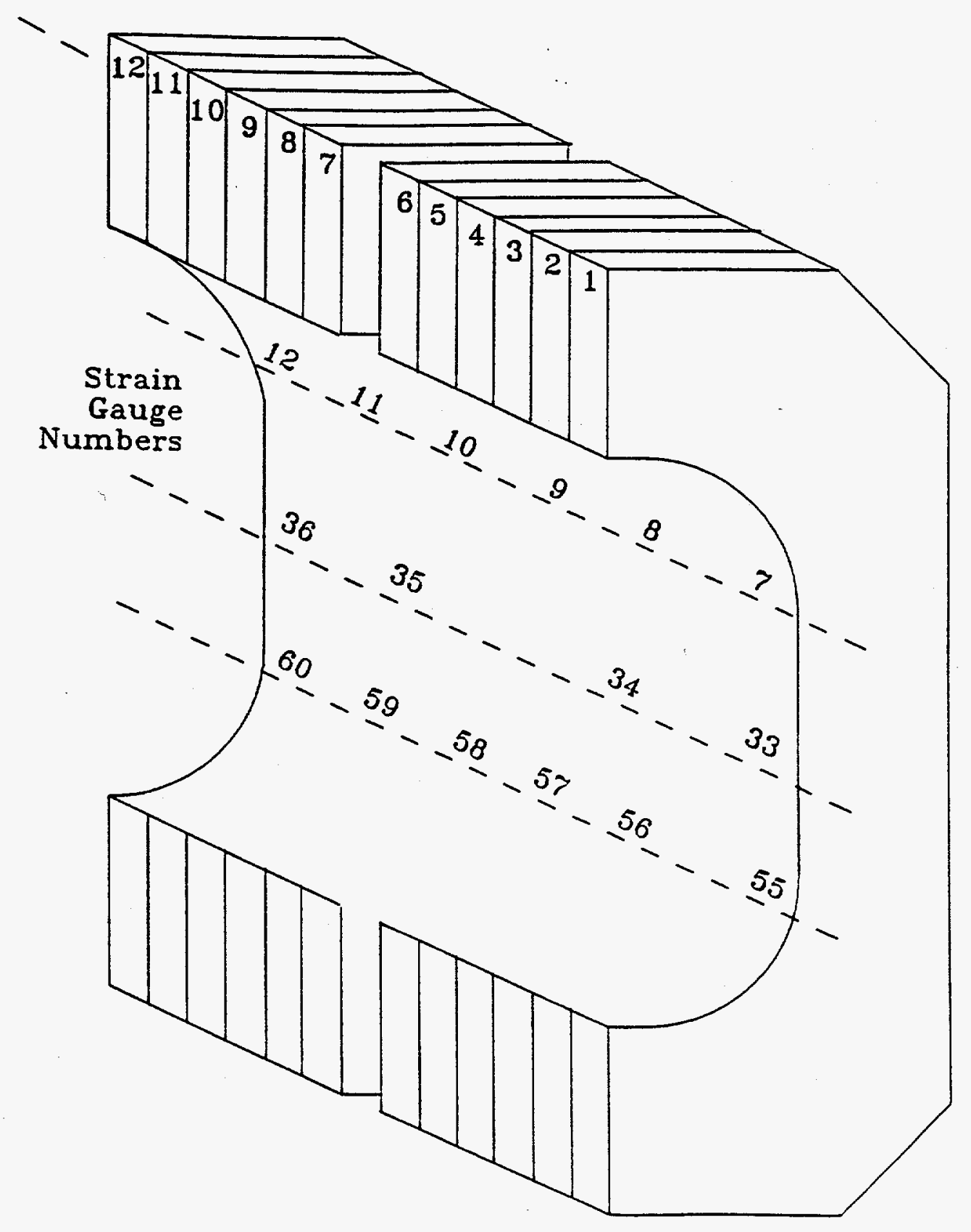

Fig. 3.1.2. Locations of strain gauges on the right inside of the frame of $P V-4$ for tests conducted in 1960. 


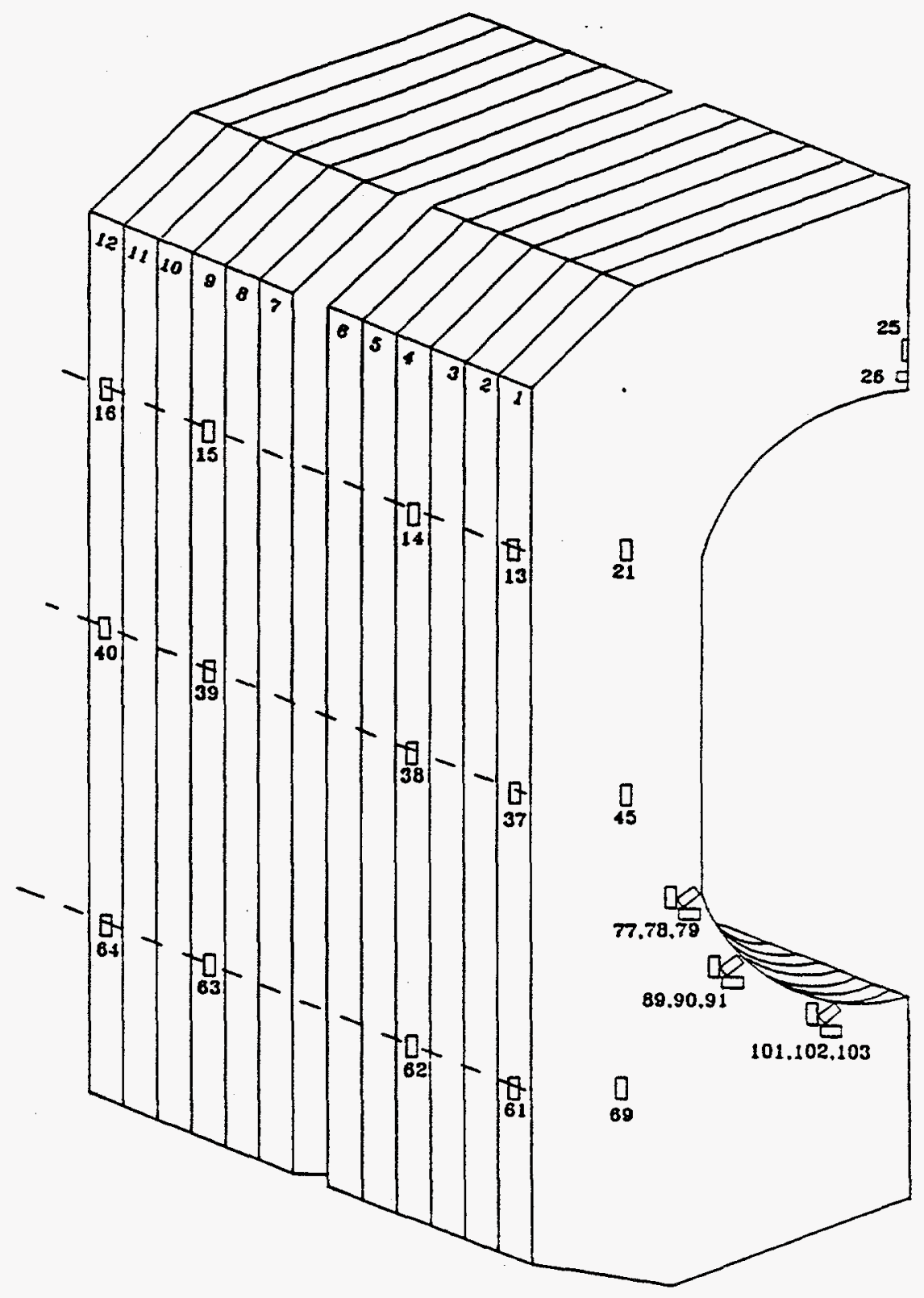

Fig. 3.1.3. Location of strain gauges on the left outside and front of the frame of PV-4 for tests conducted in 1960. 


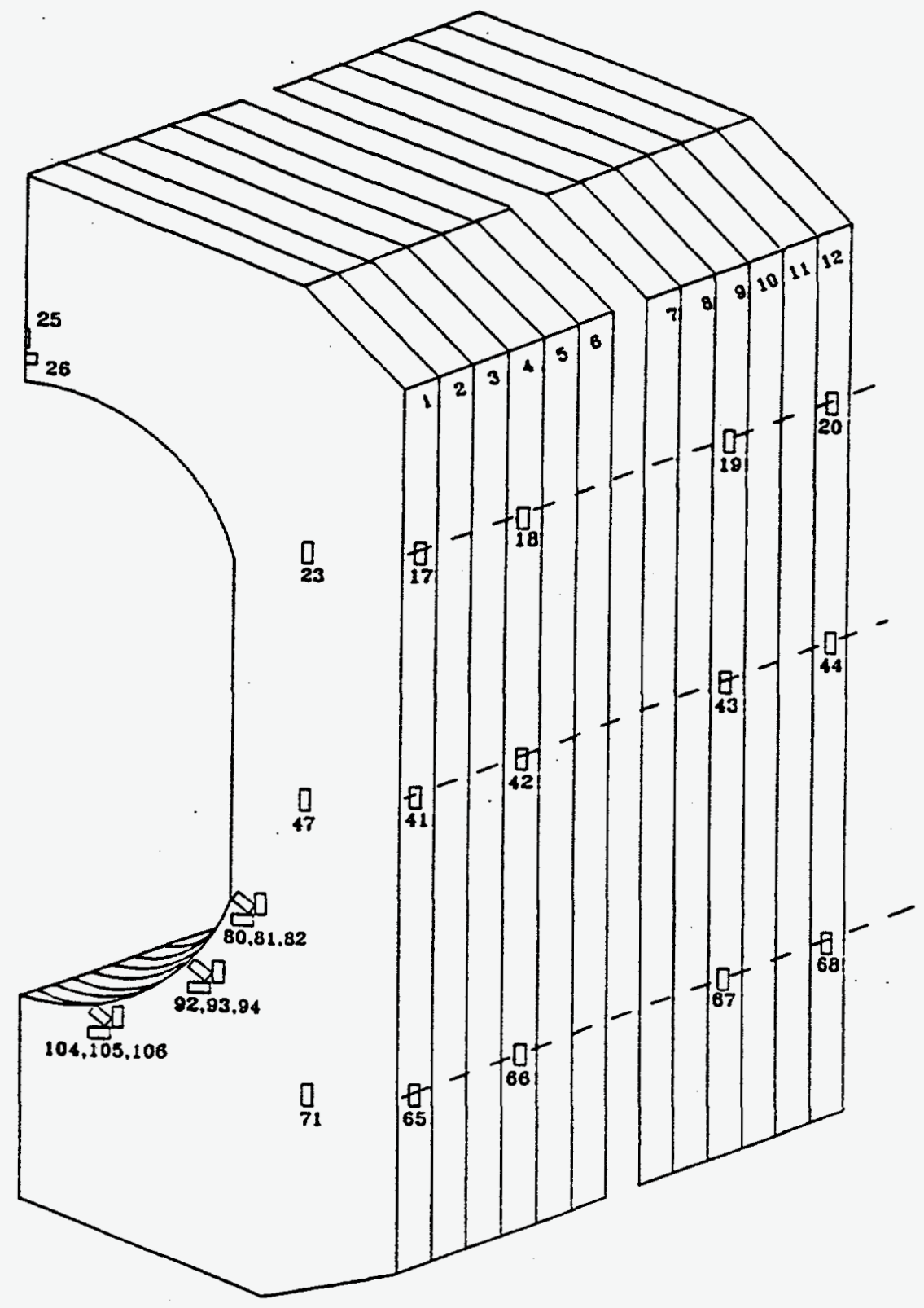

Fig. 3.1.4. Locations of strain gauges on the right outside and front of the frame of PV-4 for tests conducted in 1960. 


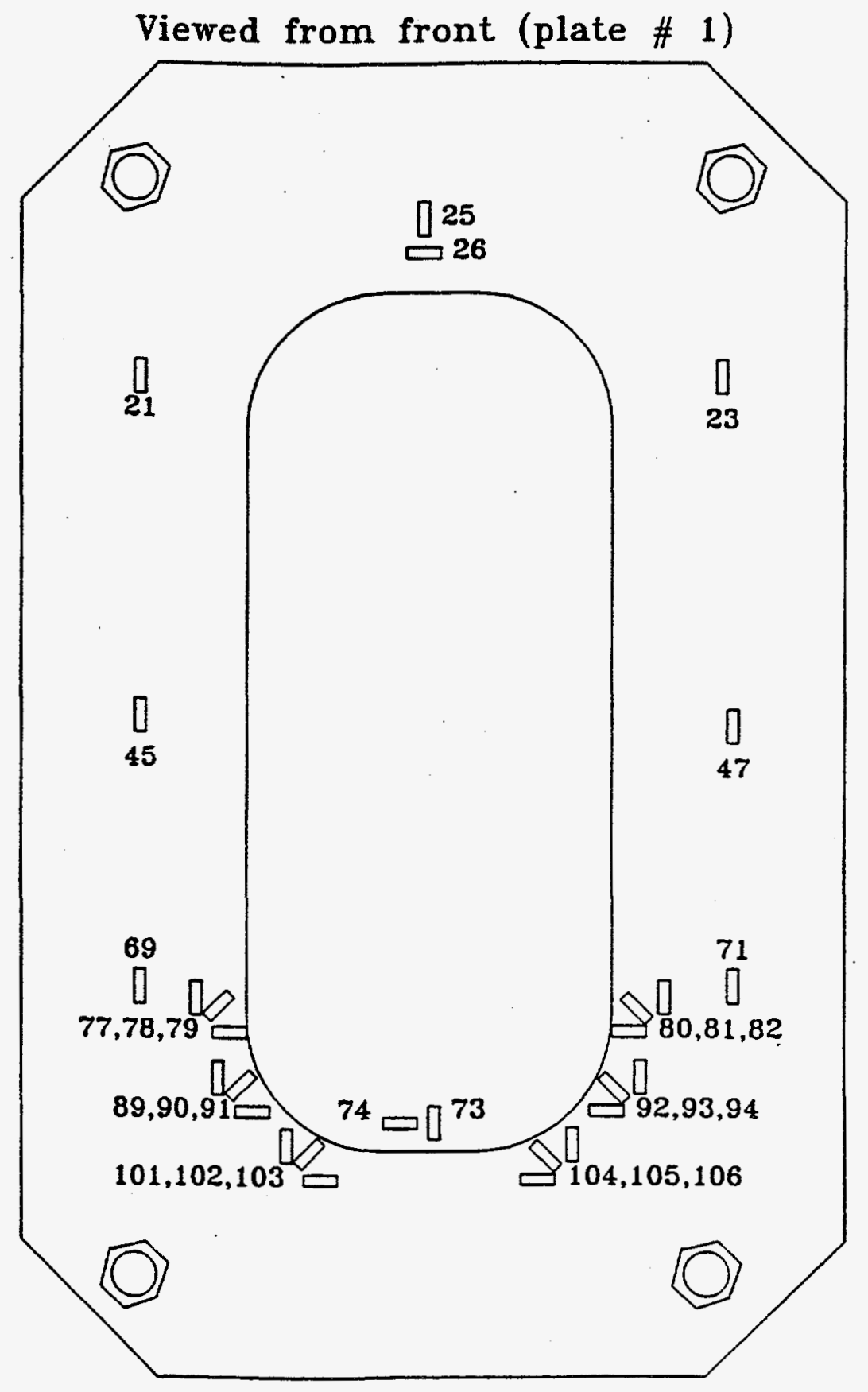

Fig. 3.1.5. Locations of the strain gauges on the front of PV-4 for the tests conducted in 1960 . 


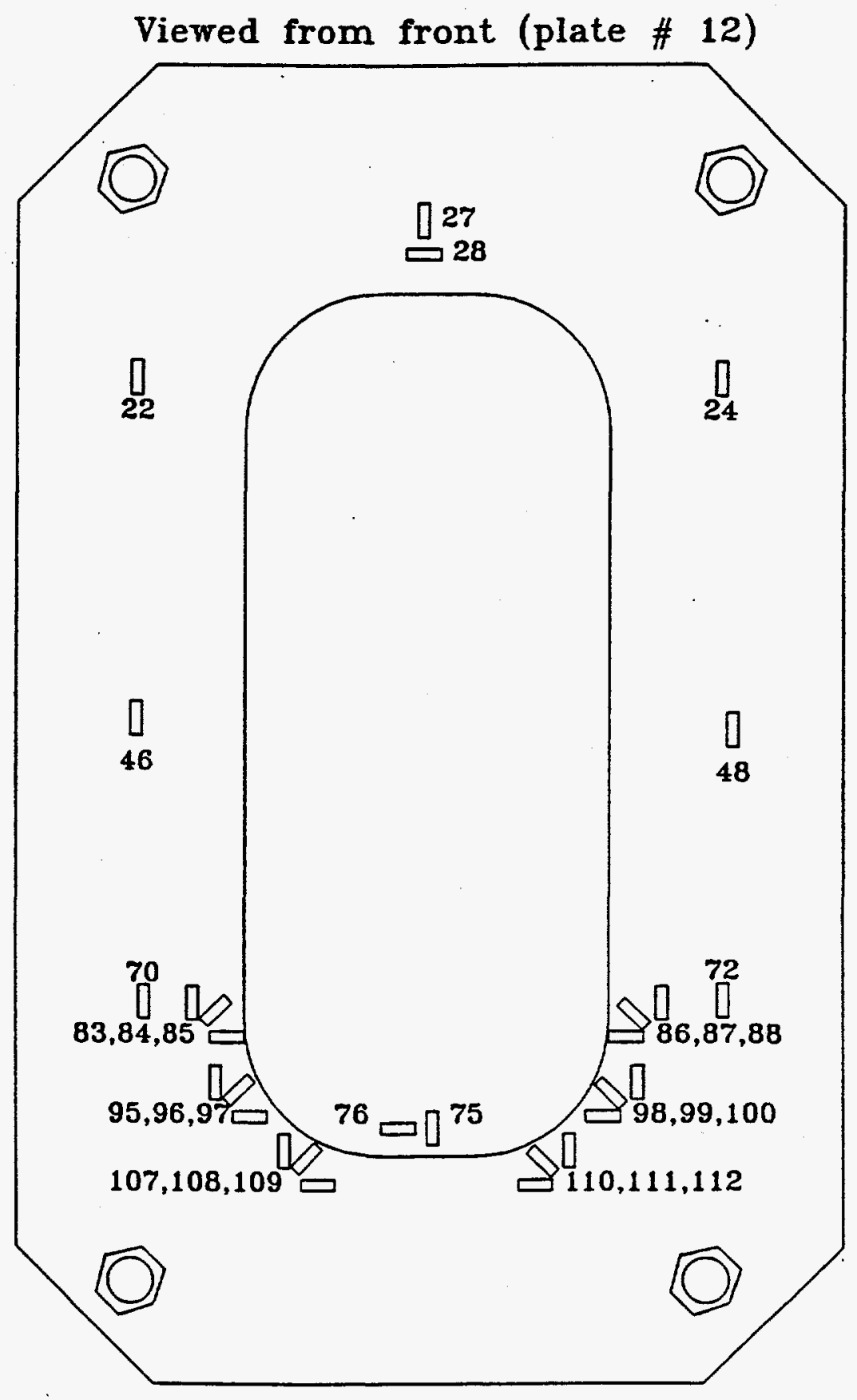

Fig. 3.1.6. Locations of the strain gauges on the back of PV-4 for the tests conducted in 1960. 
Ten two-gauge rosettes containing SR-4, type A-3 strain gauges were mounted on the outside cylindrical surface of the pressure vessel at the locations shown in Fig. 3.1.7. The gauges were mounted to provide one gauge in the axial direction and one gauge in the circumferential direction at the elevations and orientations shown.

"The strain gauges were mounted in accordance with the manufacturer's directions. Each gauge was thoroughly dried with heat lamps and then a moderately thick coat of wax was applied to waterproof each gauge" (Ref. 6). Unfortunately a reference for the manufacturer's instructions was not included in the Sturm \& Krouse report. In addition, use of wax to protect the gauges indicates that the gauges were not intended for long-term use. Some information on the electronic circuitry, zero strain measurements, and data acquisition during the tests conducted on September 8-9, 1960, is provided in Ref. 6, but Sturm \& Krouse did not provide information on the exact locations of the strain gauges on the pressure vessel or frame (dimensions in inches from a reference point) for any of the gauges. This information (exact locations of several of the Sturm \& Krouse gauges) was obtained during application of the new strain gauges by the K-25 Stress Analysis Group in July 1982. To obtain strain readings at the same locations used by Sturm \& Krouse in 1960, wherever possible, the gauges applied in 1982 and 1983 were placed at the same locations as those applied in 1960, and the dimensions to reference points were recorded.

The Sturm \& Krouse report describes the PV-4 press pre-operational test procedure: After preliminary checks, primarily visual inspection of the pressure vessel and piping at an internal pressure of $5 \mathrm{ksi}$, the pressure was reduced to zero and all of the strain gauges were checked for continuity and reliability, and the zero values were recorded. Subsequently, the pressure was increased in $5 \mathrm{ksi}$ increments to a maximum of $30 \mathrm{ksi}$. Strain values were recorded at $0,5,10,15,20,25$, and $30 \mathrm{ksi}$ internal pressures. The pressure was relieved and the zero values were recorded again. Although it is not stated in the Sturm \& Krouse report, it appears that pressure was maintained at each of the $5 \mathrm{ksi}$ increments while strain measurements were recorded manually, which would require approximately $30 \mathrm{~min}$ to record the strain values for the 132 of the 136 gauges that were operational on September 8 and 9, 1960.

On September 9, 1960, new strain gauge zero readings were recorded. Hydraulic pressure was then applied, and the pressure was increased directly to $30 \mathrm{ksi}$ and strain values recorded. The pressure was 


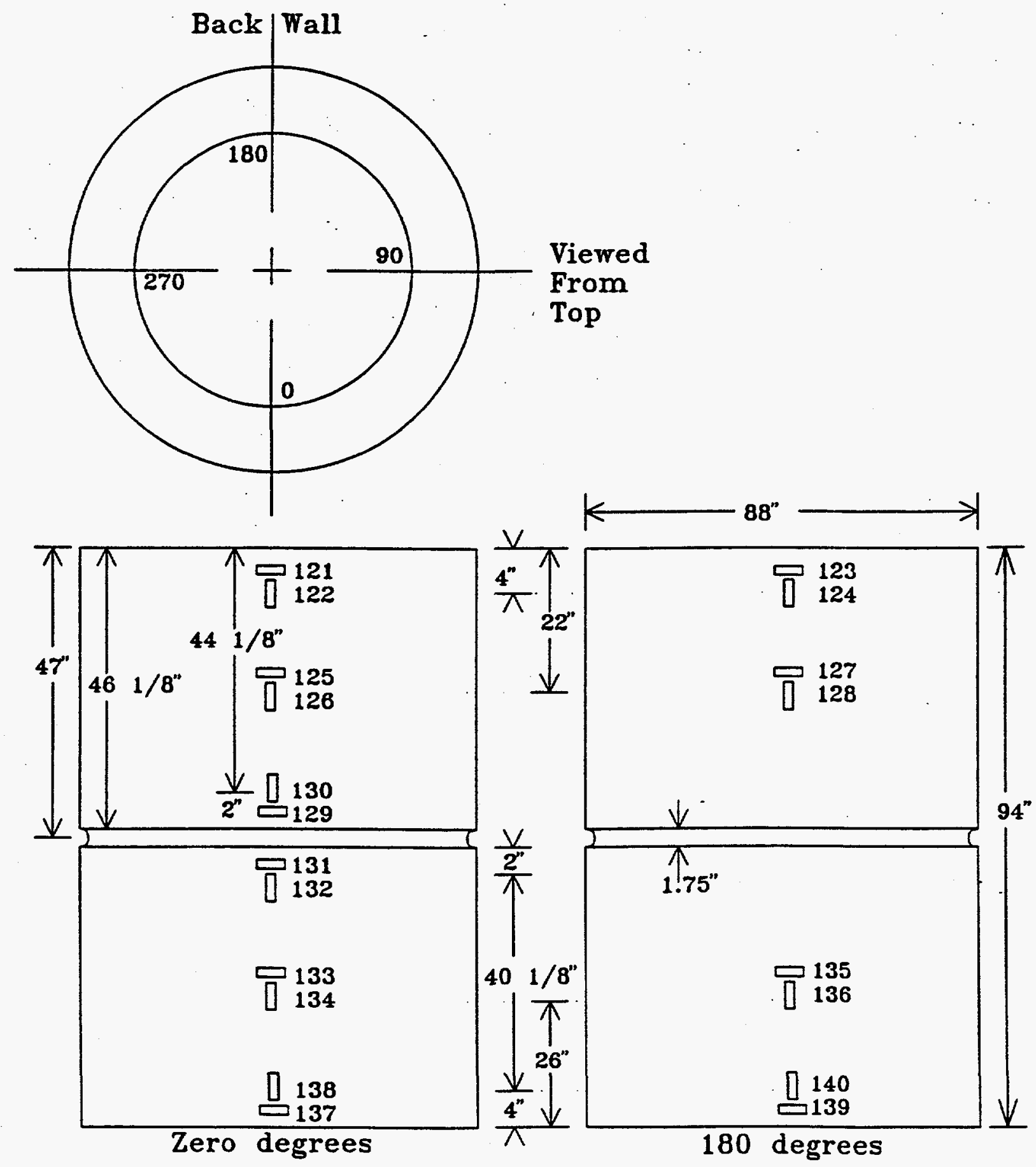

Fig. 3.1.7. Locations of strain gauges on the outer surface of the PV-4 pressure vessel for tests conducted in 1960. 
then increased to 32 and $33 \mathrm{ksi}$, with strain values being recorded at both pressures. The pressure was then relieved in increments and strain values recorded at $30,25,20,10$, and $0 \mathrm{ksi}$ internal pressures. The strain gauge zero values were subtracted from the strain values recorded at each internal pressure, and tables and plots were made of strain as a function of operating pressure from every gauge from which they obtained data. Subsequently, for operating pressures of 30,32 , and $33 \mathrm{ksi}$, the recorded strains were converted to stresses. For single strain gauges, strains were converted to stresses by multiplying the measured strain values by $30 \times 10^{6} \mathrm{psi}$, Young's modulus for steel (Ref. 4). This is also true for any gauge that has been mounted to be parallel with a major stress axis. For example, note in Figs. 3.1.1 through 3.1.7 that all of the single gauges were mounted parallel to the axial direction (or vertical axis) of the frame, all twoelement gauges were mounted with one gauge parallel to the vertical (axial) direction and one gauge parallel to the circumferential or horizontal direction, all three-element gauges were mounted with an axis parallel to each of the vertical and horizontal directions and the third gauge at $45^{\circ}$ to these two principal directions.

For the state of plane stress and two-element gauges, Poisson's ratio is included in the calculations for stresses, and strains may be converted to stresses using the relationships shown in Equations 3.1.1 and 3.1 .2 ( Refs. 5 and 8 ):

$$
\sigma_{\mathrm{H}}=\frac{E}{1-v^{2}}\left(\varepsilon_{\mathrm{H}}+v \varepsilon_{\mathrm{V}}\right)
$$

and

$$
\sigma_{\mathrm{v}}=\frac{E}{1-v^{2}}\left(\varepsilon_{\mathrm{v}}+v \varepsilon_{\mathrm{H}}\right)
$$

where

$\sigma_{\mathrm{H}}=$ horizontal stress,

$\sigma_{\mathrm{V}}=$ vertical stress,

$\mathrm{E}=$ Young's modulus, $30 \times 10^{6}$ psi for steel,

$v=$ Poisson's ratio, 0.3 for steel,

$\varepsilon_{\mathrm{H}}=$ strain measured by the horizontal strain gauge,

$\varepsilon_{\mathrm{v}}=$ strain measured by the vertical strain gauge. 
For the three-element gauges and a state of plane stress, the maximum normal and shear stresses are given by Equations 3.1.3 and 3.1.4, respectively.

$$
\sigma_{\max }=\frac{E}{2}\left[\frac{\varepsilon_{V}+\varepsilon_{H}}{1-v}+\frac{1}{1+v}\left\{\left(\varepsilon_{V}-\varepsilon_{H}\right)^{2}+\left[2 \varepsilon_{A}-\left(\varepsilon_{V}+\varepsilon_{H}\right)\right]^{2}\right\}^{1 / 2}\right] \text {, }
$$

and

$$
\tau_{\max }=\frac{E}{2(1+v)}\left[\left(\varepsilon_{\mathrm{v}}-\varepsilon_{\mathrm{H}}\right)^{2}+\left[2 \varepsilon_{\mathrm{A}}-\left(\varepsilon_{\mathrm{v}}+\varepsilon_{\mathrm{H}}\right)\right]^{2}\right]^{1 / 2}
$$

where

$\sigma_{\max }=$ maximum normal stress,

$\mathrm{E}=$ Young's modulus, $30 \times 10^{6} \mathrm{psi}$ for steel,

$\varepsilon_{\mathrm{V}}=$ strain measured by the vertical strain gauge,

$\varepsilon_{\mathrm{H}} \quad=$ strain measured by the horizontal strain gauge,

$\varepsilon_{\mathrm{A}}=$ strain measured by the strain gauge at the $45^{\circ}$ angle to the vertical and horizontal axes,

$v \quad=$ Poisson's ratio, 0.3 for steel,

$\tau_{\max }=$ maximum shear stress.

References 5 and 8 also provide formulas for the minimum normal stress and the direction of the maximum normal stress relative to the horizontal axis. However, for the frame of PV-4, maximum tensile stresses are all in the axial (vertical) direction; minimum stresses and the angle between the maximum stresses and the horizontal axis have little importance to the operation of PV-4 and are not discussed in this report. This information is provided in Reference 6.

\subsection{Strain Measurements Conducted from 1983 to 1998}

The adhesive used to mount the strain gauges in 1960 and the wax coating with which the gauges were protected from the mineral oil used in the PV-4 press were not designed for long-term operation. Therefore, when a program for long-term monitoring of strain on PV-4 was initiated in 1982, the original gauges were not considered usable and were replaced. 
Between August 1982 and July 1983, the K-25 Stress Analysis Group mounted 17 MicroMeasurements Group CEA-06-250-UR-350 strain gauge rosettes on the frame of PV-4 and 14 of these gauges on the outer surface of the pressure vessel. These gauges are three-element rosettes with one element (gauge) mounted parallel to the axial direction of the frame or vessel, the second element mounted $45^{\circ}$ to the axial direction, and the third element mounted $90^{\circ}$ to the axial gauge; for the pressure vessel outer surface, this is the circumferential direction.

Because of the limited longevity of the strain gauges mounted in 1960, there was great effort to apply the new strain gauges with an adhesive and protective coating that would provide accurate and reliable long-term strain measurements under PV-4 operating conditions. The details of installation of the new strain gauges are provided in Appendix A. The bonding and protection of the new gauges were intended to provide reliable, long-term operation of all of the gauges on the frame and pressure vessel, and their survival and useful data output from 1983 to the present time indicates that this objective was accomplished. Also, if there were measurable relaxation of the shrink-fit pressures, stresses on the outer surface of the vessel would be lower than those measured on September 8 and 9, 1960.

In order to provide as direct a comparison as possible between strains measured by Sturm \& Krouse in 1960 and by the K-25 Stress Analysis Group from 1983 to the present, several of the strain gauge rosettes mounted on the PV-4 frame and pressure vessel by the K-25 group in 1982 and 1983 were placed at the same locations as the strain gauges mounted by Sturm \& Krouse in 1960 . For the strain gauges deployed in 1982 and 1983, emphasis was on long-term monitoring of the pressure vessel for possible relaxation of the original shrink-fit pressures and/or the development of cracks or other flaws. Strain gauges were mounted at $90^{\circ}$ intervals at 4 and 21 in. from the top of the vessel and at three of these $90^{\circ}$ intervals $\left(90^{\circ}, 180^{\circ}\right.$, and $270^{\circ}$ ); gauges were also mounted at $38-3 / 4$ and 21 to $22-1 / 16$ in. from the bottom of the vessel. Gauges mounted in this configuration were intended to determine the presence and locations of any developing crack in the pressure vessel wall. In the absence of a crack, strains around the circumference of the vessel should be the same for all gauges located at the same axial elevation. If a crack were produced, the strains around the circumference would not be equal, and the quadrant in which the crack is located would be identified by an anomalously low strain reading.

Tables 3.2.1 and 3.2.2 provide the location and identification number for the strain gauges applied in 1982 and 1983 on the frame and pressure vessel, respectively. Strain gauges that were applied in 1960 that 
are at or near these 1983 gauge locations are shown in parentheses. Schematic diagrams showing the location of the strain gauge rosettes are provided in Figs. 3.2.1 through 3.2.5.

Sturm \& Krouse mounted strain gauges at some locations on the frame and vessel before the press was assembled. After complete assembly of the press, access to some of these locations is not feasible and in some locations is not possible. Therefore, no new strain gauges were mounted on the inside faces of the frame or at the bottom of the pressure vessel.

Since installation of the strain gauge rosettes in 1982 and 1983, strain measurements have been conducted 15 times between July 29, 1983, and August 5, 1997. During these measurements, strain values were recorded automatically every 59 to $61 \mathrm{sec}$ during increase of pressure from zero to the nominal operating pressure of $30 \mathrm{ksi}$ and all during the time the nominal operating pressure was maintained; and for some operations during descent to ambient pressure. Pressure was not held constant at 5-ksi increments as it was for the manual measurements taken by Sturm \& Krouse. The data acquisition system used to record strains since December 4, 1985, to the present is a Vishay 4000 data acquisition system consisting of five model 4720 strain gauge scanners, a model 4220 controller, and a Hewlett-Packard model 86 computer. It is very difficult, or impossible, to maintain an exactly constant pressure at any pressure, but especially at the lower pressures (e.g., $<15 \mathrm{ksi}$ ) for an extended period of time, such as that required to record strain measurements manually. Therefore, we believe that automatic measurements, which require only $0.6 \mathrm{sec}$ per measurement, to be more accurate and reliable than the strain measurements recorded manually at 5-ksi increments (which was the best method available in 1960). Conversion of strain to stress for these measurements was conducted with the same methodology described in Section 3.1.1 for the gauges mounted in 1960 . 
Table 3.2.1. Location and identification of strain gauge rosettes mounted on the PV-4 frame in 1982 and 1983. Gauges mounted in 1960 that are at or near the 1982 and 1983 gauge locations are shown in parentheses.

\begin{tabular}{ll}
\hline Rosette & Location \\
\hline 1. (77-79) & Left side, by bottom fillet, plate \#1, flat side, opposite \#24 \\
2. (45) & Left side, 2 in. from edge, plate \#1, flat side, mid-section \\
3. (21) & Left side, flat side by top fillet, plate \#1, 2 in. from edge \\
4. (101-103) & Left side, flat side, middle of bottom fillet \\
5. (64) & Left side, edge of plate \#12 \\
11. (40) & Left side, edge of plate \#12 \\
12. (37) & Left side, edge of plate \#1, same vertical plane as \#11 \\
22. (23) & Right side, flat side, plate \#1, by top fillet, opposite \#3 \\
23. (68) & Right side, edge of plate \#12, same vertical plane as \#24 \\
24. (80-82) & Right side, by bottom fillet, plate \#1, opposite \#1 \\
25. (104-106) & Right side, by bottom fillet, plate \#1, opposite \#4 \\
26. (83-85) & Right side, backside of plate \#12, viewed from front \\
27. (86-88) & Left side, backside of plate \#12, viewed from front \\
28. & Left side, plate \#1, above bottom tie bolts \\
29. & Left side, plate \#12, above bottom tie bolts \\
30. & Right side, plate \#1, above bottom tie bolts \\
31. & Right side, plate \#12, above bottom tie bolts \\
\hline
\end{tabular}


Table 3.2.2. Location and identification of strain gauge rosettes mounted on the outer surface of the PV-4 pressure vessel in 1982 and 1983. Gauges mounted in 1960 that are at or near the 1982 and 1983 gauge locations are shown in parentheses.

\begin{tabular}{ll}
\hline Rosette & Location \\
\hline 6. & $90^{\circ}, 4$ in. from top edge \\
7. & $90^{\circ}, 21$ in. from top edge \\
8. & $90^{\circ}, 38.75$ in., from bottom edge \\
9. & $180^{\circ}, 38.75$ in. from bottom edge \\
10. $(135,136)$ & $180^{\circ}, 22$ in. from bottom edge \\
13. & $270^{\circ}, 4$ in. from top edge \\
14. & $270^{\circ}, 21$ in. from top edge \\
15. $(121,122)$ & $0^{\circ}, 4$ in. from top edge \\
16. $(125,126)$ & $0^{\circ}, 21$ in. from top edge \\
17. & 10 in. (circ.) C.C.W. from $270^{\circ}, 38.75$ in. from bottom edge \\
18. & Offset 10 in. (circ.) C.C.W. from $270^{\circ}, 22$ in. from bottom edge \\
19. $(123,124)$ & $180^{\circ}, 4$ in. from top \\
20. $(127,128)$ & $180^{\circ}, 21$ in. from top \\
21. & $90^{\circ}, 21$ in. from bottom \\
$32 .^{a}$ & $315^{\circ}, 37$ in. C.W from $0^{\circ}, 12$ in. from top \\
33. & $315^{\circ}, 37$ in. CW from $0^{\circ}, 34$ in. from top \\
35. & $45^{\circ}, 36$ in. CCW from $0^{\circ}, 10.5$ in. from top \\
\hline
\end{tabular}

${ }^{a}$ Added in 1988. 


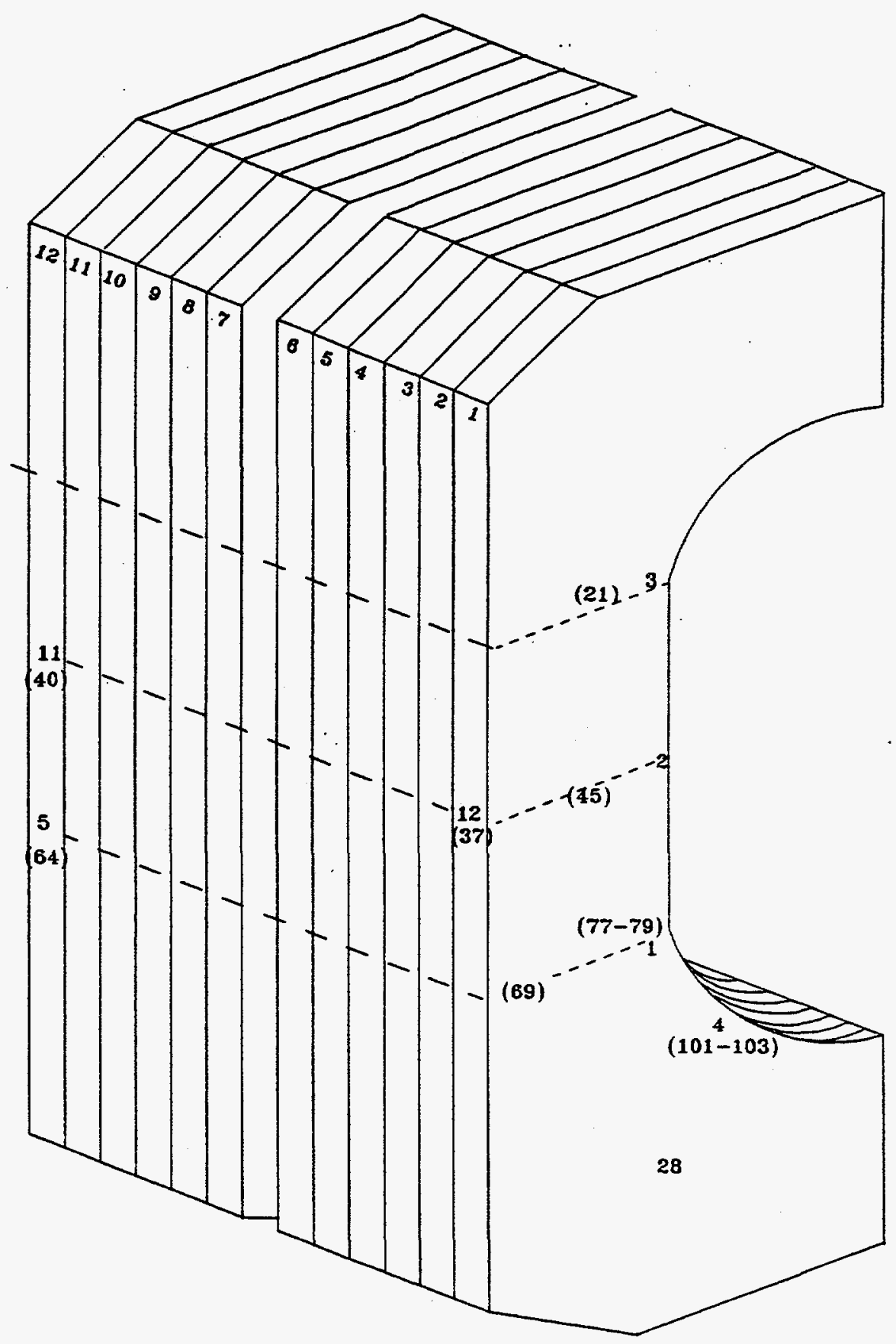

Fig. 3.2.1. Schematic diagram showing locations of strain gauge rosettes applied in 1982 and 1983 on the left outside and front of the PV-4 frame. Strain gauges that were applied in 1960 that are at or near the 1982 and 1983 rosette locations are shown in parentheses. 


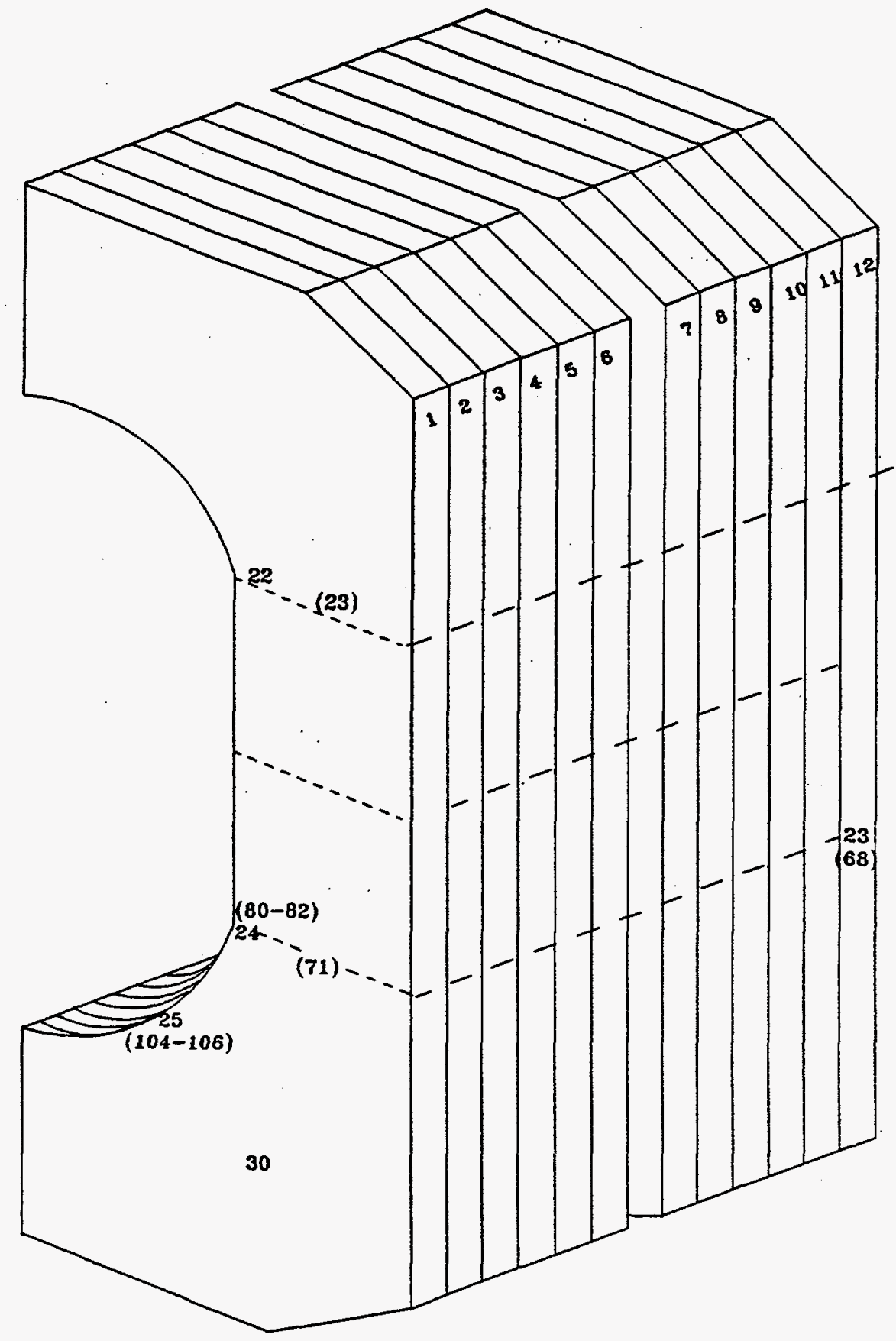

Figure 3.2.2. Schematic diagram showing locations of strain gauge rosettes applied in 1982 and 1983 on the right outside and front of the PV-4 frame. Strain gauges that were applied in 1960 that are at or near the 1982 and 1983 rosette locations are shown in parentheses. 


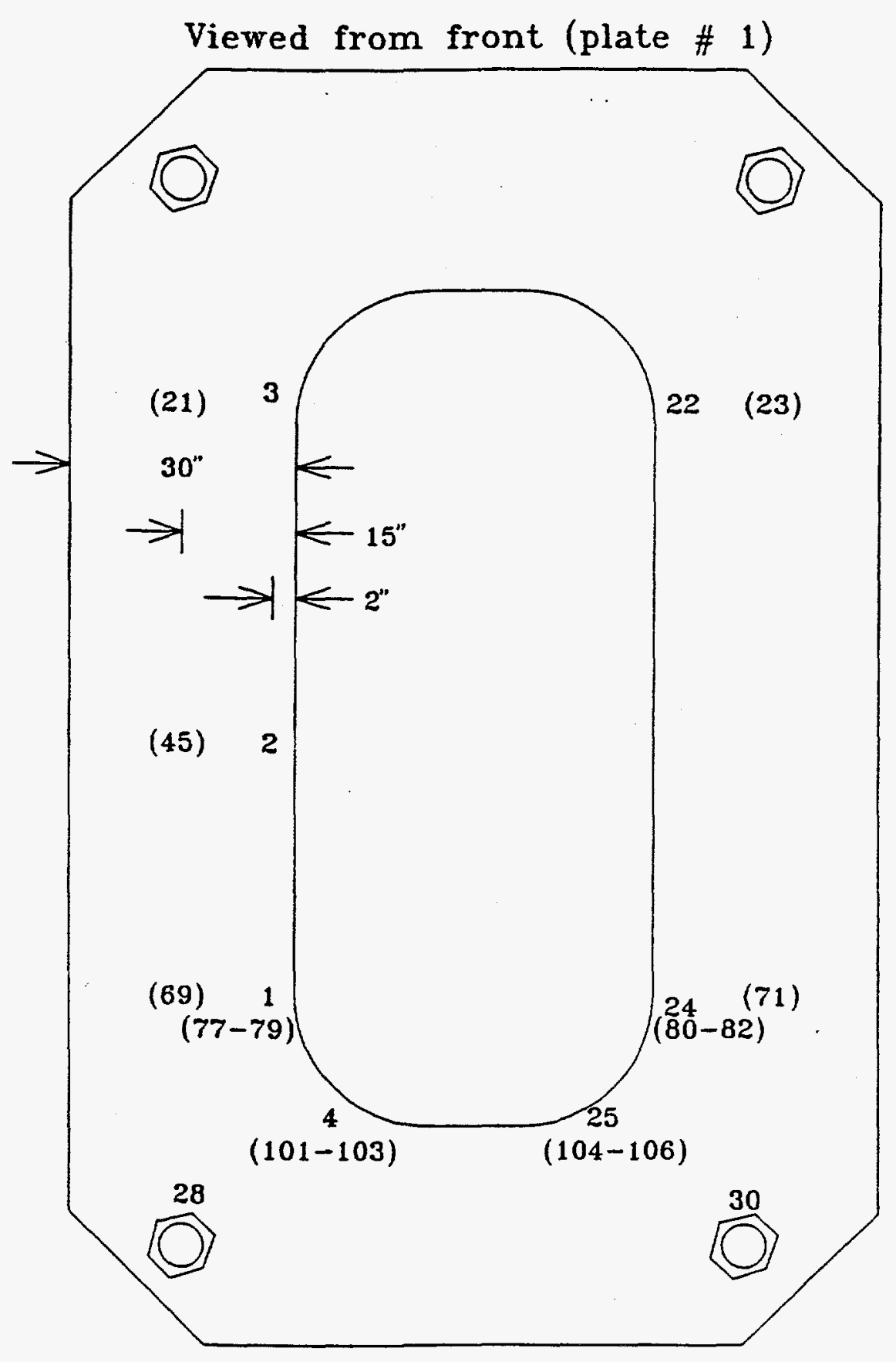

Fig. 3.2.3. Schematic diagram showing locations of strain gauge rosettes applied in 1982 and 1983 on the front plate (\#1) of the PV-4 pressure vessel frame. Strain gauges that were applied in 1960 that are at or near the 1982 and 1983 rosette locations are shown in parentheses. 


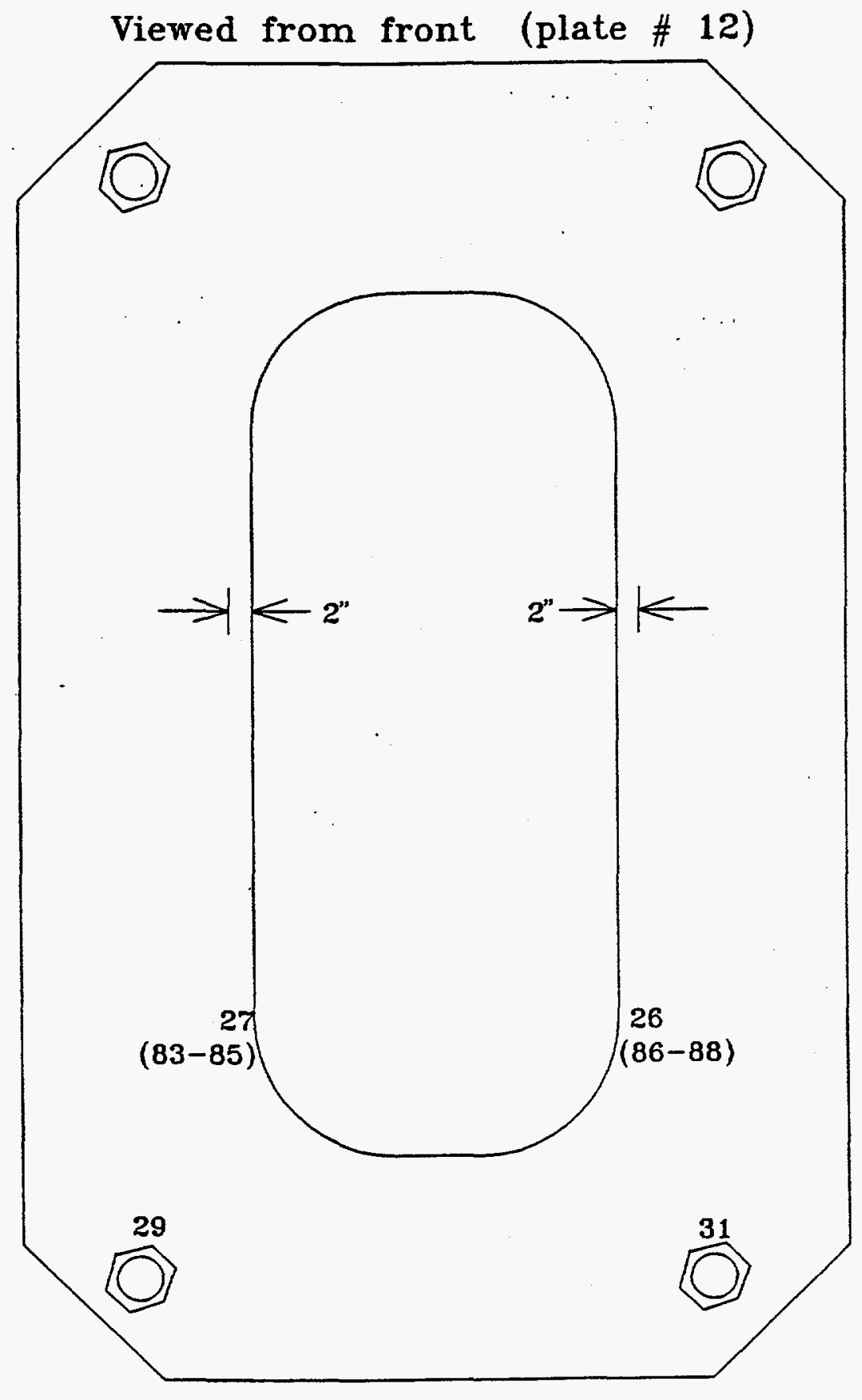

Fig. 3.2.4. Schematic diagram showing locations of strain gauge rosettes applied in 1982 and 1983 on the back plate (\#12) of the PV-4 pressure vessel frame. Strain gauges that were applied in 1960 that are at or near the 1982 and 1983 rosette locations are shown in parentheses. 

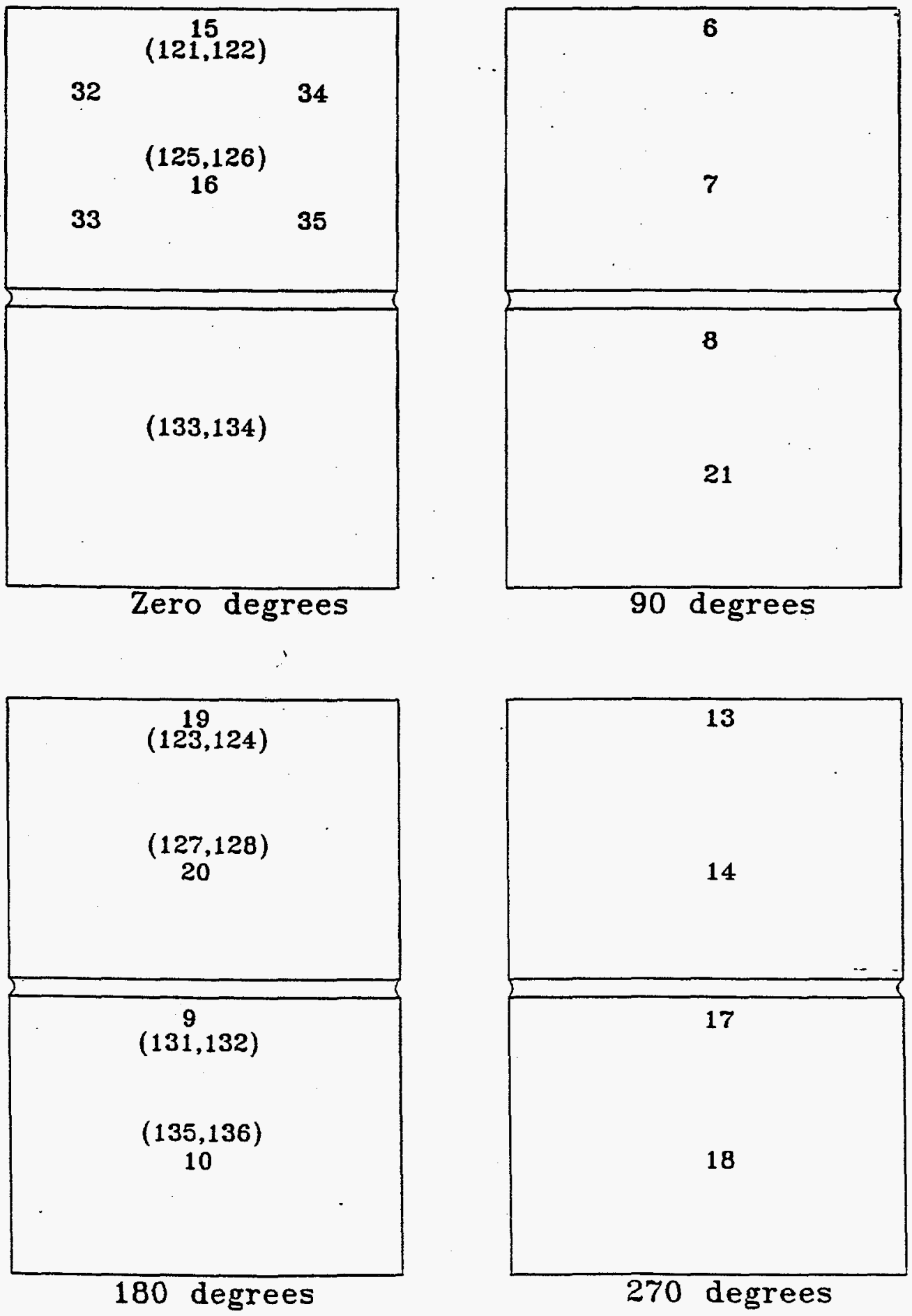

Fig. 3.2.5. Schematic diagram showing locations of strain gauge rosettes applied in 1982 and 1983 on the surface of the PV -4 pressure vessel. Strain gauges that were applied in 1960 that are at or near rosette locations are shown in parentheses. Rosettes 32-35 were added in 1988. 


\section{RESULTS AND DISCUSSION}

\subsection{Strain Measurements Conducted in 1960}

Increasing the operating pressure from 0 to $30 \mathrm{ksi}$ in 5-ksi increments, Sturm \& Krouse observed that, at every gauge on the frame and pressure vessel, strain increased linearly with increasing operating pressure. The same behavior was observed upon decreasing the pressure in 5-ksi increments from 30 to 0 ksi. These data indicated totally elastic behavior of the steels of which the press was constructed.

Subsequently, the strain gauges were rezeroed, the pressure in the internal chamber was increased directly to $30 \mathrm{ksi}$, and strain data were recorded at this pressure. To determine the effects of operating at internal pressures higher than the design maximum operating pressure, the internal pressure was increased to $32 \mathrm{ksi}$ and strain gauge data recorded; then the pressure was further increased to $33 \mathrm{ksi}$ and strain gauge data were again recorded. The pressure was then relieved incrementally and strain gauge values recorded at $30,25,20,10$, and $0 \mathrm{ksi}$ internal pressure (Ref. 6). Based on these measurements, their report contains plots of strain as a function of internal pressure for every gauge for which data were obtained. From these plots they provide the slope of the measured strain as a function of internal pressure for all 133 gauges. This information and stresses at internal pressures of 30,32, and $33 \mathrm{ksi}$ are contained in nine summary tables in their report (Ref. 6).

Tables 4.1.1 through 4.1.3 show the stresses for the strain gauges located at the top, axial midplane and bottom, respectively, of the PV-4 frame for an operating pressure of $30 \mathrm{ksi}$. As shown in Appendix B, in accordance with a linear increase in strain as a function of applied stress in the elastic deformation range, stresses at $33 \mathrm{ksi}$ are, within experimental accuracy, $10 \%$ higher than the stresses at $30 \mathrm{ksi}$. The pressure vessel had been proof tested at $37.5 \mathrm{ksi}$ by the manufacturer, and linear elastic behavior was expected for the tests at 32 and $33 \mathrm{ksi}$ (Ref. 1). Because the design operating pressure of PV-4 was $30 \mathrm{ksi}$ and the press has never been operated at a pressure greater than $31 \mathrm{ksi}$ since the preoperational tests on September 9,1960, emphasis in this report is on measured stresses on the frame and vessel at operating pressures between 0 and $30 \mathrm{ksi}$. These measurements are the most important for this report because it is the measured stresses at an internal pressure of $30 \mathrm{ksi}$ and the slopes of the strain as a function of 
Table 4.1.1. Stresses at the top of the PV-4 frame for an operating pressure of $30 \mathrm{ksi}$

\begin{tabular}{|c|c|c|c|}
\hline & \multicolumn{2}{|c|}{ Location } & \multirow{2}{*}{$\begin{array}{r}\text { Stress (ksi) } \\
\text { Pressure (30 ksi) }\end{array}$} \\
\hline Gauge & Plate & Side & \\
\hline \multicolumn{4}{|c|}{ Inside Faces at Top } \\
\hline 1 & 1 & Left & 51.8 \\
\hline 2 & 4 & Left & 50.4 \\
\hline 3 & 6 & Left & 47.3 \\
\hline 4 & 7 & Left & 50.0 \\
\hline 5 & 9 & Left & 49.5 \\
\hline 6 & 12 & Left & 51.8 \\
\hline 7 & 1 & Right & 46.8 \\
\hline 8 & 4 & Right & 46.4 \\
\hline 9 & 6 & Right & 50.0 \\
\hline 10 & 7 & Right & 50.0 \\
\hline 11 & 9 & Right & 49.1 \\
\hline 12 & 12 & Right & 50.4 \\
\hline \multicolumn{4}{|c|}{ Midway Between Inside and Outside Surfaces } \\
\hline 21 & 1 & Left front & 23.4 \\
\hline 22 & 12 & Left back & 30.6 \\
\hline 23 & 1 & Right front & 29.4 \\
\hline 24 & 12 & Right back & 30.6 \\
\hline \multicolumn{4}{|c|}{ Inside Faces at Top } \\
\hline 13 & 1 & Left & 23.4 \\
\hline 14 & 4 & Left & 24.3 \\
\hline 15 & 9 & Left & 24.8 \\
\hline 16 & 12 & Left & 24.8 \\
\hline 17 & 1 & Right & 24.8 \\
\hline 18 & 4 & Right & 24.3 \\
\hline 19 & 9 & Right & 25.2 \\
\hline 20 & 12 & Right & 26.1 \\
\hline
\end{tabular}


Table 4.1.2. Stresses at the middle of the PV-4 frame for an operating pressure of $30 \mathrm{ksi}$

\begin{tabular}{|c|c|c|c|}
\hline & \multicolumn{2}{|c|}{ Location } & \multirow{2}{*}{$\begin{array}{r}\text { Stress (ksi) } \\
\text { Pressure (30 ksi) }\end{array}$} \\
\hline Gauge & Plate & Side & \\
\hline \multicolumn{4}{|c|}{ Inside Faces of Frame at Axial Midplane } \\
\hline 29 & 1 & Left & 37.8 \\
\hline 30 & 4 & Left & 37.4 \\
\hline 31 & 9 & Left & 38.7 \\
\hline 32 & 12 & Left & 38.7 \\
\hline 33 & 4 & Right & 37.4 \\
\hline 34 & 4 & Right & 37.8 \\
\hline 35 & 9 & Right & 39.6 \\
\hline 36 & 12 & Right & 39.6 \\
\hline \multicolumn{4}{|c|}{ Midway Between Inside and Outside Faces at Axial Midplane } \\
\hline 45 & 1 & Left Front & 36.9 \\
\hline 46 & 12 & Left Back & 27.9 \\
\hline 47 & 1 & Right Front & 24.3 \\
\hline 48 & 12 & Right Back & 30.3 \\
\hline \multicolumn{4}{|c|}{ Outside Faces of Frame and Axial Midplane } \\
\hline 37 & 1 & Left & 46.8 \\
\hline 38 & 4 & Left & 46.4 \\
\hline 39 & 9 & Left & 50.0 \\
\hline 40 & 12 & Left & 50.0 \\
\hline 41 & 1 & Right & 21.2 \\
\hline 42 & 4 & Right & 21.2 \\
\hline 43 & 9 & Right & 22.5 \\
\hline 44 & 12 & Right & 23.0 \\
\hline
\end{tabular}


Table 4.1.3. Stresses at the bottom of the PV-4 frame for an operating pressure of $30 \mathrm{ksi}$

\begin{tabular}{|c|c|c|c|}
\hline & \multicolumn{2}{|c|}{ Location } & \multirow{2}{*}{$\begin{array}{r}\text { Stress (ksi) } \\
\text { Pressure (30 ksi) }\end{array}$} \\
\hline Gauge & Plate & Side & \\
\hline \multicolumn{4}{|c|}{ Inside Faces of Frame at Bottom } \\
\hline 49 & 1 & Left & 54.0 \\
\hline 50 & 4 & Left & 52.7 \\
\hline 51 & 6 & Left & 52.2 \\
\hline 52 & 7 & Left & 53.6 \\
\hline 53 & 9 & Left & 55.8 \\
\hline 54 & 12 & Left & 51.3 \\
\hline 55 & 1 & Right & 50.4 \\
\hline 56 & 4 & Right & 51.3 \\
\hline 57 & 6 & Right & 52.7 \\
\hline 58 & 7 & Right & 54.0 \\
\hline 59 & 9 & Right & 54.9 \\
\hline 60 & 12 & Right & 52.7 \\
\hline \multicolumn{4}{|c|}{ Midway Between Inside and Outside Faces at Bottom } \\
\hline 69 & 1 & Left Front & 24.8 \\
\hline 70 & 12 & Left Back & 30.6 \\
\hline 71 & 1 & Right Front & 31.1 \\
\hline 72 & 12 & Right Back & 29.7 \\
\hline \multicolumn{4}{|c|}{ Outside Faces of Frame at Bottom } \\
\hline 61 & 1 & Left & 23.0 \\
\hline 62 & 4 & Left & 22.5 \\
\hline 63 & 9 & Left & 22.1 \\
\hline 64 & 12 & Left & 23.4 \\
\hline 65 & 1 & Right & 21.6 \\
\hline 66 & 4 & Right & 20.7 \\
\hline 67 & 9 & Right & 23.9 \\
\hline 68 & 12 & Right & 24.3 \\
\hline
\end{tabular}


internal pressure from 0 to $30 \mathrm{ksi}$ measured in 1960 that we compare with our measurements of the same parameters from 1983 to 1997 to provide an evaluation of the condition of the press, to assess the structural integrity of the pressure vessel, and to ascertain that no relaxation of the shrink-fit pressure has occurred. To provide all of the pertinent data in one document, all of the measured strains and calculated stresses on the PV-4 frame and vessel for an operating pressure of $33 \mathrm{ksi}$ are provided in Appendix B. Strains and stresses at $20 \mathrm{ksi}$ contained in Ref. 6 are not included in this report.

Figures 4.1.1 and 4.1.2 are schematic diagrams showing the stresses at the locations of the highest stresses on the frame, on the inside surfaces. As expected, stresses were highest on the inside surface at the top and bottom intersection of the straight and curved portions of the frame. This is most probably why Sturm \& Krouse placed six strain gauges on each half of the frame at these intersections and only four strain gauges at the center of the frame. The stress values shown in Figs. 4.1.1 and 4.1.2 indicate that the load transfer blocks at the top and bottom of the pressure vessel were extremely effective in transferring the stresses for the cylindrical pressure vessel to the rectangular frame. Stresses are similar from the front of the frame to the back of the frame (plates 1 through 12), from the left side to the right side, and at the top and bottom of the frame. Note however, in Figs. 4.1.1 and 4.1.2, the stresses are slightly higher at the bottom of the frame than at the top of the frame and on the left side of the frame than on the right side of the frame.

This difference in stresses may have been eliminated after the vessel had been rolled out of and back into the frame a few times for loading and unloading of the materials to be isostatically pressed. Recall that Sturm \& Krouse conducted these measurements prior to any actual use of the press. There are no indications in their report that they repeated these measurements after simulating loading and unloading of materials into the compression chamber. Also, it may well be that within the accuracy of machining and assembling of the press, the distribution of stresses varies slightly from operation to operation but the magnitude of the stresses remains approximately the same for each operation.

Figure 4.1.3 shows the average stresses for the strain gauges on the inside surface, midway between the inside and outside surfaces and on the outside surface of PV-4 while at an internal pressure of $30 \mathrm{ksi}$ on September 9, 1960. Except for one location, stresses decrease significantly more rapidly than linear from the inside surface to the mid-thickness of the frame, and then decrease slowly (less than linear) from the mid-thickness to the outer surface. As shown in Fig. 4.1.3, the one exception to this pattern is in 


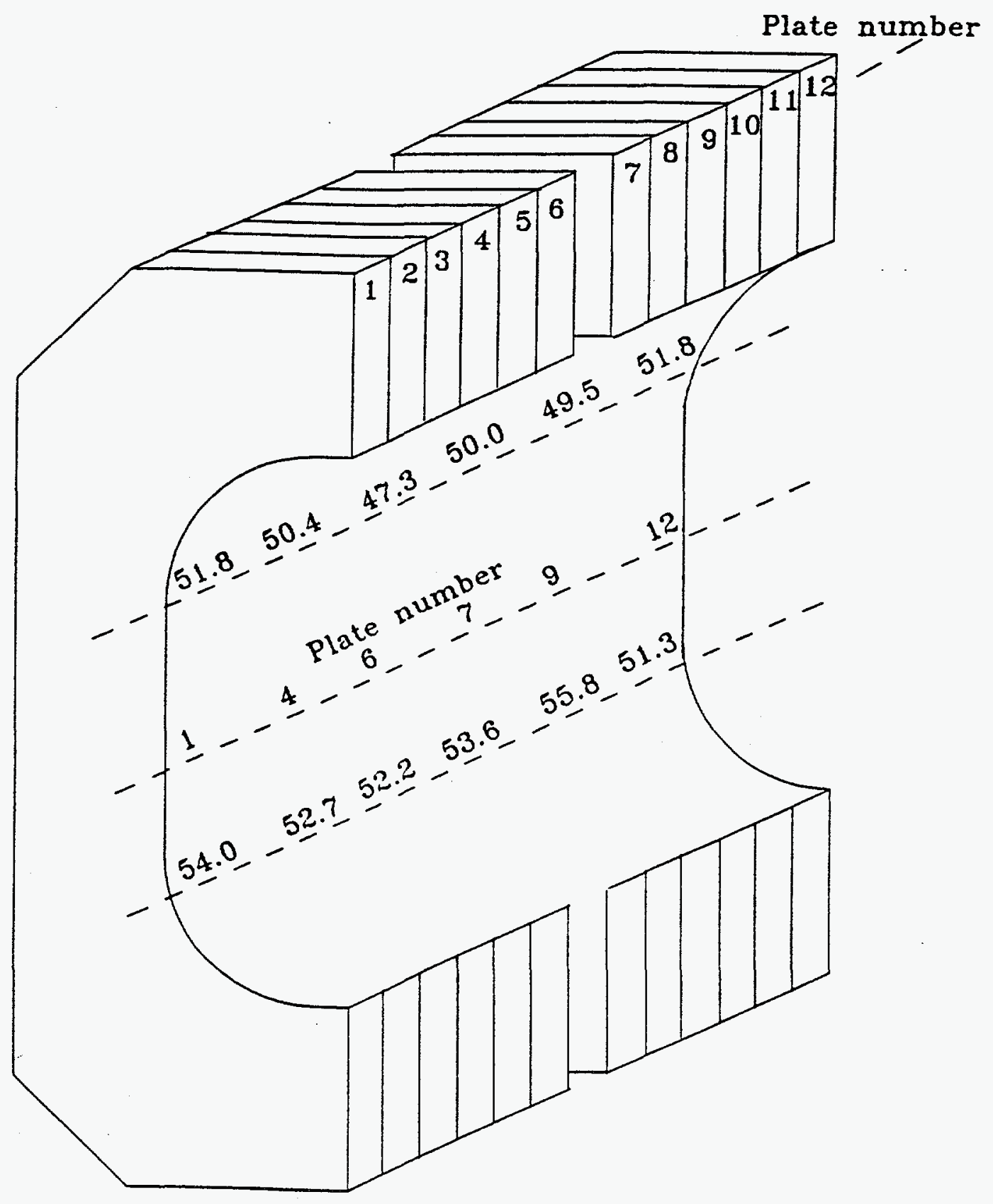

Fig. 4.1.1. Stresses (ksi) on the left inside surface of the frame of PV-4 during operation at a nominal internal pressure of $30 \mathrm{ksi}$ on September 9, 1960. 


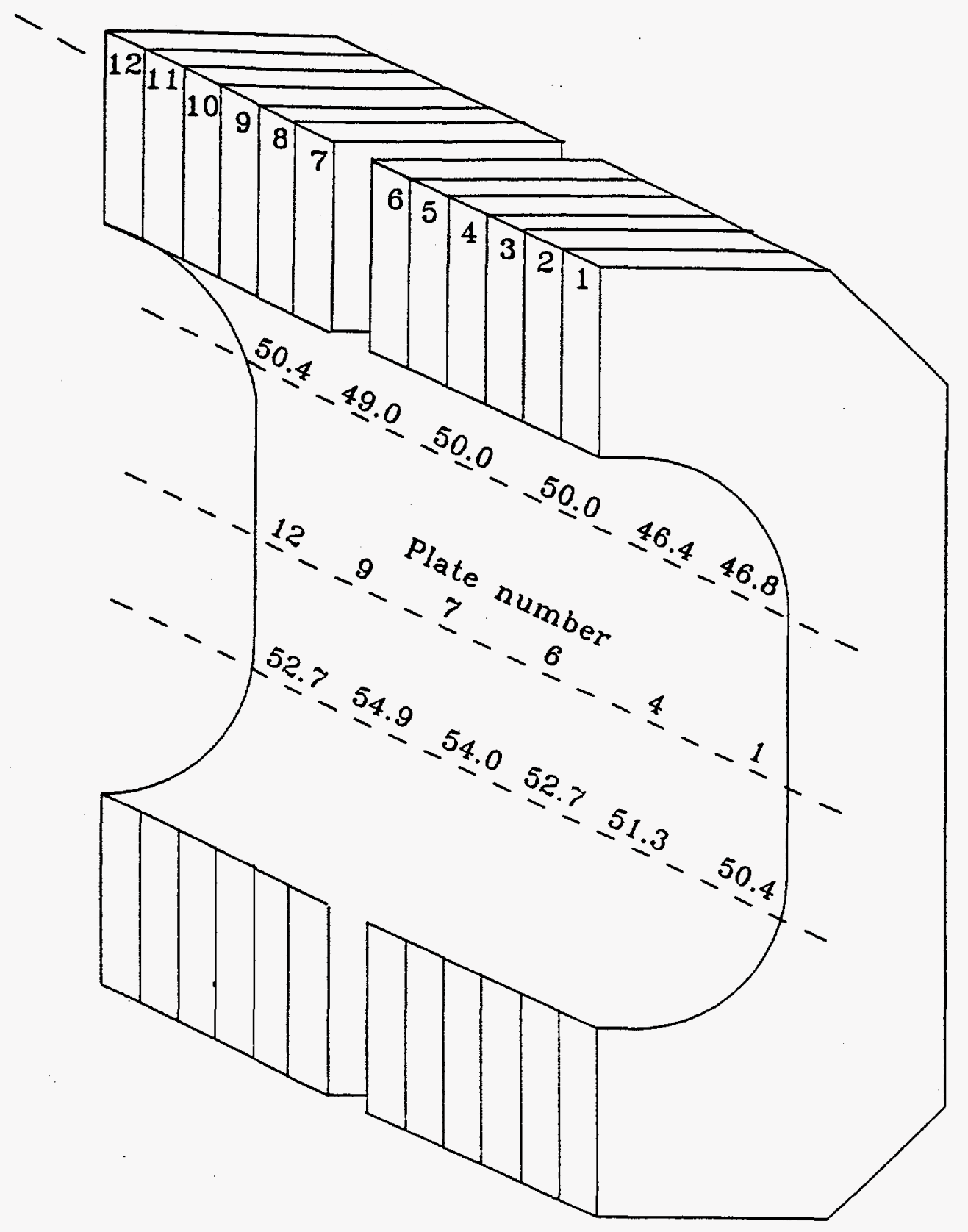

Fig. 4.1.2. Stresses (ksi) on the right inside surface of the frame of PV -4 during operation at a nominal internal pressure of $30 \mathrm{ksi}$ on September 9, 1960. 

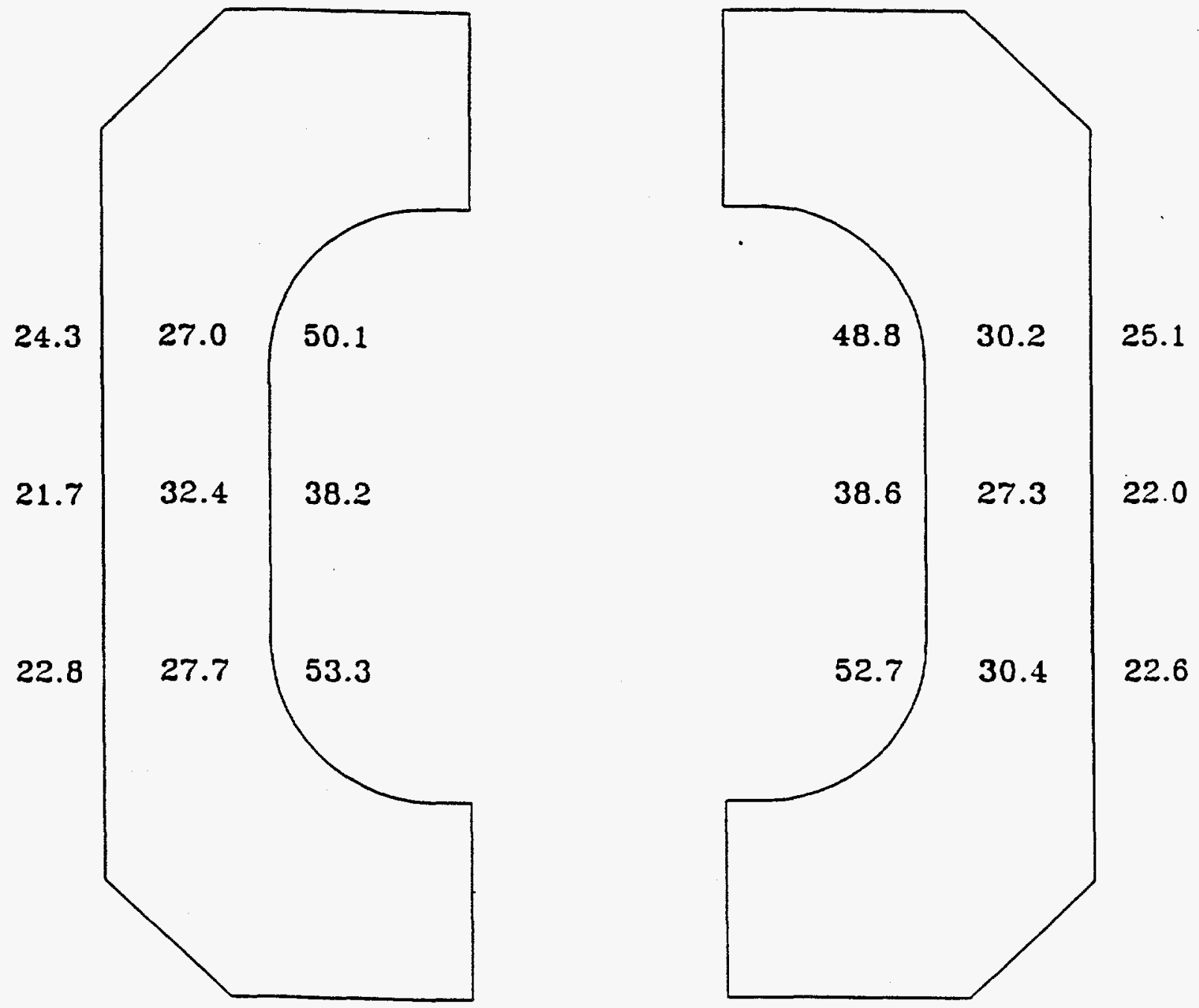

Fig. 4.1.3. Average stresses (ksi) at inside faces, outside faces, and midway between these faces for PV -4 at an operating pressure of $30 \mathrm{ksi}$ on September 9, 1960. 
the stresses at the axial mid-plane on the left side of the frame. At this location, the decrease in stress from the inner surface to the mid-thickness is less than the decrease from the mid-thickness to the outer surface. Although Sturm \& Krouse recorded strain values at least three times while the internal pressure was at 30 ksi, they did not present any other information on the repeatability of the strain measurements. As shown in Tables 4.1.1 through 4.1.3, stresses on the outside surfaces were so low that diagrams similar to those shown in Figs. 4.1.1 and 4.1.2 were not prepared for the outside surfaces.

Figures 4.1.4 and 4.1.5 show the stresses for the strain gauges mounted on the front (plate 1) and back (plate 12) of the frame. The data are consistent except for the stresses at gauges 89 to 91 on the front plate and gauges 110 to 112 on the back plate. The maximum stress at gauges 89 to 91 was only $11.2 \mathrm{ksi}$, whereas stresses at symmetrical locations on the front plate (gauges 92 to 94) and back plate (gauges 95 to 97 and 98 to 100) range from 37.2 to $38.6 \mathrm{ksi}$. The maximum stress for gauges 110 to 112 on the back plate was only $6.7 \mathrm{ksi}$, whereas stresses at symmetrical locations on the front plate (gauges 104 to 106) and back plate (gauges 107 to 109) were 14.8 and $13.9 \mathrm{ksi}$, respectively. No data were reported for gauges 101 to 103. As stated previously, Sturm \& Krouse did not report data for repeat tests which may have provided information on why stresses at these locations were so low relative to the stresses at symmetrical locations. The most probable explanation for the observed low stresses is inadequate bonding of the strain gauge to the frame, resulting in poor transfer of the strain from the plate to the gauge.

Table 4.1.4 shows the stresses on the outside surface of the PV-4 pressure vessel at an operating pressure of $30 \mathrm{ksi}$ on September 9, 1960. To provide a direct comparison with the stresses measured on the frame with single strain gauges, the stresses on the pressure vessel using the single strain gauge calculation are shown in column one and the stresses using the two strain gauge calculations are shown in column two. Stresses calculated using the two strain gauge calculations include Poisson's ratio; therefore, they include contributions of stresses normal to the two principal directions listed in Table 4.1.4. For the circumferential stresses, there is a $5 \%$ or less difference in the stresses calculated by the two different methods. A larger difference is seen in the axial stresses, which change from negative low values to positive low values. Schematic diagrams showing these stresses and their locations on the surface of the pressure vessel are provided in Figs. 4.1.6 and 4.1.7, respectively. 


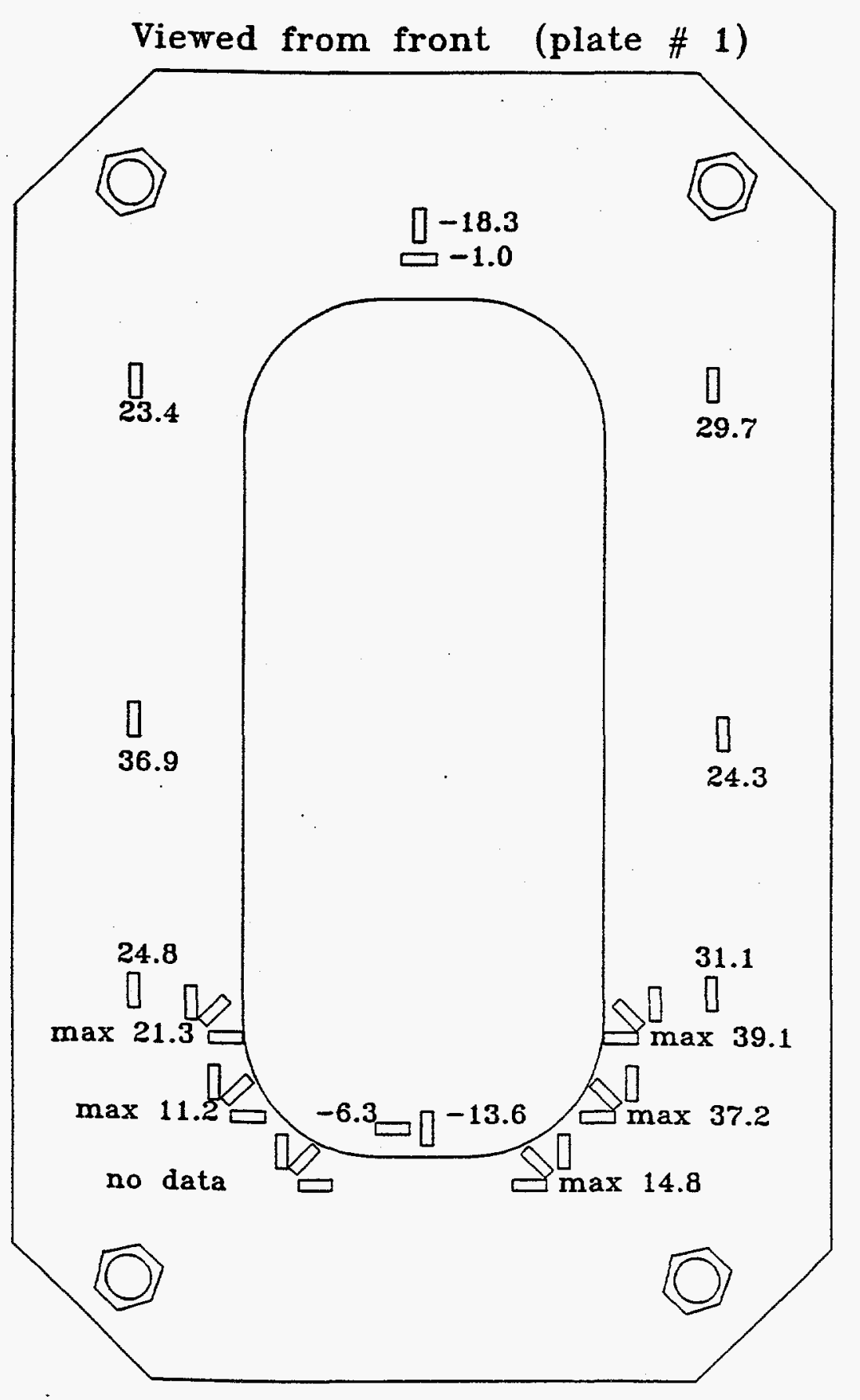

Fig. 4.1.4. Stresses (ksi) on the front of the frame of PV-4 at a nominal internal pressure of $30 \mathrm{ksi}$ on September 9, 1960. 


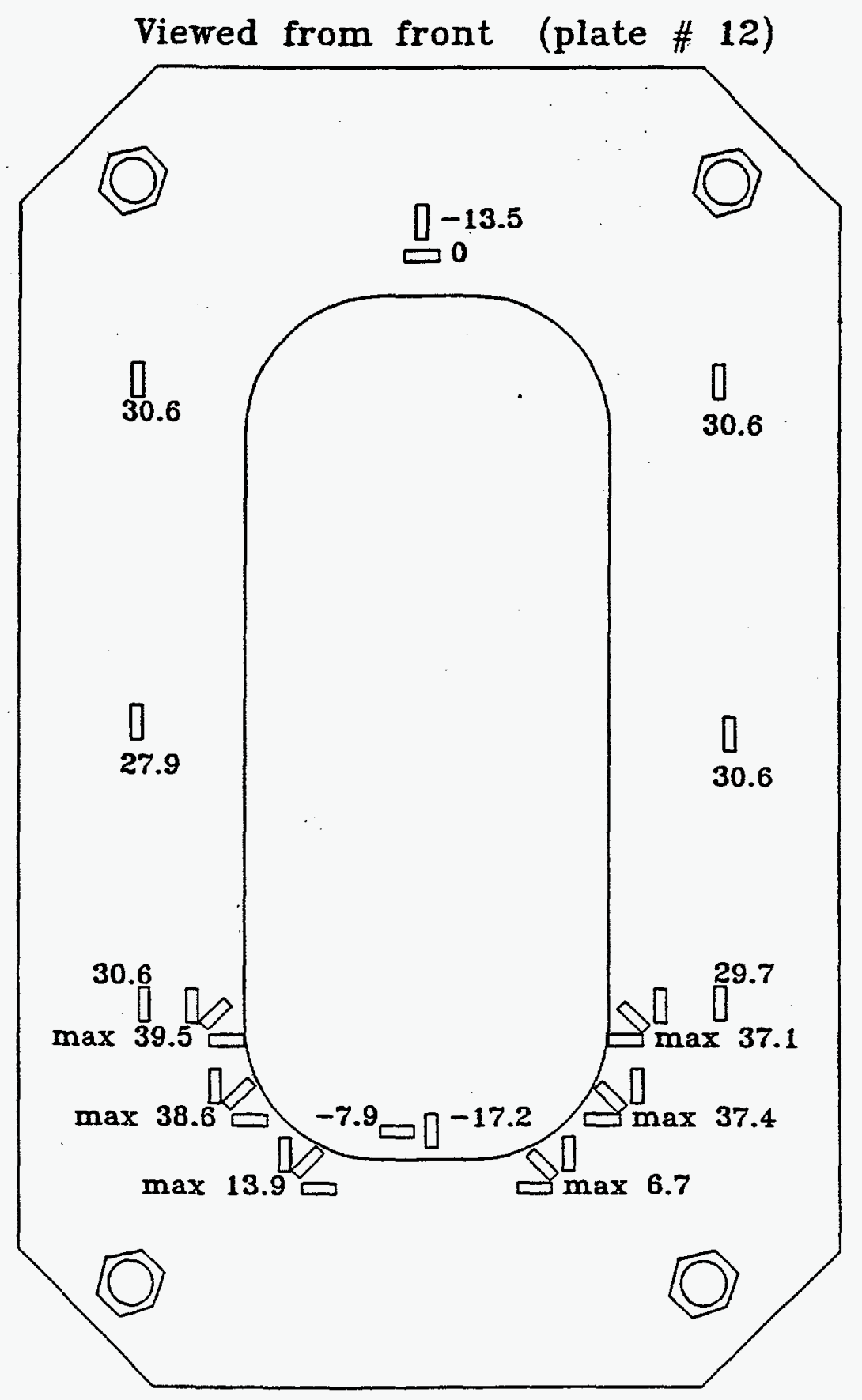

Fig. 4.1.5. Stresses (ksi) on the back of the frame of PV -4 at a nominal internal pressure of $30 \mathrm{ksi}$ on September 9, 1960. 
Table 4.1.4 Stresses on the surface of the PV-4 pressure vessel on September 9, 1960, with an internal pressure of $30 \mathrm{ksi}$

\begin{tabular}{|c|c|c|c|}
\hline \multirow[b]{2}{*}{ Gauge $^{a}$} & \multirow[b]{2}{*}{ Location } & \multicolumn{2}{|c|}{ Stress (ksi) } \\
\hline & & Single gauge value & $\begin{array}{c}\text { Two element rosette } \\
\text { calculation }\end{array}$ \\
\hline 121 & $0^{\circ}, 4$ in. from top & 40.5 & 42.5 \\
\hline 122 & $0^{\circ}, 4$ in. from top & -6.1 & 6.7 \\
\hline 123 & $180^{\circ}, 4$ in. from top & 40.5 & 42.5 \\
\hline 124 & $180^{\circ}, 4$ in. from top & -6.3 & 6.4 \\
\hline 125 & $0^{\circ}, 21$ in. from top & 51.8 & 54.4 \\
\hline 126 & $0^{\circ}, 21$ in. from top & -7.6 & 8.7 \\
\hline 127 & $180^{\circ}, 21$ in. from top & 52.6 & 55.2 \\
\hline 128 & $180^{\circ}, 21$ in. from top & -8.1 & 8.5 \\
\hline 129 & $0^{\circ}$, top, 2 in. from center & 55.8 & 56.4 \\
\hline 130 & $0^{\circ}$, top, 2 in. from center & -14.6 & 2.1 \\
\hline 131 & $0^{\circ}$, bottom, 2 in. from center & 56.2 & 57.8 \\
\hline 132 & $0^{\circ}$, bottom, 2 in. from center & -12.2 & 5.2 \\
\hline 133 & $0^{\circ}, 21$ in. from bottom & 49.5 & 53.1 \\
\hline 134 & $0^{\circ}, 21$ in. from bottom & -4.0 & 11.9 \\
\hline 135 & $180^{\circ}, 21$ in. from bottom & 50.4 & 53.2 \\
\hline 136 & $180^{\circ}, 21$ in. from bottom & -6.6 & 9.4 \\
\hline 137 & $0^{\circ}, 4$ in. from bottom & 33.3 & 35.0 \\
\hline 138 & $0^{\circ}, 4$ in. from bottom & -5.0 & 5.6 \\
\hline 139 & $180^{\circ}, 4$ in. from bottom & 33.3 & 35.2 \\
\hline 140 & $180^{\circ}, 4$ in. from bottom & -4.5 & 6.0 \\
\hline
\end{tabular}

"Gauges with even numbers are axial gauges and gauges with odd numbers are circumferential gauges. 

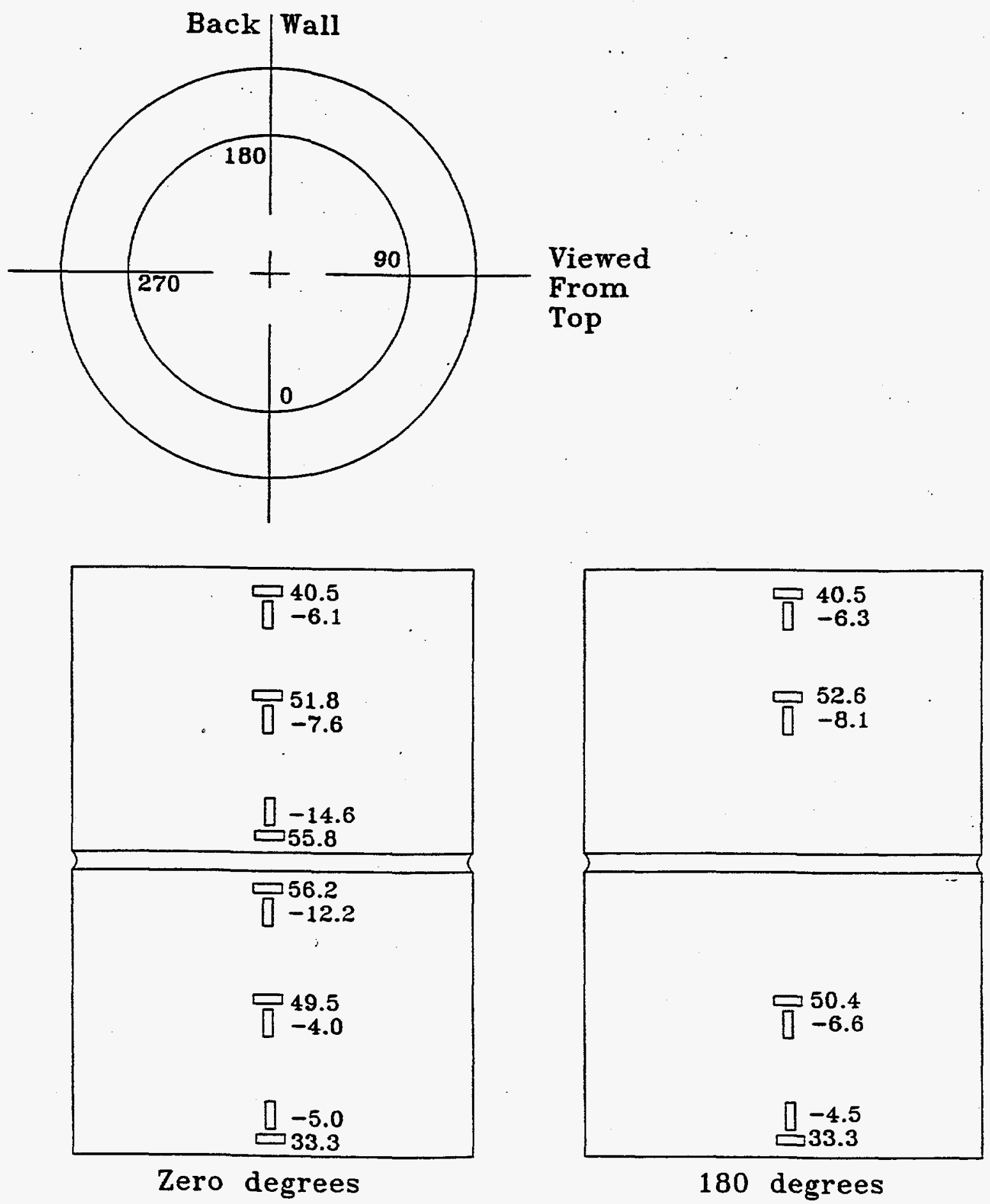

Fig. 4.1.6. Stresses (ksi) measured for individual strain gauges on the outer surface of the PV-4 pressure vessel on September 9,1960 , at a pressure of $30 \mathrm{ksi}$ in the working chamber. 

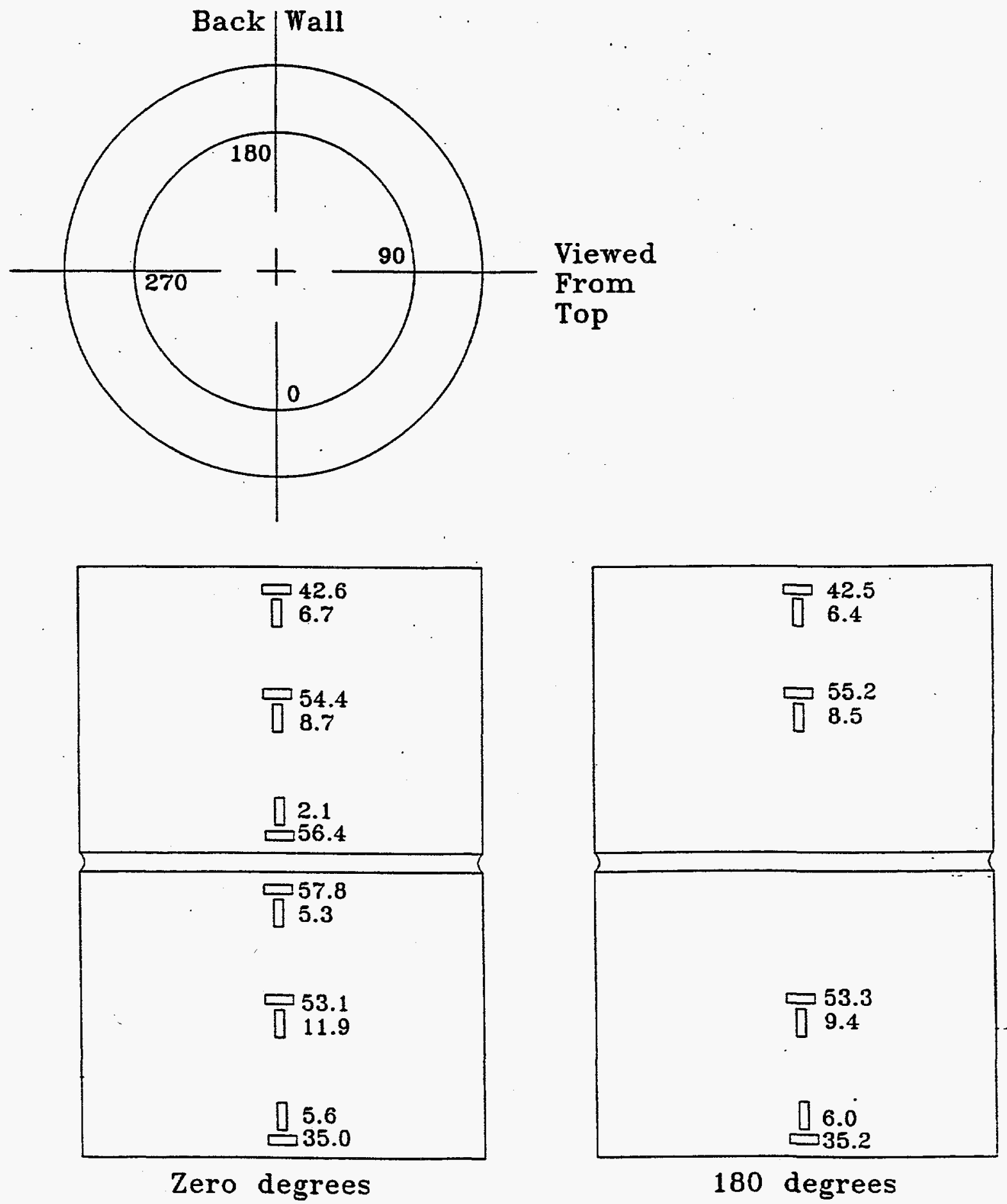

Fig. 4.1.7. Stresses (ksi) on the outer surface of the PV-4 pressure vessel calculated with the twogauge rosette equations on September 9, 1960, at a pressure of $30 \mathrm{ksi}$ in the working chamber. 
There is excellent agreement of the stresses which are at the same vertical locations on the vessel. Stresses are maximum near the circumferential groove at the axial mid-plane of the vessel. Note also in Fig. 4.1.6 that circumferential stresses 4 in. from the bottom of the vessel are approximately $20 \%$ lower (35.1 vs. $42.6 \mathrm{ksi}$ ) than those 4 in. from the top of the vessel. Axial stresses were all very low with maximum stresses of 8.5 to $11.9 \mathrm{ksi}$ occurring midway between the ends of the vessel and the groove at the axial centerplane. This groove includes the 0.030-in. gap between the top and bottom halves of the outermost cylinder of the pressure vessel. This difference in stresses at the top and bottom of the vessel is due primarily to the 1-in. greater thickness of the lower $10.4 \mathrm{in.}$ of the liner, the inner membrane of the triplex vessel wall. There may also be some influence of the precise locations of the gauges near the top and bottom of the pressure vessel.

\subsection{Strain Measurements Conducted from 1983 to the Present}

Strain data on the PV-4 frame and pressure vessel have been recorded at 15 different times from July 29,1983 , to August 5,1997. With the data acquisition system available in 1983, only 20 channels of data could be recorded at the same time. Therefore, for the different dates on which strain data were obtained between July 29, 1983, and August 7, 1985, strains were recorded for only three to five rosettes on each date. In 1985 a new data acquisition system was procured that was capable of recording up to 100 channels of data at the same time. For the different dates on which strain data were obtained between December 4, 1985, and August 5, 1987, strains were recorded for 25 to 28 rosettes on each date. In addition, the new data acquisition system provided the capability to measure and record the strain gauge zero point for each strain gauge on the frame and vessel. The zero strain value is the strain value of a gauge when the pressure vessel is open to the atmosphere and there is no pressure within the chamber. Minor changes in the zero reading almost always exist from one data acquisition time to another. These are usually associated with electrical noise due to changes in contact resistance among the many electrical circuits in the data acquisition hardware, strain gauges and strain gauge lead wires being connected to different terminals at different data acquisition times, or aging of the adhesive that bonds the strain gauge to the frame and vessel. At PV-4, the ubiquitous presence of mineral oil could be a significant source of differences in contact resistance for strain readings taken at different times. 
Variations in zero values are usually random and of magnitudes of a few microstrain to several tens of microstrain. Continued bias of the zero reading in one direction over long periods of time is most often due to aging of the adhesive that is used to bond the strain gauge to the surface to be monitored and/or aging of the resin in which the strain gauge wires are embedded. In this section, analyses of the zero strain readings from December 4, 1985, to August 5, 1997, are used to determine if there has been a relaxation of the shrink-fit pressures at the interfaces of the three layers of the pressure vessel. Strain data were recorded every 59 to $61 \mathrm{sec}$ during increase of the pressure from 0 to the nominal operating pressure of $30 \mathrm{ksi}$ and all during the time the nominal operating pressure was maintained. For some monitoring operations, data were recorded during descent to ambient pressure. As shown in Table 4.2.1, strain data were obtained for large variations in the time required to reach the nominal operating pressure and for the time that this pressure was maintained. There were small variations in the maximum operating pressure attained and the range of pressures that occurred while maintaining the nominal operating pressure. Table 4.2 .1 shows that there was no standard schedule for increasing the pressure and for the time held at maximum pressure. Therefore, the strain data obtained is a true representation of actual operation of the press and is more relevant and valuable for the monitoring of PV-4 than data obtained with a procedure requiring a standard rate for increasing the pressure and for the time at nominal operating pressure. For these measurements, strain on both the frame and vessel increased linearly with increasing operating pressure, just as it did during the initial measurements on September 8-9, 1960.

Table 4.2.2 provides the stresses and locations of the measured axial stresses on the PV- 4 frame from January 25, 1984, through August 5, 1997, while the internal pressure was at $30 \mathrm{ksi}$. Table 4.2 .2 also includes the measurements made on September 9, 1960, by Sturm \& Krouse. For all comparisons of stresses from September 9, 1960, and January 25, 1984, to August 5, 1997, a nominal internal pressure of $30 \mathrm{ksi}$ is employed. Tables 4.2.2 through 4.2.4 and Figs. 4.2.1 through 4.2.10 are based on a nominal pressure of $30 \mathrm{ksi}$; the resulting actual stress during each measurement is shown in Table 4.2.2. Note in Table 4.2.2 that the nominal pressure of $30 \mathrm{ksi}$ is very close to the actual pressure, and use of nominal internal pressure of $30 \mathrm{ksi}$ rather than an actual measured pressure has no effect on the interpretations of the results. Figures 4.2.1 through 4.2.5 provide graphic illustration of the information shown in Table 4.2.2. For strain gauges mounted at the same positions on the frame in 1960 and in 1983, the measured 
Table 4.2.1 Times to reach nominal operating pressure of $\mathbf{3 0} \mathrm{ksi}$ and time at pressure for strain measurements conducted between December 4, 1985, and August 5, 1997

Range of pressures at

Time to reach

operating pressure
Time at operating

pressure

(min)

29

9

7

10

10

9

10

31

37

39 nominal operating pressure

(psi)

$30,025-30,225$

$30,125-30,500$

$29,375-29,600$

$29,750-30,050$

$29,700-29,975$

$29,525-29,675$

$30,250-31,150$

$29,750-29,775$

$29,725-29,825$

$29,025-30,775$ 


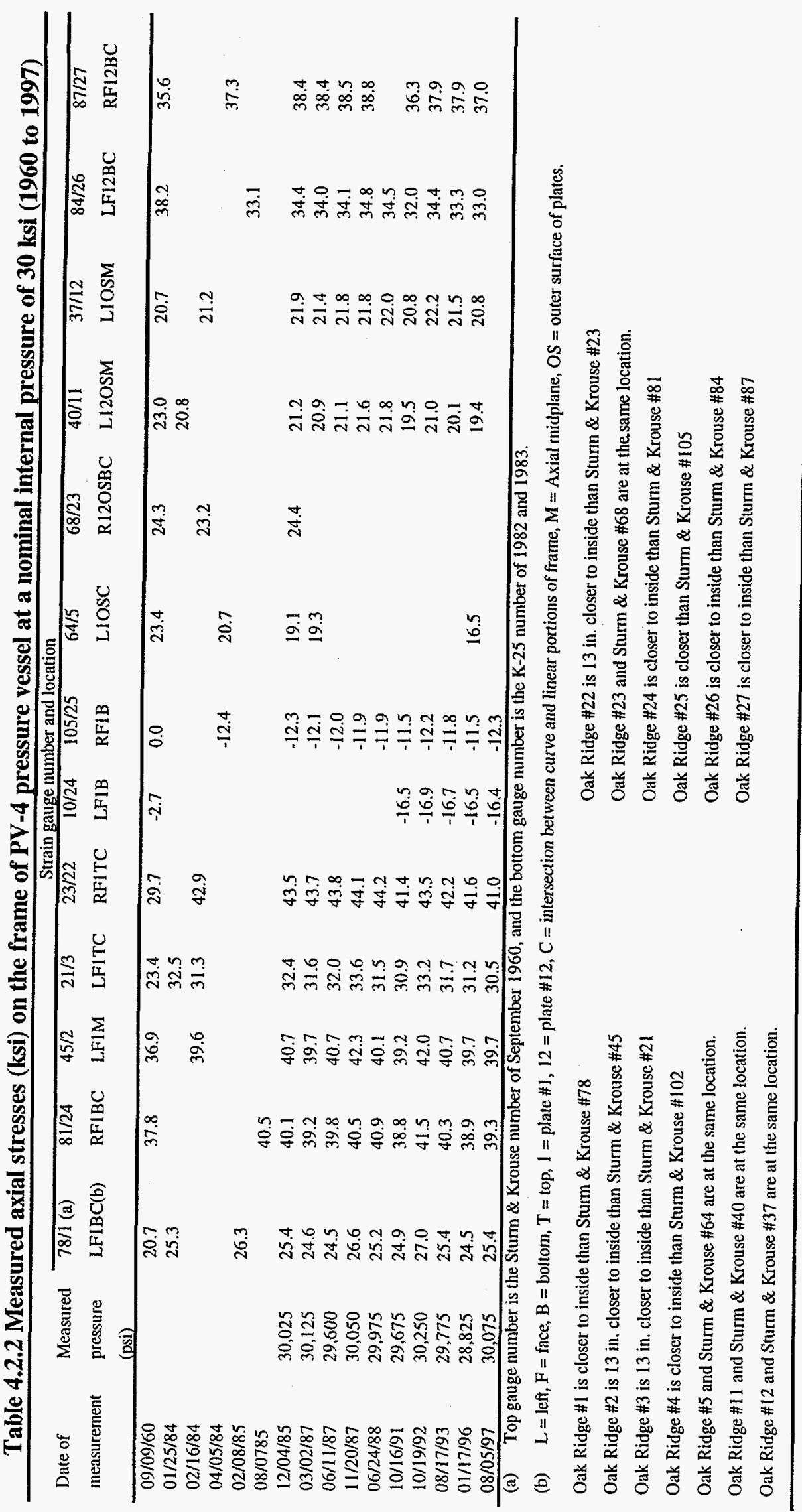


stresses in 1960 and those through 1997 are in good to excellent agreement. Figure 4.2.1 shows the measured stresses on the left and right outer surfaces of plates 1 and 12 at the axial midplane of the frame. At this section of the frame, stresses vary only slightly over short distances, and the stresses measured in 1960 and from 1983-1997 are in excellent agreement. The minimum in stress shown for the measurements made on October 16,1991, appears in the data for every strain gauge measurement made on that date. A review of the operational records for PV-4 shows that the actual internal pressure was only $29.5 \mathrm{ksi}$ when the strain measurements were made on October 16,1991; and the minimum in all of the stress as a function of time plots is attributed to the lower pressure on this date.

Figure 4.2.2 shows the measured stresses on the left and right faces of plate 12 at the region near the bottom of the frame near the intersection of the curved and linear portion of the frame. At this position, stresses vary significantly over short distances, and the agreement in the stresses measured in 1960 and from 1984 through 1997 is not quite as good as that shown in Fig. 4.2.1. Both figures show little variation in measured stress over the entire $\sim 37$ years of operation from October 1960 to August 1997.

Figure 4.2.3 shows the stresses near the bottom of the frame on the left and right sides of the frame. For those dates for which there are data, stresses are compressive and essentially constant over the entire times of measurement; however, stresses on the right side of the frame are slightly more compressive than on the left side of the frame ( $\sim 16.5$ vs $\sim 12 \mathrm{ksi})$. Stresses measured in 1960 and from 1984 through 1997 are not in as good agreement with those shown in Figs 4.2.1 and 4.2.2. For the locations used in Fig. 4.2.3, the strain gauges mounted in 1983 were not as close to the locations of the strain gauges mounted in 1960 as those for the data shown in Figs. 4.2.1 and 4.2.2.

Figures 4.2.4 and 4.2.5 summarize the stress measurements conducted in 1960 and from 1983 through 1997 for similar locations on the front (plate 1) and back (plate 12) of PV-4. Figure 4.2.4 shows stresses near the bottom of the frame at the intersection between the linear and curved portions (tangent points) of the frame. For plate 1 stresses on the right side of the frame are $\sim 35 \%$ higher ( 43 vs $\sim 32 \mathrm{ksi}$ ); at plate 12 this difference decreased to $\sim 15 \%$ higher ( $\sim 38 \mathrm{vs} \sim 33 \mathrm{ksi}$ ). Figure 4.2 .5 provides the stresses near the top of the frame at the intersection between the linear and curved portions of the frame for plate 1 . At this location, stresses on the right side of the frame are $\sim 30 \%$ higher ( $\sim 3$ vs $-33 \mathrm{ksi}$ ) than on the left side of the frame. It is expected that stresses on the frame would be very sensitive to the actual configuration of the 


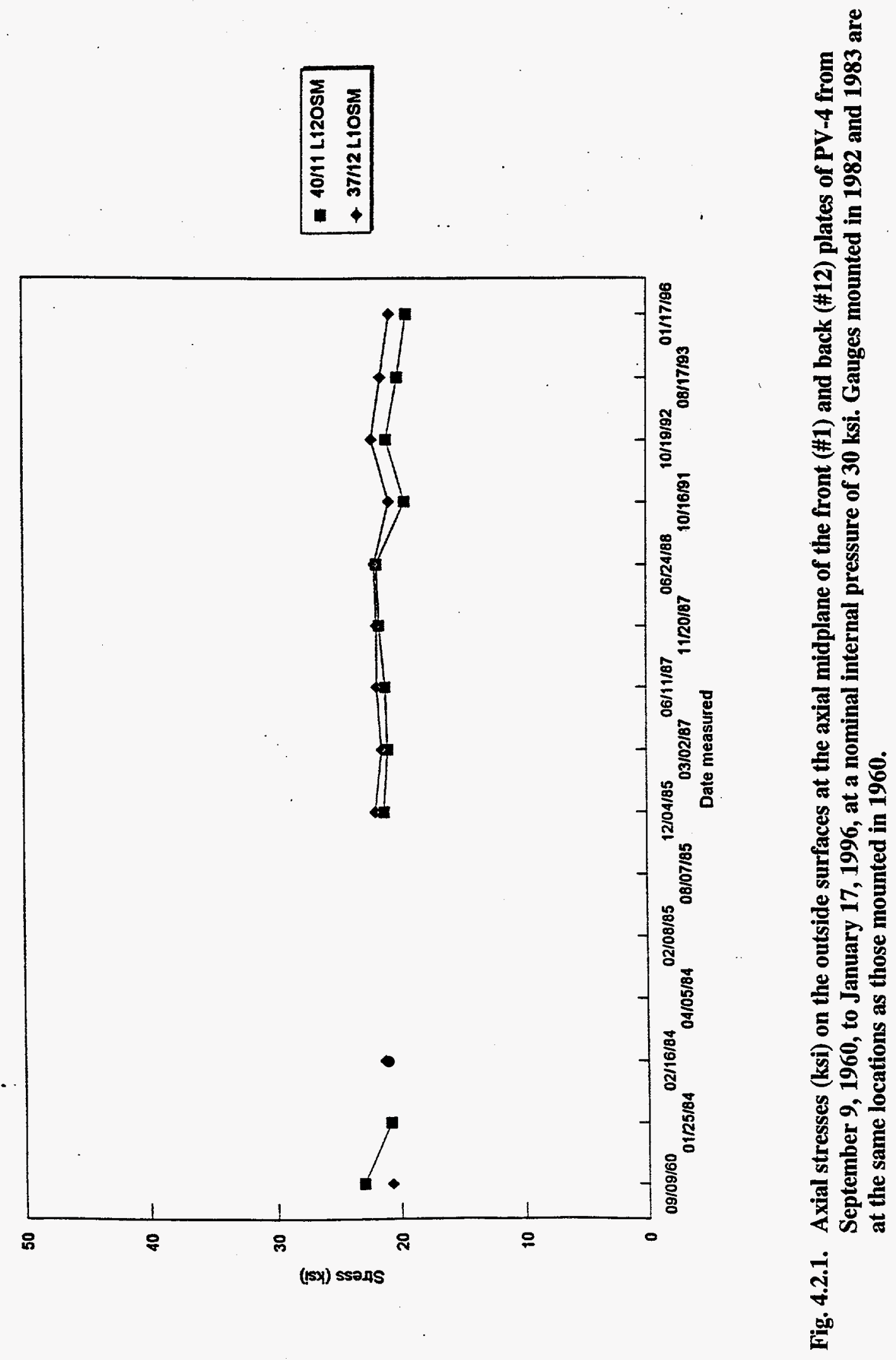




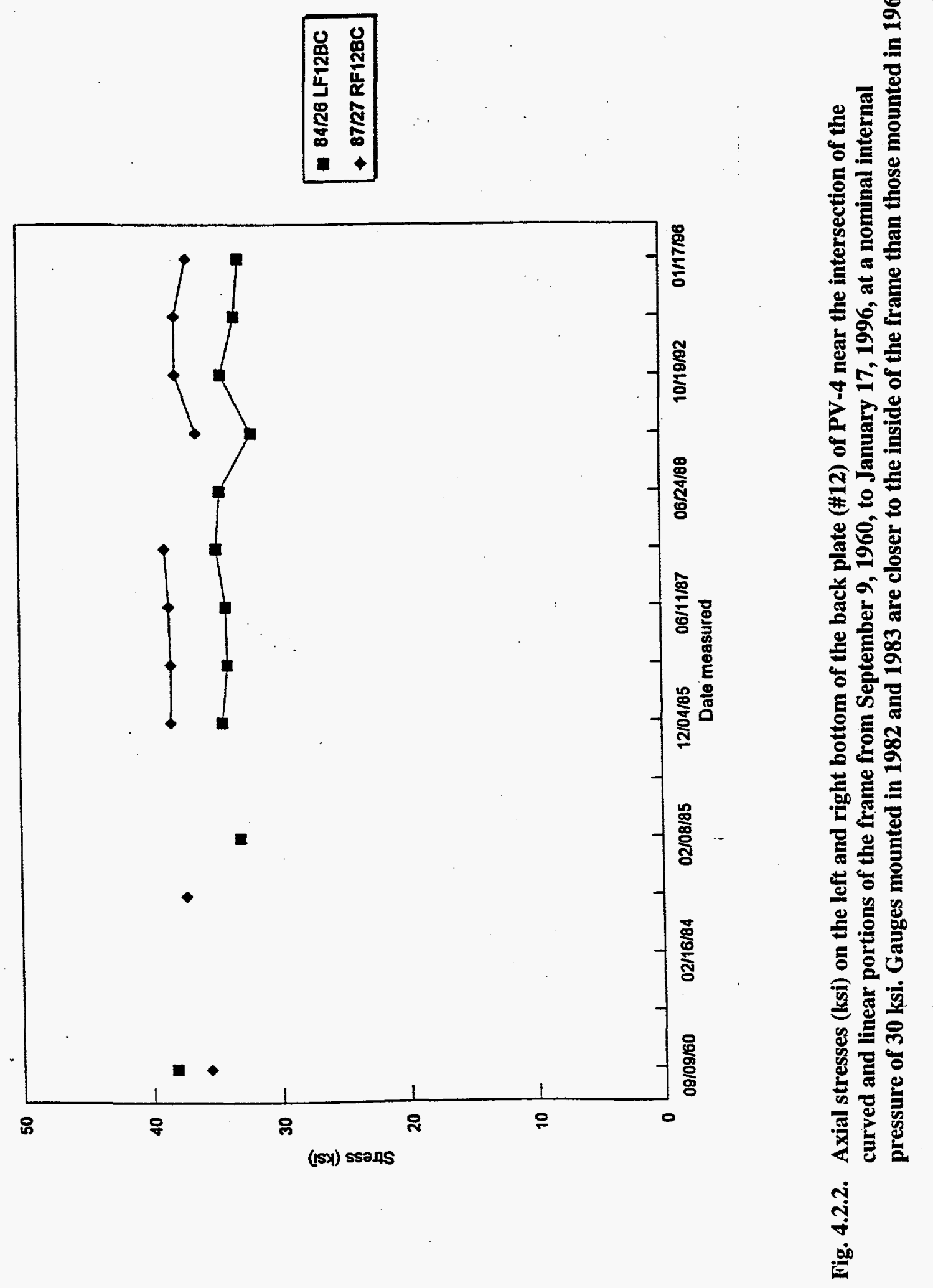




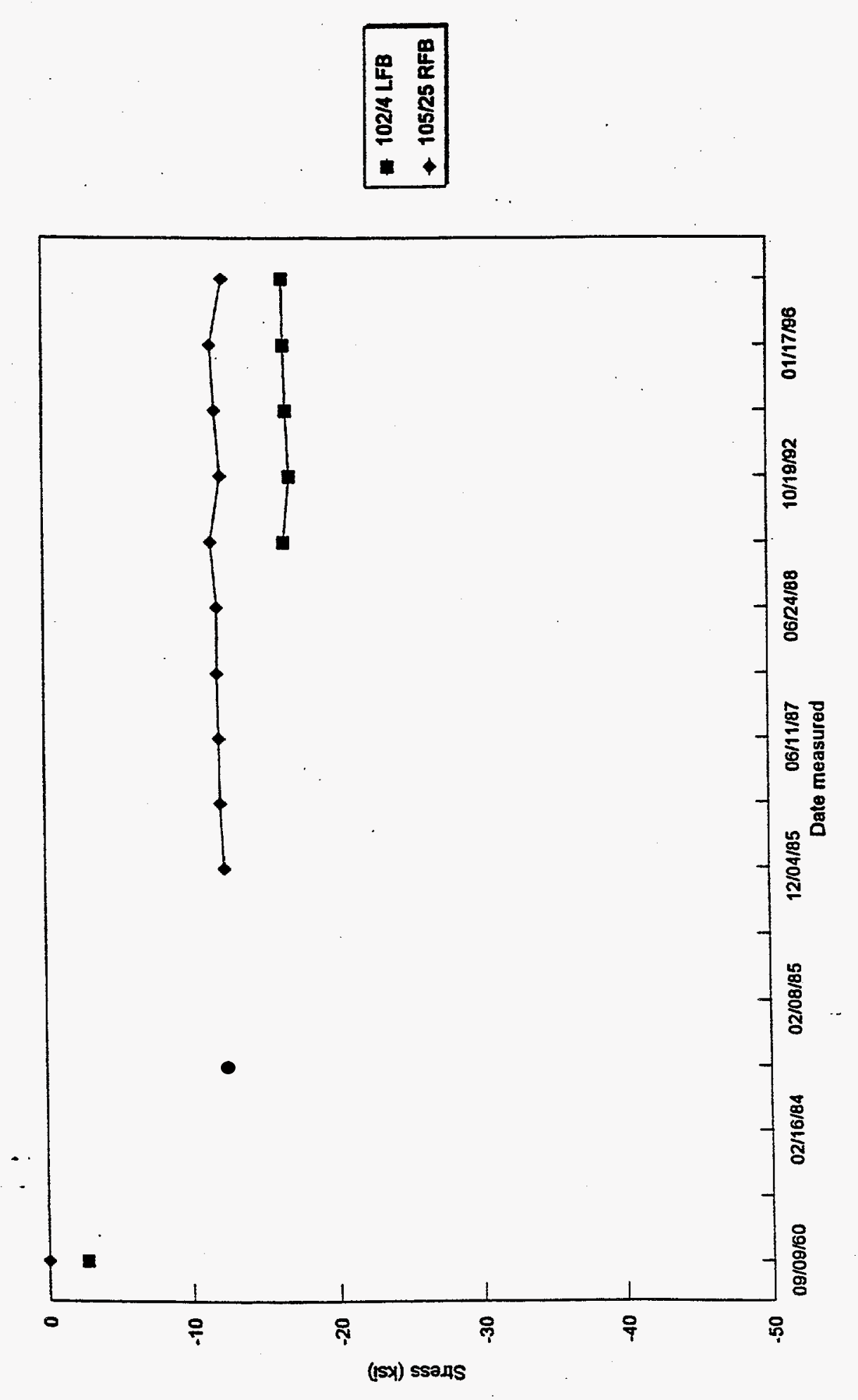

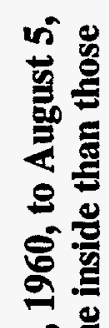

a

농

톨

흉

ह

总

$\dot{7}$

ธั ช

콩

훙

홀

홀 을

을

5

홍

흐

홍

를

를

을

흥.

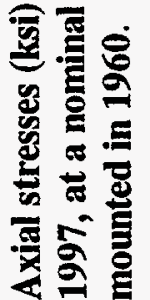

ชั่

番 


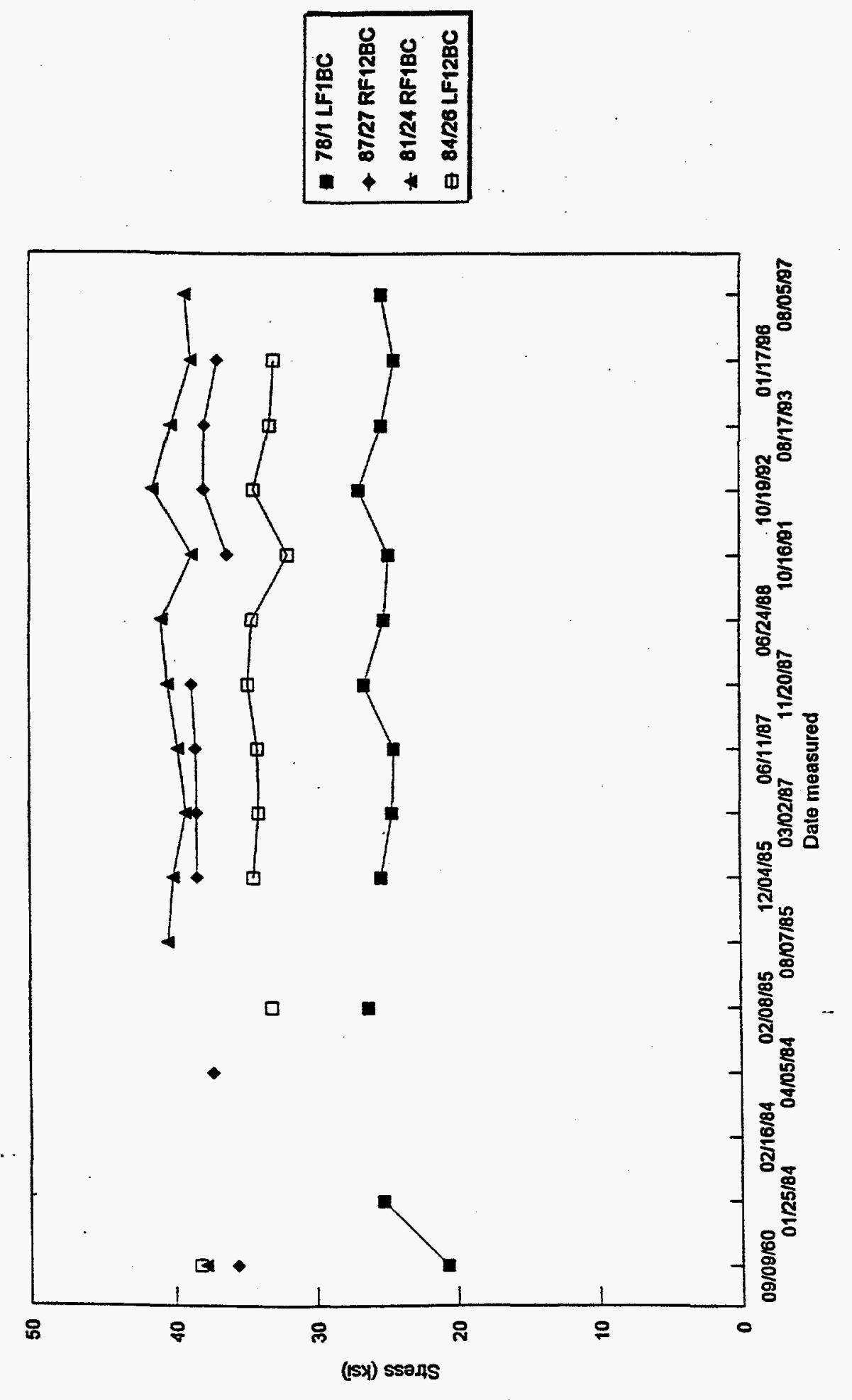

ज

응 흥

$>$ in

흥 불

홀

옹

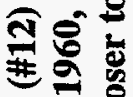

중

잏

롤

苛

\#

흘을

导

喽

틍 능 을

농홀

큼 흥

롤

을 트응

흉 흥

웡

흘

西

훙호옹

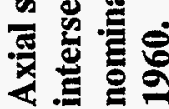

i்

量 


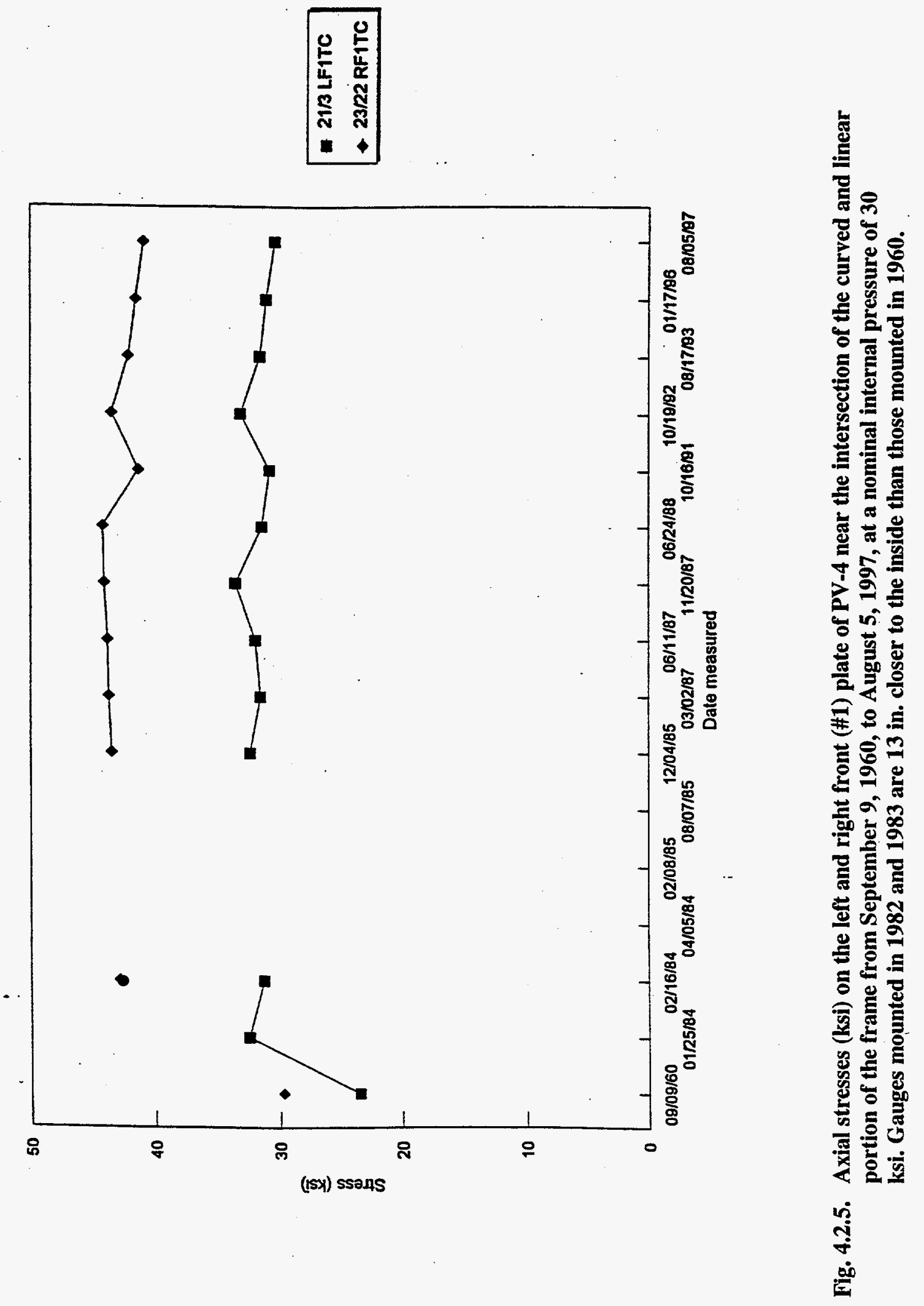


vessel and frame and their components from operation to operation, especially at locations of combined high loading at the intersections of the curved and linear portions of the frame.

Strain measurements conducted on the pressure vessel are far more valuable and more important than those conducted on the frame for the following reasons: the pressure vessel is the most important component of the press and is also its most highly stressed component. In addition, for most strain gauge locations, strain gauges mounted on the pressure vessel in 1982 and 1983 are coincident with or very close to the locations of the strain gauges mounted in 1960. Especially on the front (\#1) and back (\#12) plates of the frame, there are distances from a few inches to several inches (13 in.) between the locations of the strain gauges used in 1960 and those used in 1982 and 1983 (compare Figs. 3.1.5 with 3.2.4 and Fig. 3.1.6 with 3.2.5); and, because there are significant gradients in strain from the inside faces to the outside faces of the frame, it is difficult to obtain quantitative comparisons in strains for the gauges mounted in 1960 and those mounted in 1982 and 1983 . This is clearly obvious in Figs. 4.2 .1 through 4.2 .5 . Because of the symmetry of the cylindrical pressure vessel, the stresses are more uniform around the circumference of the vessel for strain gauges mounted at or near the same axial positions on the vessel in 1960 and in 1982 and 1983. As shown in Fig. 3.2.5, there are several locations on the pressure vessel where the gauges mounted in 1982 and 1983 are at the same elevation (axial position) or within 1/16 in. of the same elevation as the gauges mounted in 1960. In 1960, gauges 133, 134, 135, and 136 were mounted at 22-1/16 in. and in 1982 and 1983 gauges 10 and 18 were mounted at 22 in. from the bottom of the vessel at $180^{\circ}$ and $270^{\circ}$, respectively. Also, in 1960, gauges $121,122,123$, and 124 were mounted at $4 \mathrm{in}$. from the top of the vessel at $0^{\circ}$ and $180^{\circ}$, respectively, and in 1982 and 1983 gauges $6,13,15$, and 19 were also mounted at 4 in. from the top of the vessel at $90^{\circ}, 270^{\circ}, 0^{\circ}$, and $180^{\circ}$, respectively. Finally, in 1960 , gauges $125,126,127$, and 128 were mounted at $22-1 / 16 \mathrm{in}$. below the top of the vessel at $0^{\circ}$ and $180^{\circ}$, respectively, and in 1982 and 1983 , gauges $7,14,16$, and 20 were mounted at $21 \mathrm{in}$. from the top of the vessel at $90^{\circ}, 270^{\circ}, 0^{\circ}$, and $180^{\circ}$, respectively. The close proximities of the gauges mounted on the vessel in 1982 and 1983 with those mounted in 1960 give much closer agreement in measured strains than those that are observed for the frame. For these reasons, our emphasis is focused on the pressure vessel in comparing strains measured in 1960 with those measured from 1983 to 1997 and interpretation of these measurements and the implications of these measurements to evaluating the status and structural integrity of PV-4.

Tables 4.2.3 and 4.2.4 present the circumferential and axial stresses, respectively, on the pressure vessel measured in 1960 and from 1983 to 1997 . This information is provided graphically in Figs. 4.2.6 
through 4.2.9. Figure 4.2.6 shows the circumferential stresses at 4 in. below the top of the vessel at $0^{\circ}$ and $180^{\circ}$ from the front of the vessel. The data are in excellent agreement for the entire $\sim 37$ year operating and monitoring history. Figure 4.2 .7 provides stress as a function of time for the gauges at $21 \mathrm{in}$. from the top of the vessel at $0^{\circ}, 90^{\circ}, 180^{\circ}$, and $270^{\circ}$, respectively. Except for the one low stress value at gauge seven on March 2, 1987, the data are in excellent agreement. Figures 4.2 .8 and 4.2 .9 show stress for an operating pressure of $30 \mathrm{ksi}$ over the period of 1960 to 1997 for the strain gauges mounted 38-3/4 in. and $21 \mathrm{in}$. from the bottom of the vessel, respectively; the level of agreement from 1960 to 1997 is similar to that observed on the top half of the pressure vessel.

Figure 4.2.10 provides the average circumferential and axial stresses on the pressure vessel for measurements taken between July 29, 1983, and August 5, 1997, at a nominal operating pressure of $30 \mathrm{ksi}$. Also, the stresses measured on September 9, 1960, are shown in parentheses. The excellent agreement on the surface of the pressure vessel over the entire $\sim 37$ year operational period indicates that no stressperturbing flaws or cracks have been initiated in the vessel, and there has been no change in the structural integrity of the vessel since its construction in 1960.

In addition to providing assurance of the integrity of the pressure vessel, it is necessary for analyses of the stresses in the vessel, or for estimates of the fatigue life of the vessel (such as those described in references 2 and 3), to be able to verify that there has been no relaxation of the original shrink-fit pressures between the layers of the vessel. If relaxation of the shrink-fit pressure has occurred, the strains on the surface of the vessel would be decreased compared with the strains measured during preoperational testing on September 8 and 9, 1960. To determine if there have been changes in these shrink-fit pressures, the slopes of strain as a function of operating pressure measured in 1960 have been compared with the slopes measured from December 4, 1985, through August 5, 1997, for several locations on the surface of the vessel. If the slopes of strain as a function of operating pressure measured from 1985 to 1997 remainwithin experimental accuracy or reproducibility - the same as those measured in 1960, no measurable relaxation of shrink-fit pressures has occurred. 


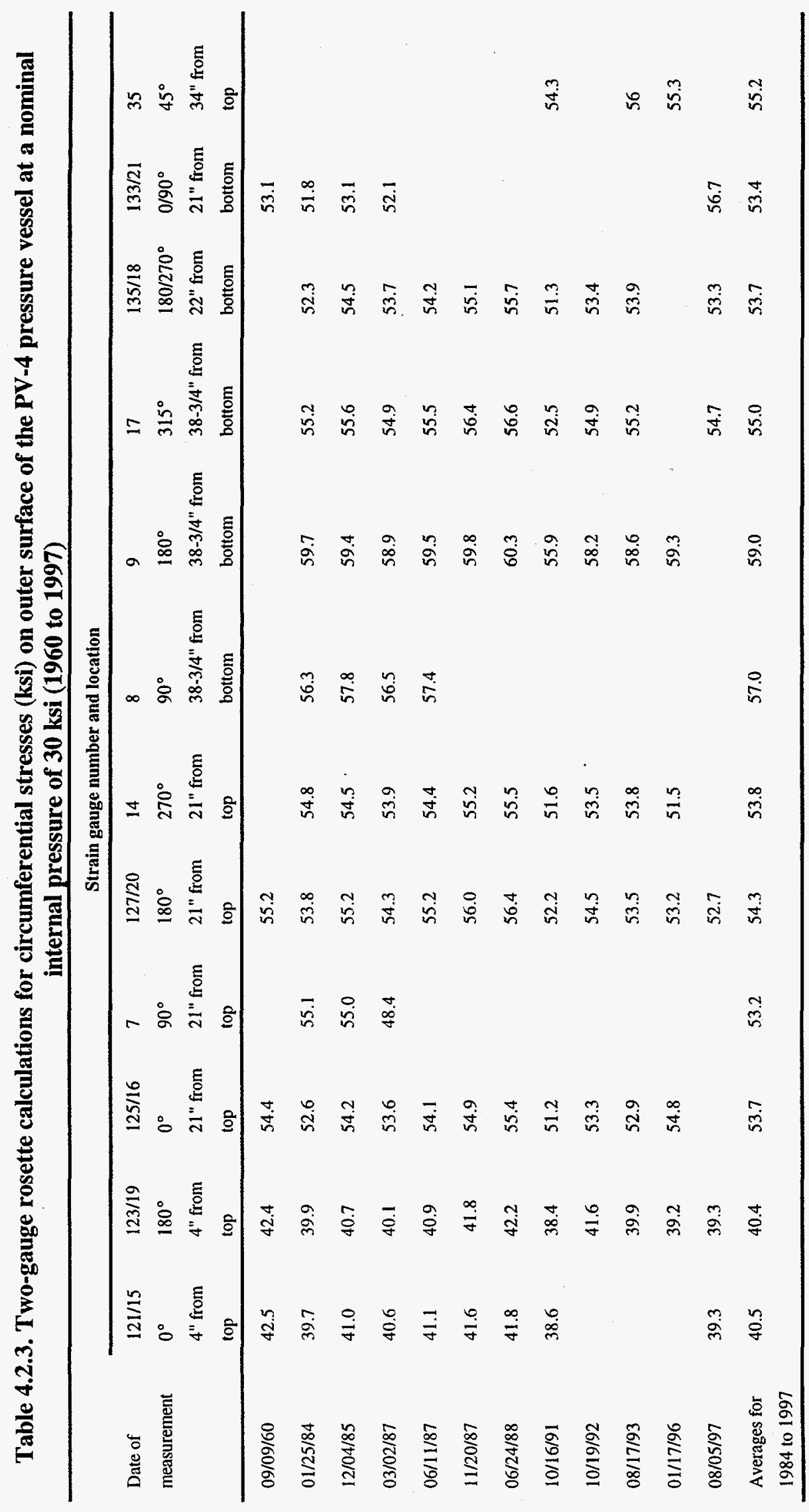




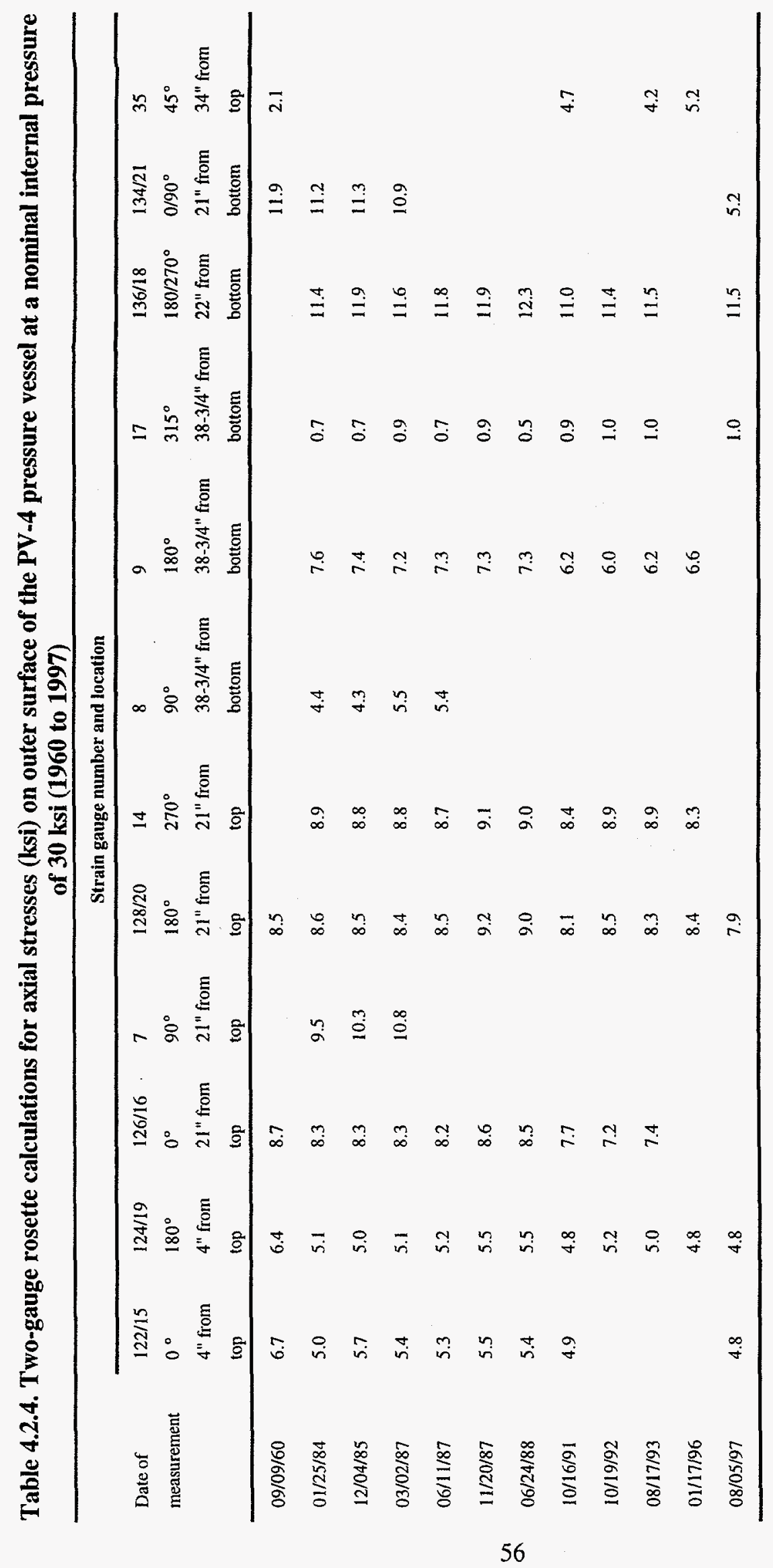



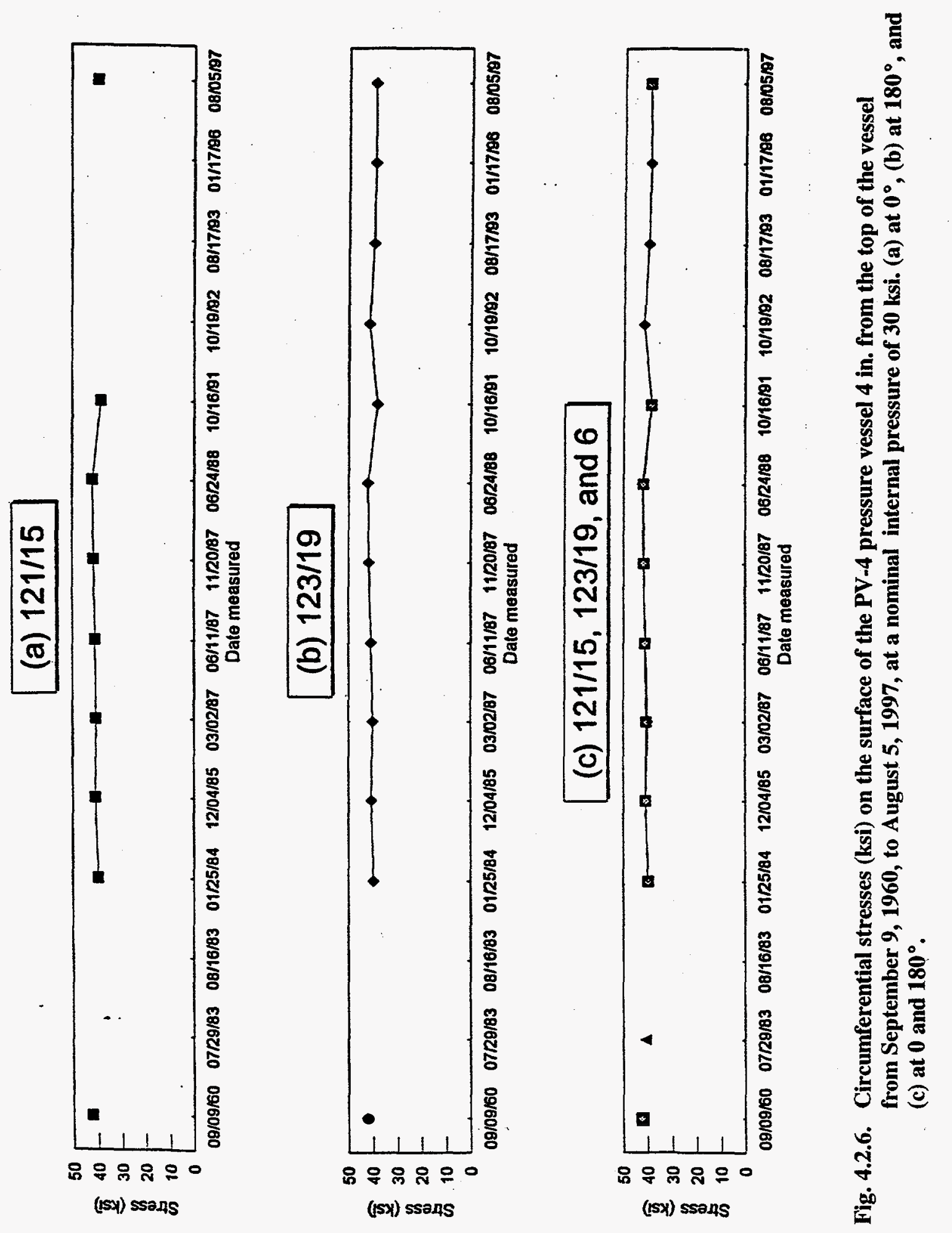

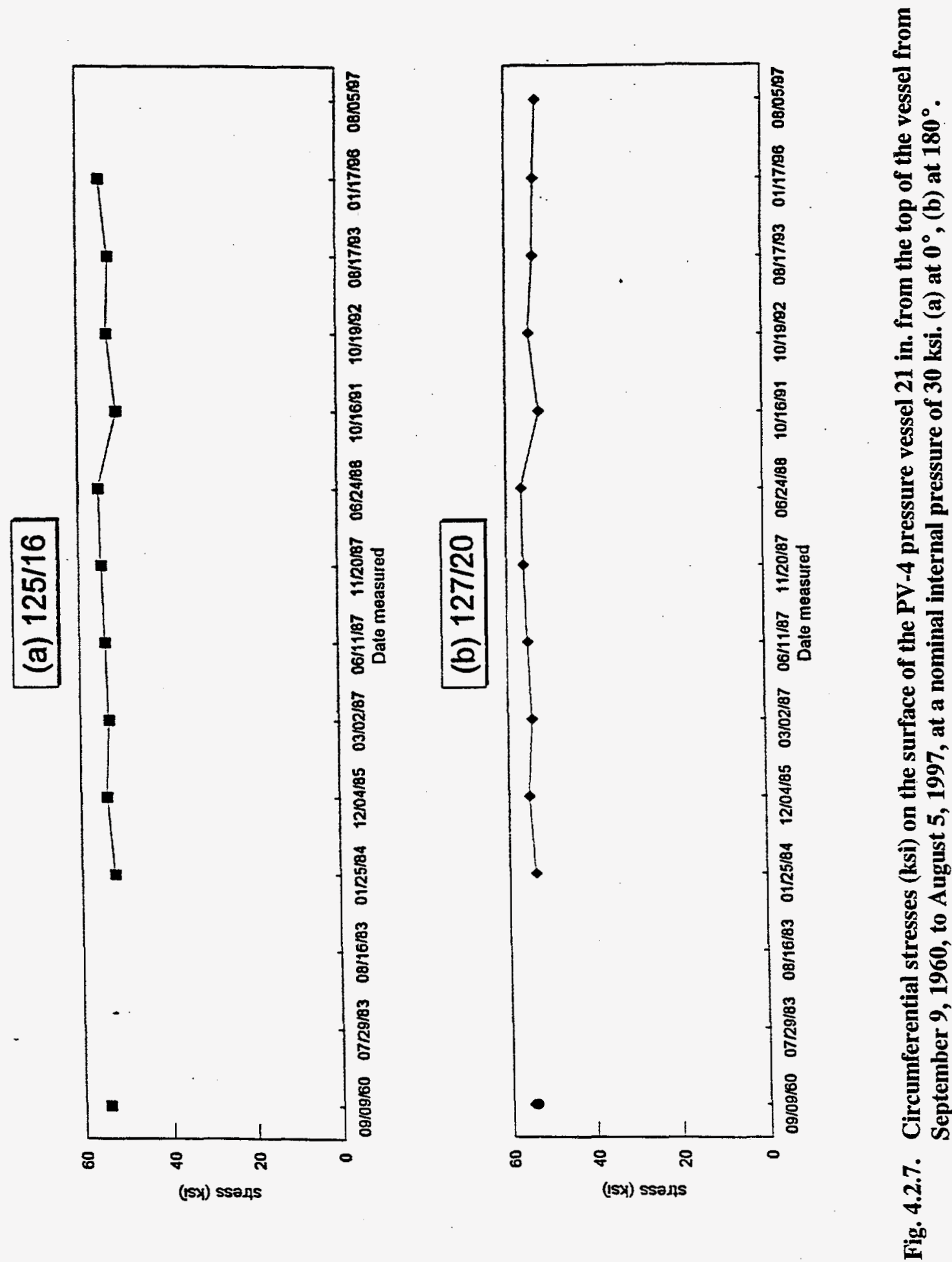


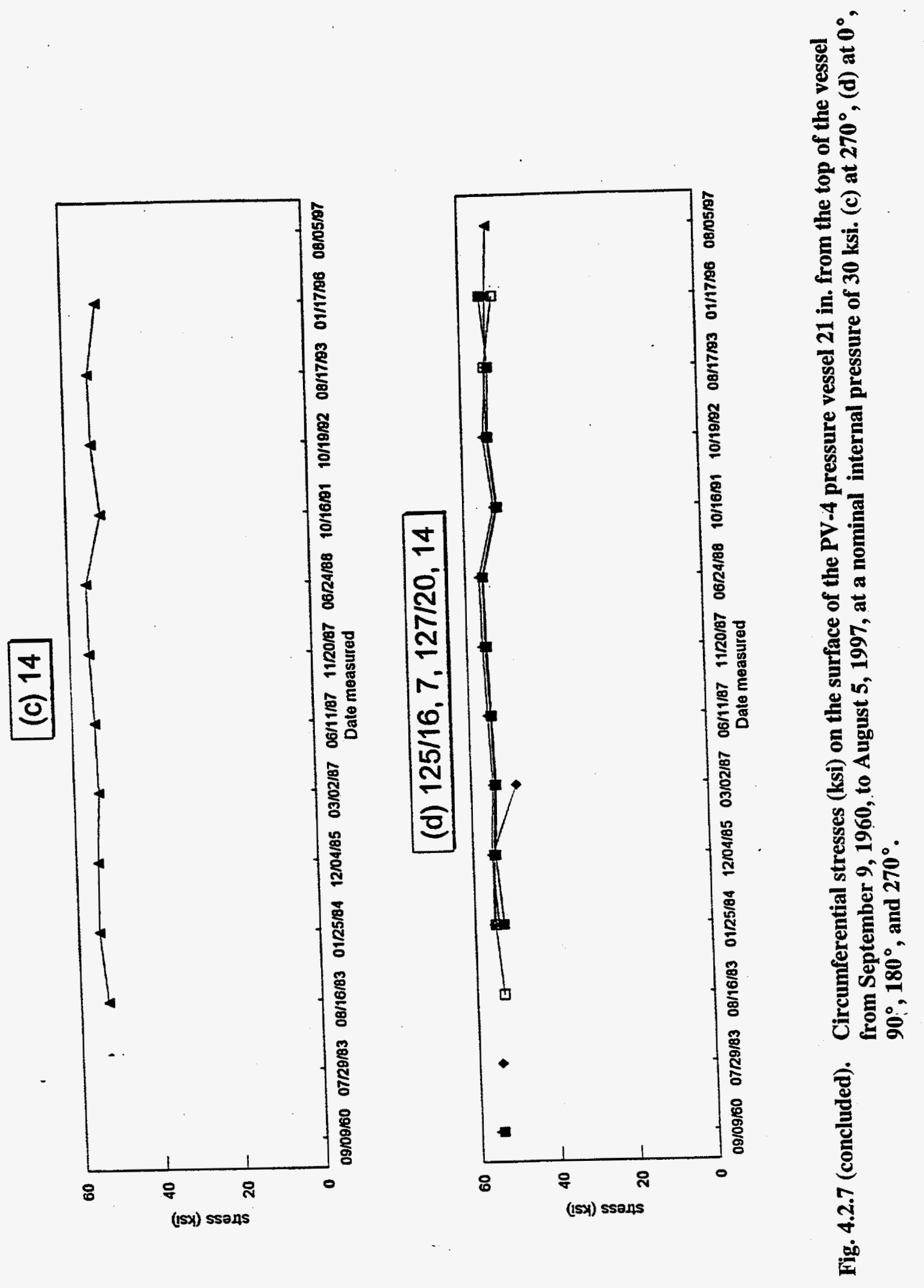




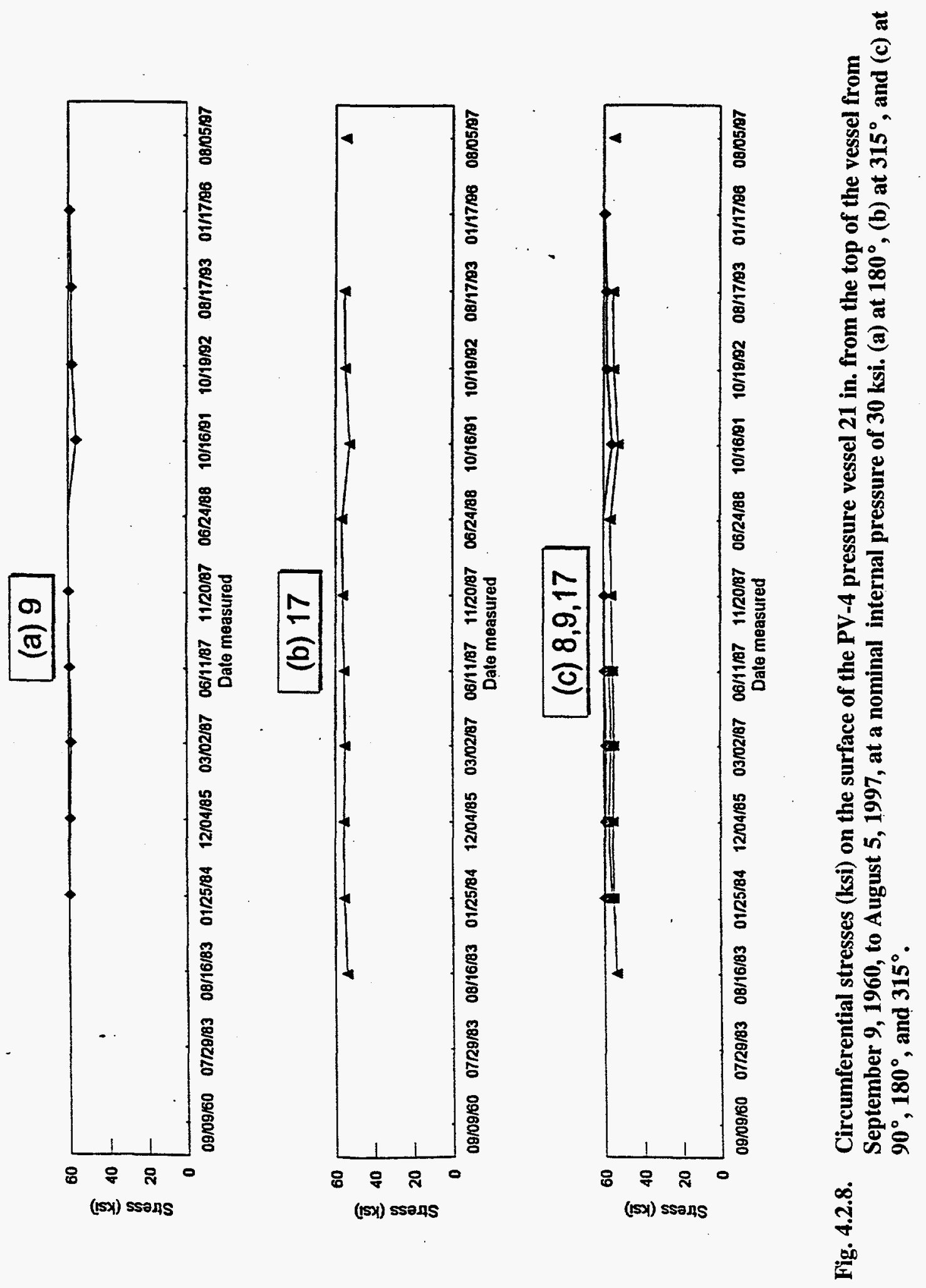




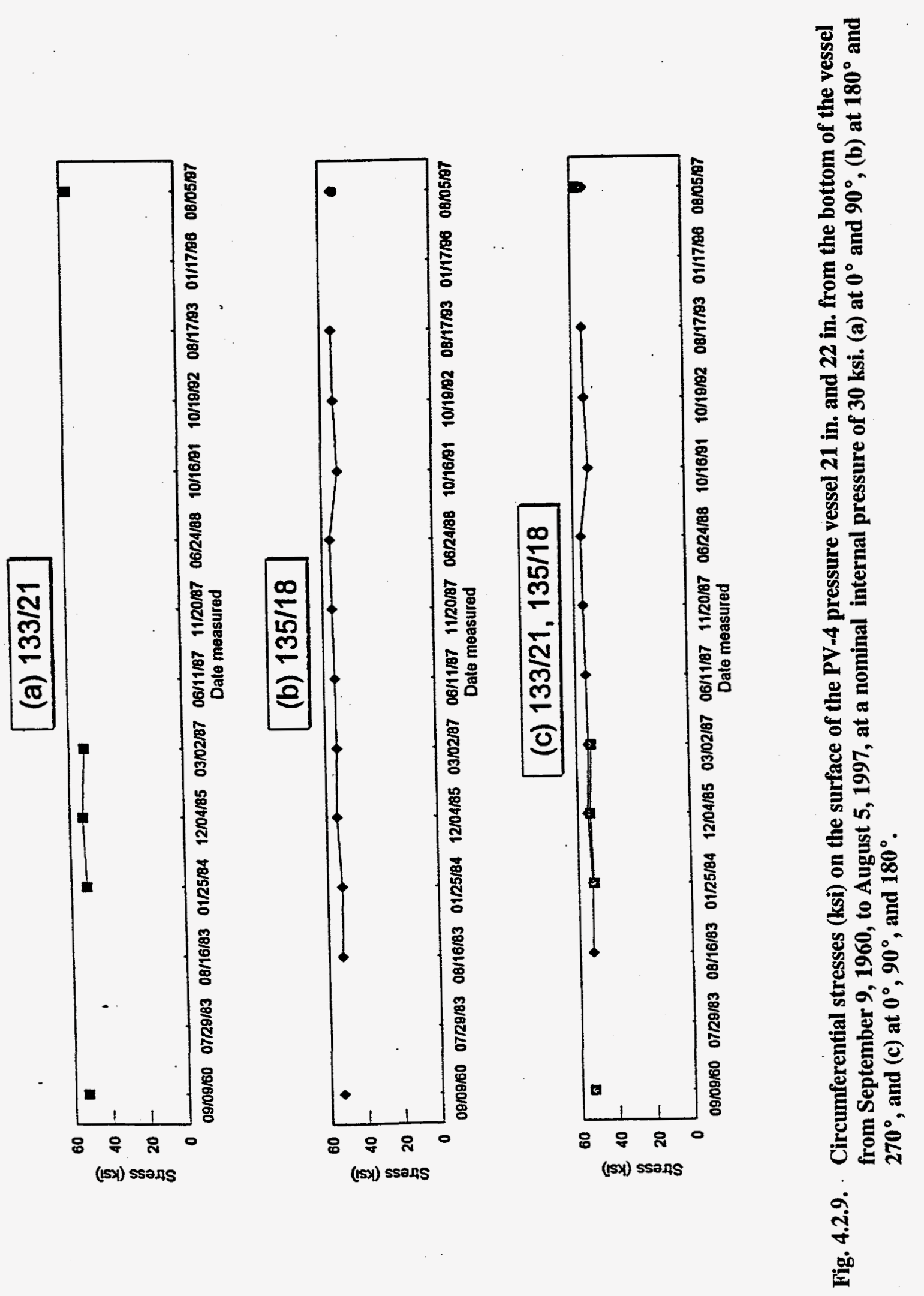



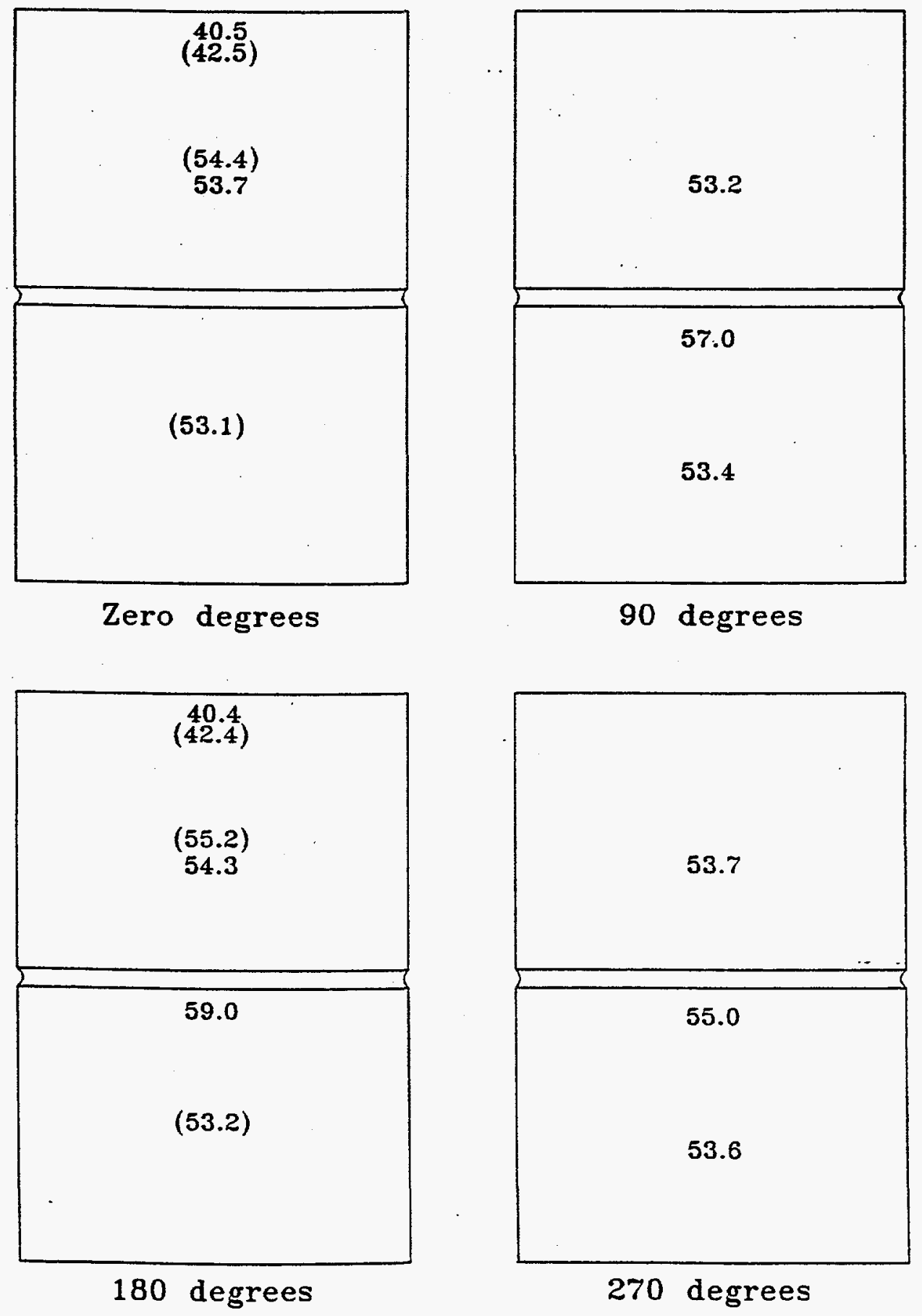

Fig. 4.2.10. Average circumferential stresses (ksi) on the PV-4 pressure vessel from July 29, 1983, to August 5, 1987, at a nominal internal pressure of $30 \mathrm{ksi}$. Values in parentheses are the stresses measured on September 9, 1960. 
For comparison of the slopes measured from 1985 to 1997 with those measured at the same locations in 1960, the zero strain values for these gauges from 1985 to 1997 must be known. A significant systematic change in zero strain values between 1985 and 1997 could indicate changes in shrink-fit pressure.

Conversely, random fluctuations in zero strain values from those measured in 1985 are not construed as a change in shrink-fit pressure.

For all of the strain measurements conducted from December 4, 1985, to August 5, 1997, a linear regression analysis of strain as a function of internal pressure was performed for the measurements of locations on the pressure vessel where strain gauges were mounted at or close to the same locations in 1960 and 1982 and 1983. Table 4.2.5 provides the slope of strain as a function of internal pressure for the measurements conducted on September 9, 1960, and from December 12, 1984, through August 5, 1997 , for the locations shown in the table. For every measurement date from December 4, 1985, to August 5 , 1997, the linear regression analysis included between 37 and 100 individual measurements of strain as a function of internal pressure for each strain gauge. In addition, to obtain information most relevant to the operating pressures most often used in PV-4, significantly more measurements were conducted between 15 and $30 \mathrm{ksi}$ than between 0 and $14 \mathrm{ksi}$.

For every measurement date, there is a plot of strain as a function of internal pressure for each gauge listed in Table 4.2.5, a total of 75 plots. We cannot include all 75 plots in this report, but, for illustrative purposes, we have included three of the (strain as a function of internal pressure) plots for one of the more important gauge locations on the pressure vessel. Gauge 20 is located at $0^{\circ}$ and $21 \mathrm{in}$. from the top of the vessel and is close to the Sturm \& Krouse gauge 127, which was located at 22-1/16 in. from the top of the vessel. Figures 4.2.11 through 4.2.13 are plots of strain as a function of internal pressure for gauge 20 for the first measurement date with the new data acquisition system, December 4, 1985; the middle measurement date, June 24, 1988; and a later measurement on January 17,1996 , respectively. Figure 4.2.14 was copied directly from the Sturm \& Krouse report (Ref. 6) and shows strain as a function of internal pressure measured on September 8 and 9, 1960, for gauge 127. The slope of $58.7 \times$ $10^{-9} \mathrm{in./in./psi} \mathrm{measured} \mathrm{for} \mathrm{gauge} 127$ on December 4, 1985, (Fig. 4.2.11) is almost identical to the slope of $58.5 \times 10^{-9} \mathrm{in} . / \mathrm{in} . / \mathrm{psi}$ measured on September 8 and 9,1960, indicating that there was no change in the integrity of the vessel or of the shrink-fit pressure during the 23-year period during which measurements were not obtained. The slope of $59.9 \times 10^{-9} \mathrm{in}$./in./psi measured on June 24, 1988, (Fig. 4.2.12) was the 


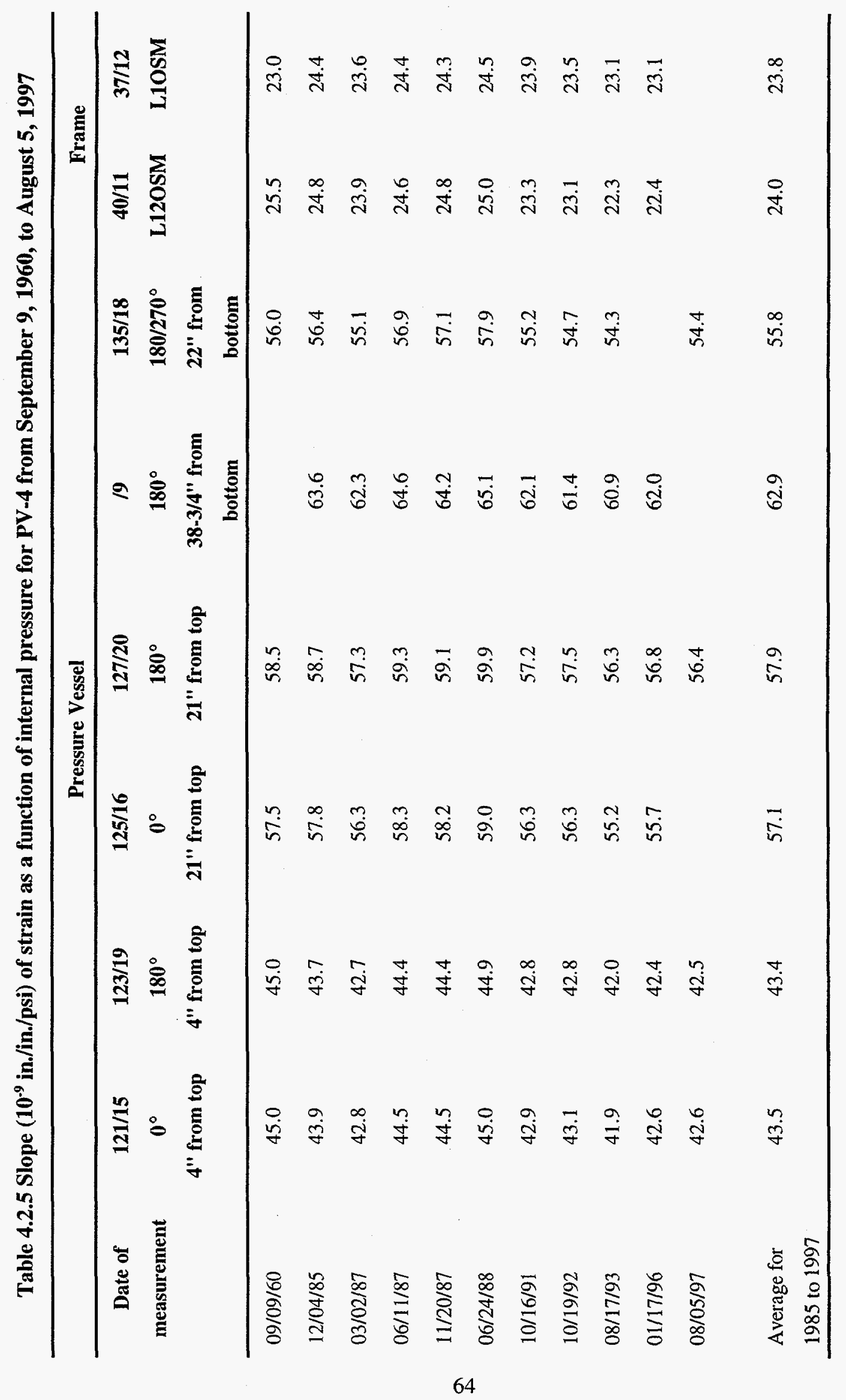



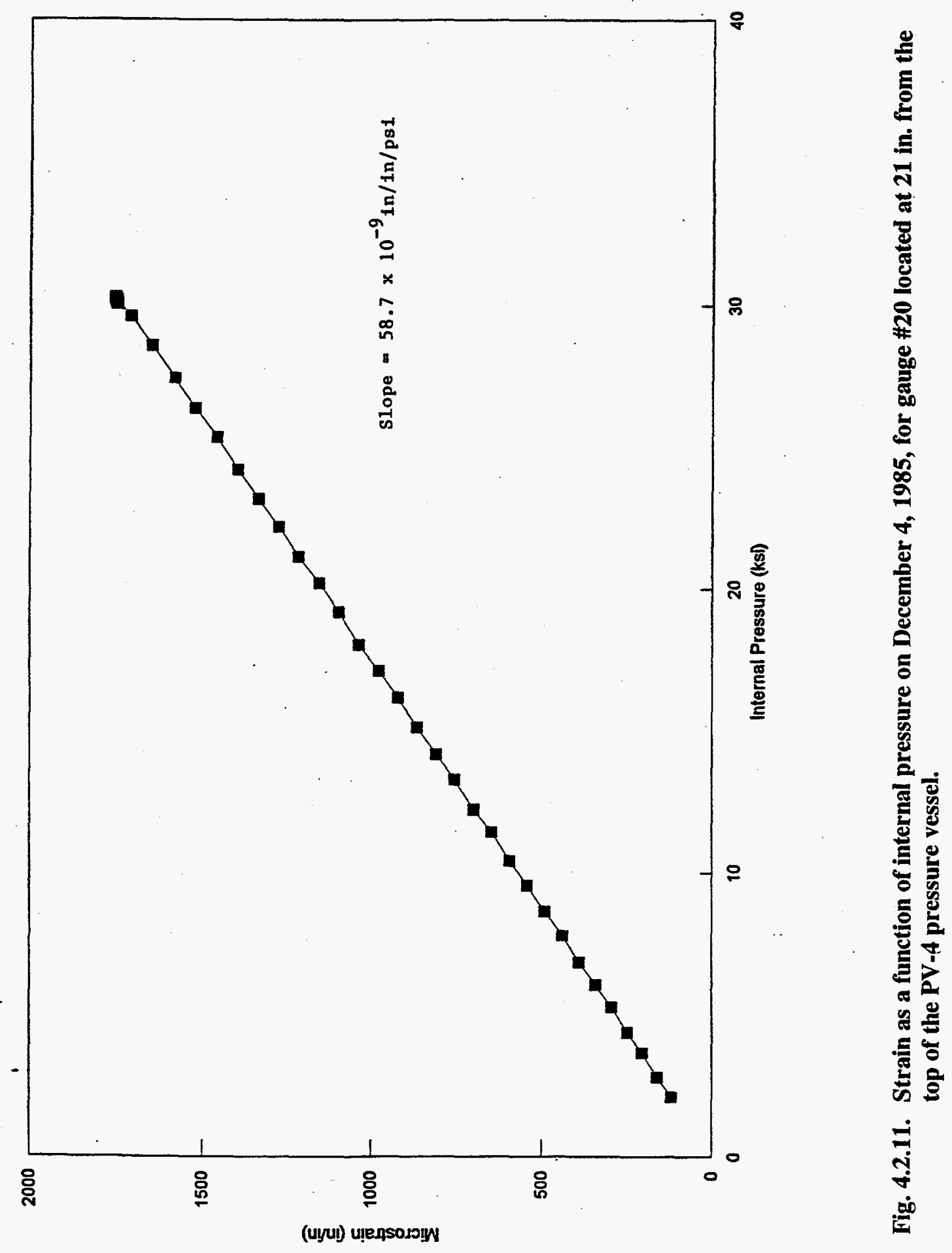


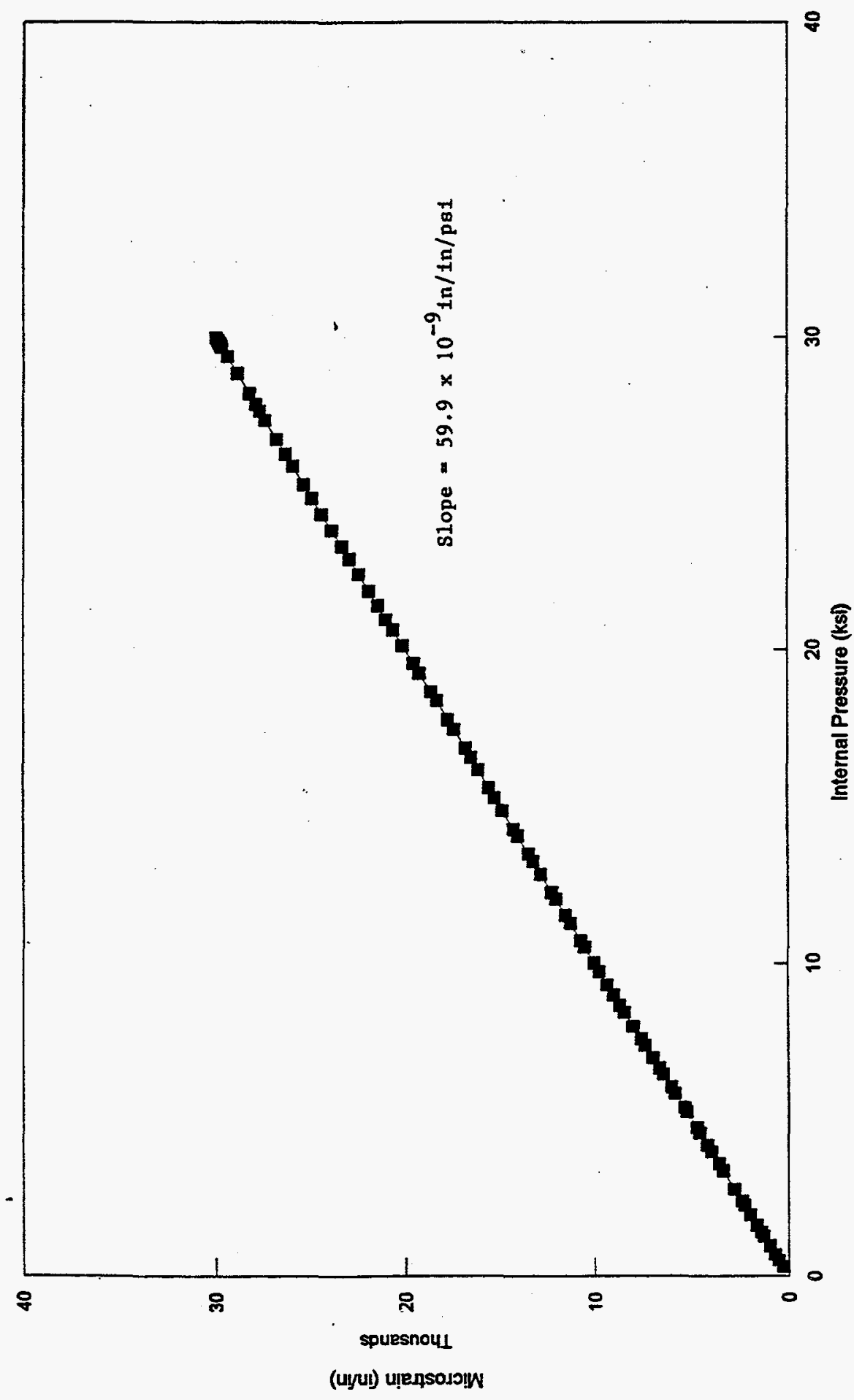

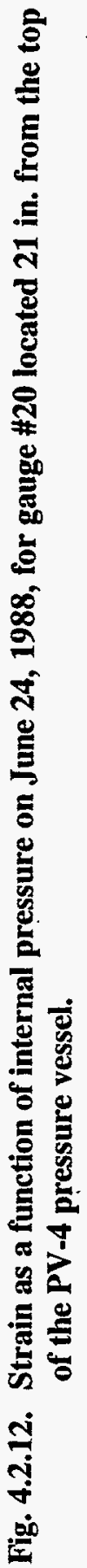




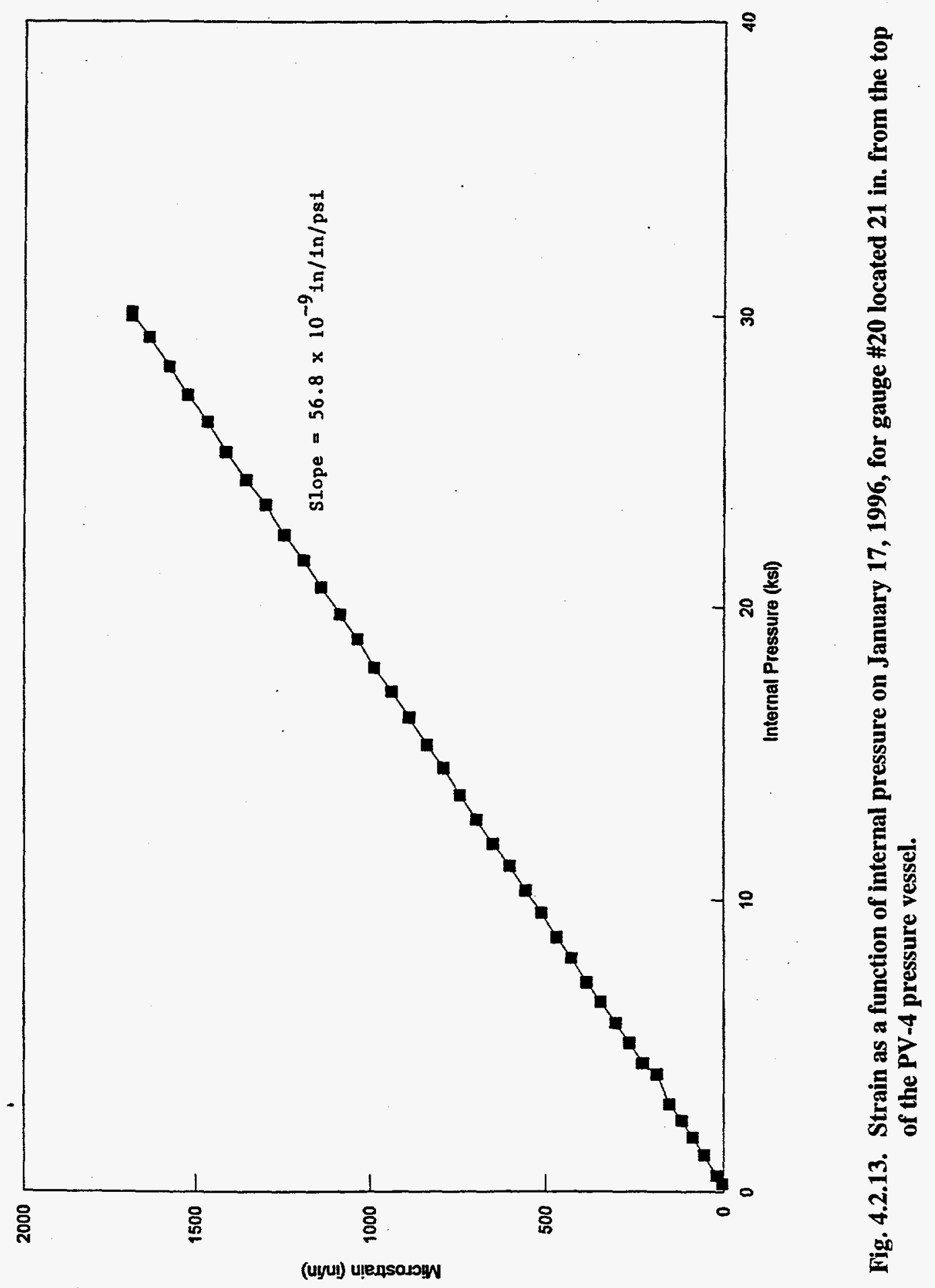




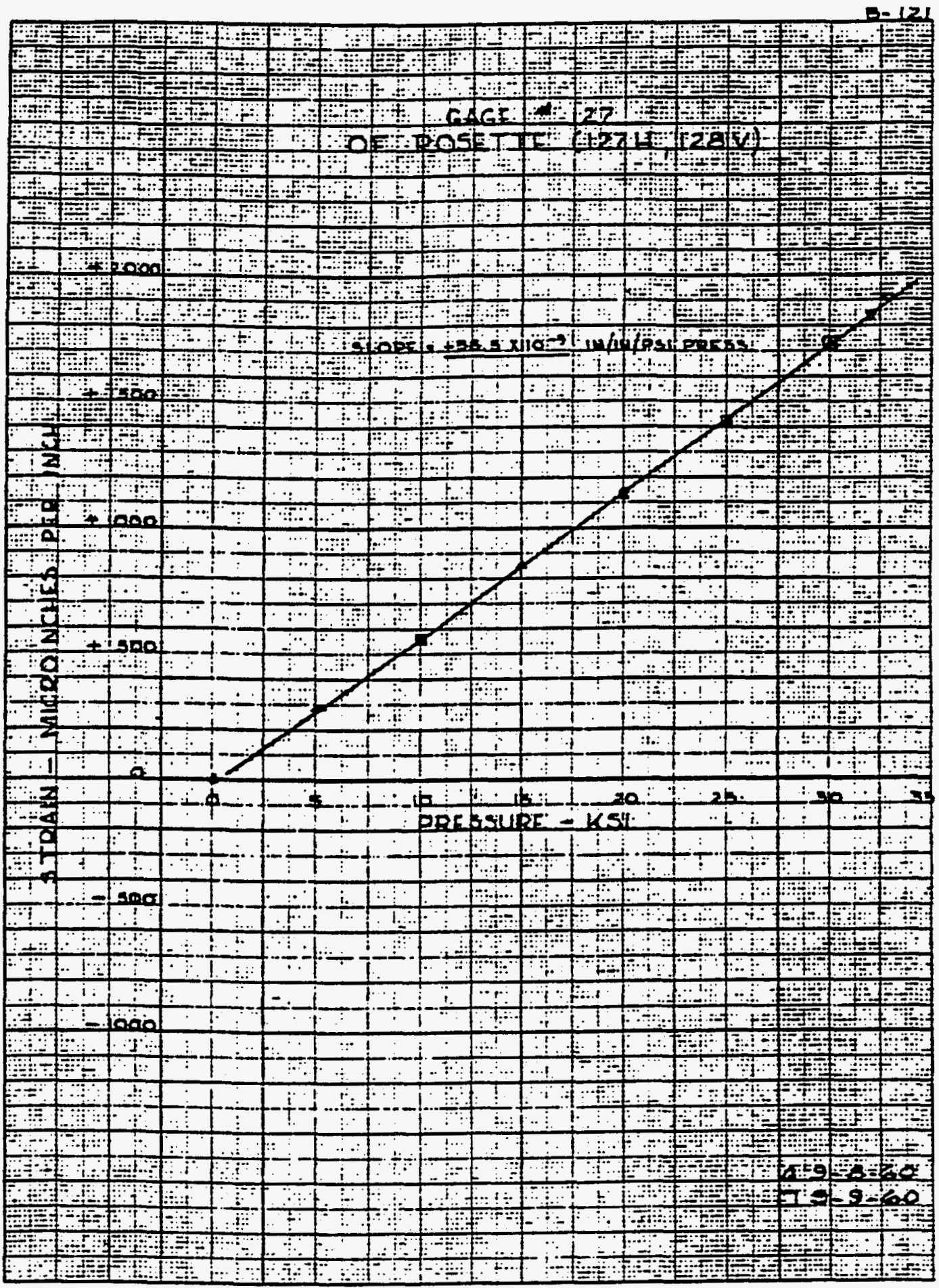

Fig. 4.2.14. Strain as a function of internal pressure for gauge 127 measured by Sturm $\&$ Krouse on September 8 and 9, 1960. 
maximum slope measured for the ten measurement dates, and the slope of $56.8 \times 10^{-9} \mathrm{in}$./in./psi measured on January 17, 1996, (Fig. 4.2.13) was very close to the lowest slope of $56.3 \times 10^{-9} \mathrm{in} . / \mathrm{in} . / \mathrm{sec}$ measured on August 17, 1993.

Table 4.2.6 provides the zero strain measurements from December 4, 1985, through August 5, 1997, for the strain gauges listed in Table 4.2.5. Figures 4.2.15A and B provide plots of the zero strain values as a function of time for the gauges listed in Table 4.2.5. Also provided in Tables 4.2.5 and 4.2.6 are the slopes and zero values, respectively, for two sets of strain gauges, $40 / 11$ and $37 / 12$, that were mounted at the axial midpoint on the left outside of the frame. Gauges 37/12 were mounted on plate \#1 and gauges $40 / 11$ were mounted on plate \#12. Strains at these locations are among the lowest on the entire PV-4 system. Slopes and zeros for these gauges are included in Tables 4.2.5 and 4.2.6 to determine if the slopes and zeros at regions of lowest strains exhibit the same agreement and repeatability as was observed for regions of highest strains.

In Table 4.2.5, the slopes shown for the measurements conducted on September 8 and 9, 1960, were obtained by hand plotting the strains at internal pressures of $5,10,15,20,25$, and $30 \mathrm{ksi}$ and drawing a straight line through all, or in some cases, most of the five or six measurements. Copies of these plots (excluding gauge 127), taken directly from the Sturm \& Krouse report, are provided in Appendix D for the gauge locations shown in Table 4.2.5. Also included in Appendix D are the plots of strain as a function of operating pressure for the three compensator (reference) gauges, 115,116 , and 117 , for the tests conducted on September 8 and 9,1960 . The slopes for the compensator gauges are 1.0 and $1.5 \times 10^{-9} \mathrm{in} . / \mathrm{in} . / \mathrm{psi}$; which is negligible compared with the slopes shown in Table 4.2.4. Even though these slopes are low and do not affect our interpretation of the strain measurements, we are at a loss to explain any slope in the reference gauges. They were supposed to be at a location where the strain due to operation of the press was zero. Their purpose was to monitor for changes in the electrical resistance of the strain measuring circuit. The principal contribution to change in electrical resistance of the circuit is a change in temperature. The electrical resistivity of copper wire increases with increasing temperature, and an increase in ambient temperature could result in an increase in the electrical resistance of the strain measuring circuit. This increase in electrical resistance increases the zero value for the strain gauges, which is then subtracted from the actual strain measurements; it should be independent of strain on the vessel. The most logical explanation for the slopes of strain as a function of operating pressure for the Sturm \& Krouse reference 


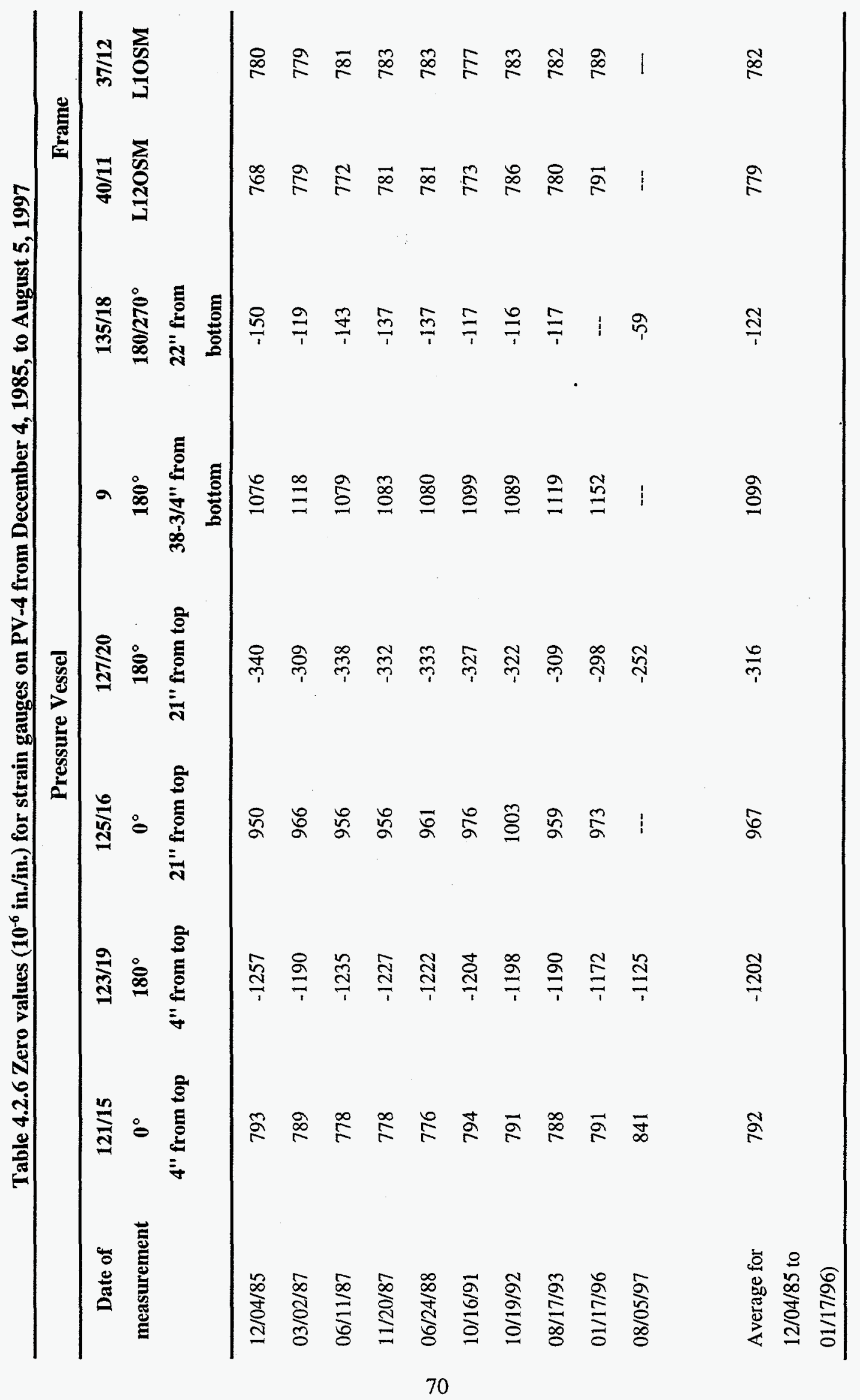




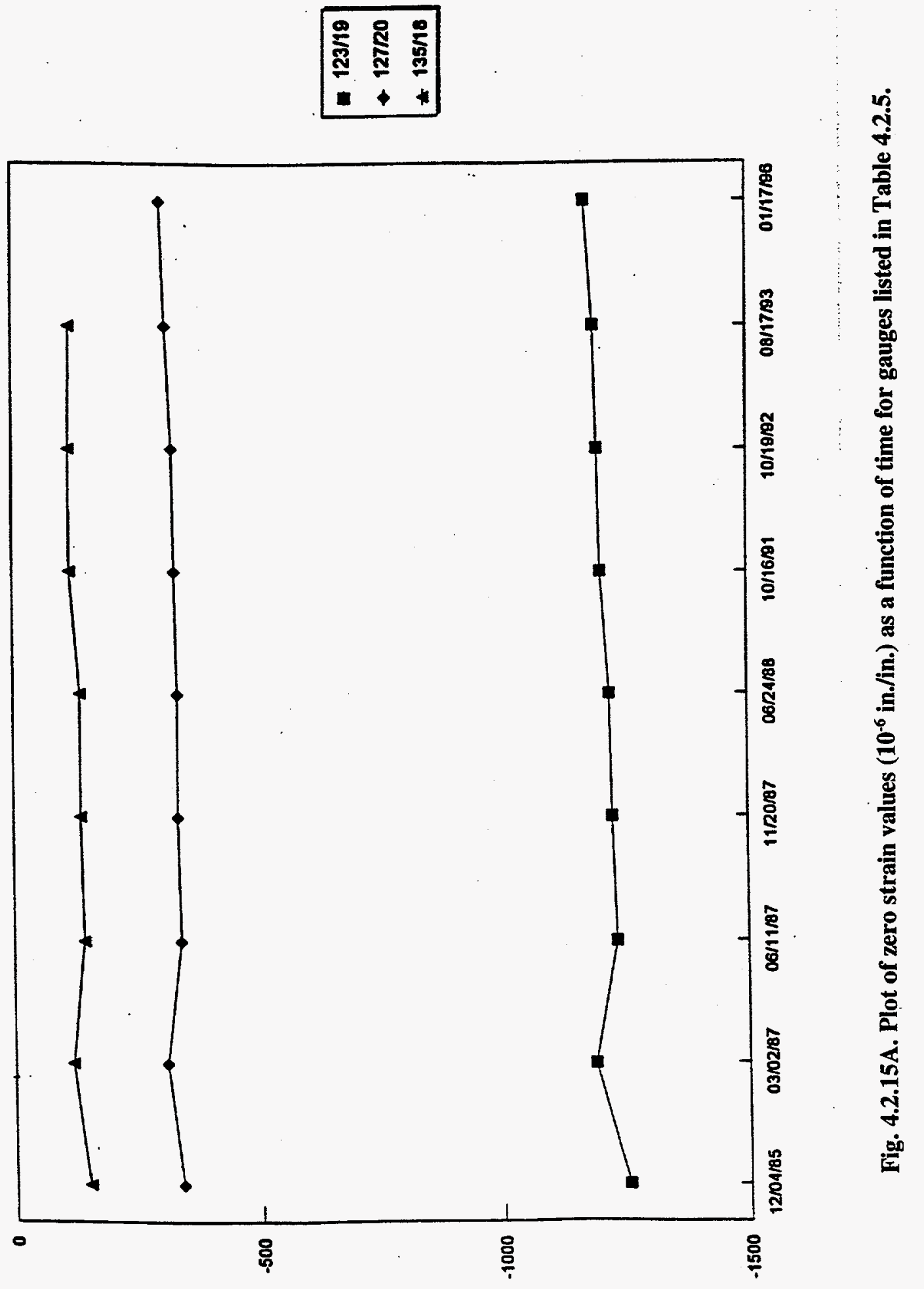




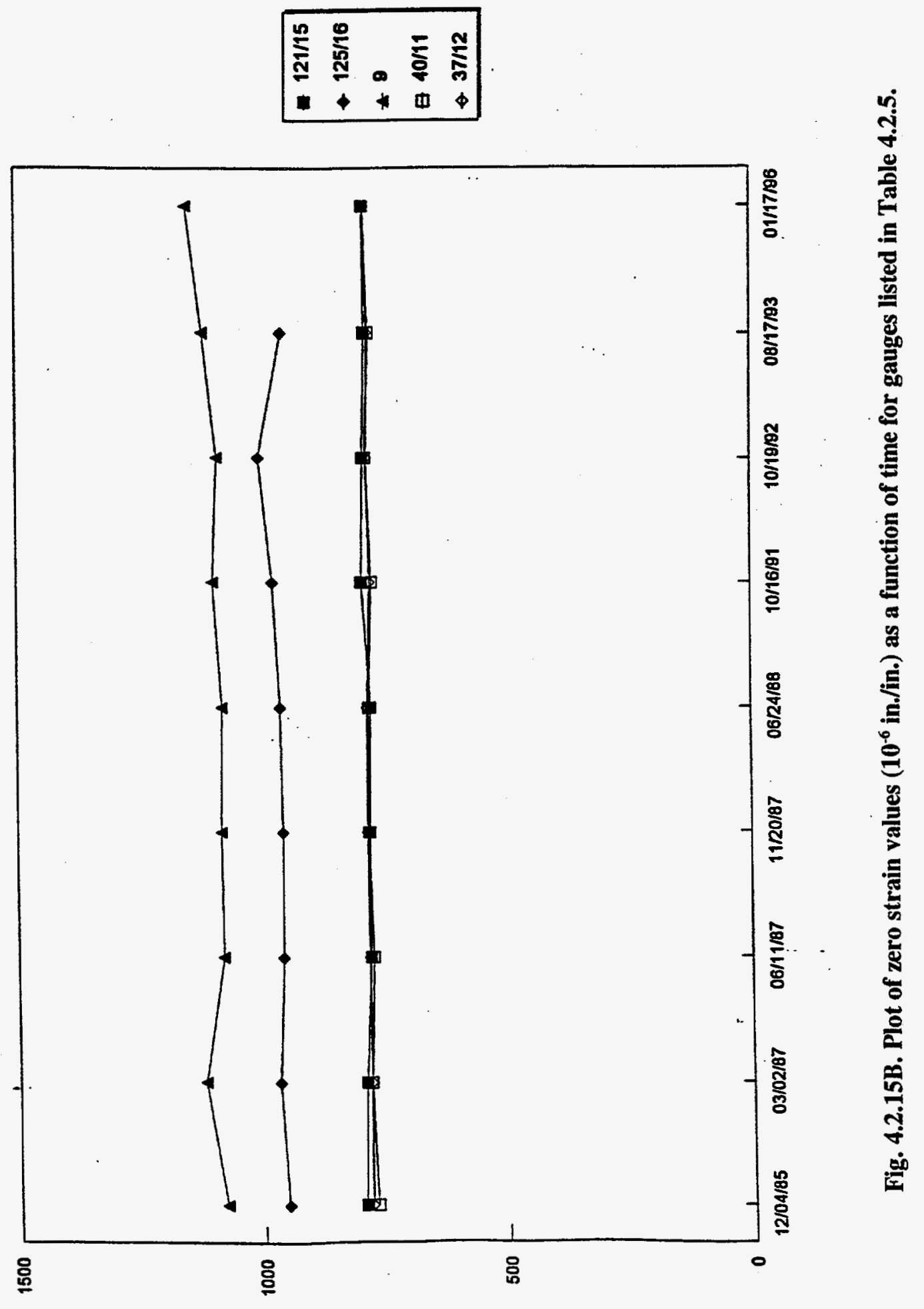


gauges is that they were mounted at a location at which strain due to operations of the press was not zero, but some small but measurable value. Considering the difficulties in attempting to manually record strain values at a constant pressure (several minutes) compared with the instantaneous strain measurements (0.6 $\mathrm{sec}$ ), described in Sect. 3.2, and the degree of technical rigor used to calculate the slopes from December 4, 1985 , to August 5, 1997, relative to that employed by Sturm \& Krouse, we place greater confidence in the slopes measured since 1985 than in the slopes measured in 1960.

As shown in Table 4.2.6, the zero strain values measured on August 5, 1997, are significantly different from those measured from December 4, 1985, through January 17, 1996. Between January 17, 1996, and August 5, 1997, there was an off-normal operation of PV-4 (Ref. 9) and a malfunction of the data acquisition system. Strain gauge measurements taken immediately after the off-normal operation and on August 5, 1997, indicate that there has been no permanent damage to the press as a result of the offnormal operation. However, the off-normal operation and/or equipment malfunction resulted in a shift in the zero strain values; and the zero strain values measured after January 17, 1996, cannot be compared with the zero strain values measured prior to that date.

Tables 4.2.5 and 4.2.6 and Figs. 4.12 and 4.15A and B show that within experimental accuracy, there has not been any systematic change or, in fact, any significant change in the slope of strain as a function of internal pressures or of the zero strain values. These data indicate that there has not been a measurable relaxation of the original shrink-fit pressures; therefore, the original shrink-fit pressures may be used for conducting stress analyses for the pressure vessel and for estimating the fatigue life of the vessel.

Mechanically, this is exactly as expected. The pressure vessel was proof-tested at an internal pressure of $37.5 \mathrm{ksi}$ by the Bliss Co., and preoperational tests were conducted at pressures up to $33 \mathrm{ksi}$. Since the preoperational tests were completed on September 9, 1960, the maximum operating pressure has never exceeded $31 \mathrm{ksi}$, and the stresses produced by operations at pressures of $31 \mathrm{ksi}$ and below do not alter the shrink-fit pressure existing after the proof tests at $37.5 \mathrm{ksi}$.

Metallurgically, this is also exactly as expected. The microstructure that is responsible for the high strength and toughness of this alloy steel was produced by austenitizing at $1550^{\circ} \mathrm{F}$, quenching in water, and tempering at $1120^{\circ} \mathrm{F}$. To alter the microstructure produced by this heat treatment process, which could result in relaxation of the shrink-fit pressure, the vessel would have to be heated to a temperature high enough for diffusion of iron atoms to occur. Diffusion in metals and alloys increases exponentially with increasing temperature as shown in Eq. 4.2.1 (Ref. 10). 


$$
\mathrm{D}=\mathrm{D}_{\circ} \cdot \exp -\left(\frac{\mathrm{Q}}{\mathrm{kT}}\right) \text {, }
$$

where

$D=$ diffusion coefficient in $\mathrm{cm}^{2} / \mathrm{s}$,

$\mathrm{D}_{0}=\mathrm{a}$ temperature-independent constant which includes a geometric factor associated with crystal structure and the entropy for formation and motion of a lattice vacancy,

$\mathrm{Q}=$ the activation energy for diffusion, which is the sum of the activation energy for formation and motion of a lattice vacancy (for iron this is $\sim 1.5 \mathrm{eV}$ ),

$\mathrm{k}=$ Boltzman constant, $0.86 \times 10^{-4} \mathrm{eV} / \mathrm{K}$,

$\mathrm{K}=$ temperature in Kelvin.

For tempering at the lowest temperature of $1120^{\circ} \mathrm{F}$, the diffusion coefficient for iron is

$$
\begin{gathered}
D_{1120^{\circ} \mathrm{F}}=\mathrm{D}_{0} \cdot \exp -\left(\frac{1.5 \mathrm{eV}}{0.86 \times 10^{-4} \frac{\mathrm{eV}}{\mathrm{K}} \cdot 877 \mathrm{~K}}\right) \mathrm{cm}^{2} / \mathrm{s}, \\
D_{1120^{\circ} \mathrm{F}}=D_{0} \cdot \exp -(19.9) \mathrm{cm}^{2} / \mathrm{s}, \\
D_{1120^{\circ} \mathrm{F}}=2.3 \times 10^{-9} \mathrm{D}_{0} \mathrm{~cm}^{2} / \mathrm{s} .
\end{gathered}
$$

If the maximum temperature experienced by $\mathrm{PV}-4$ has been $100^{\circ} \mathrm{F}$, the diffusion coefficient at $100^{\circ} \mathrm{F}$ is

$$
\begin{gathered}
\mathrm{D}_{100^{\circ} \mathrm{F}}=\mathrm{D}_{0} \cdot \exp -\left(\frac{1.5 \mathrm{eV}}{0.86 \times 10^{-4} \frac{\mathrm{eV}}{\mathrm{K}} \cdot 311 \mathrm{~K}}\right) \mathrm{cm}^{2} / \mathrm{s}, \\
\mathrm{D}_{100^{\circ} \mathrm{F}}=\mathrm{D}_{\circ} \cdot \exp -(56) \mathrm{cm}^{2} / \mathrm{s}, \\
\mathrm{D}_{100^{\circ} \mathrm{F}}=4.8 \times 10^{-25} \mathrm{D}_{0} \mathrm{~cm}^{2} / \mathrm{s},
\end{gathered}
$$


and the ratio of diffusion at $1120^{\circ} \mathrm{F}$ relative to that at $100^{\circ} \mathrm{F}$ is

$$
\frac{D_{1120^{\circ} \mathrm{F}}}{D_{100^{\circ} \mathrm{F}}}=\frac{2.3 \times 10^{-9} \mathrm{D}_{0} \mathrm{~cm}^{2} / \mathrm{s}}{4.8 \times 10^{-25} \mathrm{D}_{\mathrm{o}} \mathrm{cm}^{2} / \mathrm{s}}=4.8 \times 10^{15}
$$

and diffusion occurs $\sim 5 \times 10^{15}$ times more rapidly at $1120^{\circ} \mathrm{F}$ than at $100^{\circ} \mathrm{F}$. The standard "rule of thumb" for heat treating metals and alloys is $1 \mathrm{hr} / \mathrm{in}$. of thickness; and the thickness of the PV-4 pressure vessel is $\sim 12 \mathrm{in}$. The diffusion that would occur in $12 \mathrm{~h}\left(4.32 \times 10^{4} \mathrm{~s}\right)$ at $1120^{\circ} \mathrm{F}$ is:

$$
\mathrm{D}_{1120}{ }^{\circ} \mathrm{F}=2.3 \times 10^{-9} \mathrm{~cm}^{2} / \mathrm{s} \times 4.3 \times 10^{4} \mathrm{~s}=9.8 \times 10^{-5} \cdot \mathrm{D}_{\mathrm{o}} \mathrm{cm}^{2}=-1 \times 10^{-4} \mathrm{D}_{\mathrm{o}} \mathrm{cm}^{2}
$$

The time to produce diffusion at $100^{\circ} \mathrm{F}\left(t_{100^{\circ} \mathrm{F}}\right)$ equal to that achieved in $12 \mathrm{~h}$ at $1120^{\circ} \mathrm{F}$ would require

Diffusion at $1120^{\circ} \mathrm{F}=$ Diffusion at $100^{\circ} \mathrm{F}$

$$
\begin{gathered}
9.8 \times 10^{-5} \mathrm{D}_{0} \mathrm{~cm}^{2}=4.8 \times 10^{-25} \cdot \mathrm{t}_{100^{\circ} \mathrm{F}} \cdot \mathrm{D}_{0} \mathrm{~cm}^{2} / \mathrm{s}, \\
\mathrm{t}_{100^{\circ} \mathrm{F}}=\frac{9.8 \times 10^{-5} \mathrm{D}_{0} \mathrm{~cm}^{2}}{4.8 \times 10^{-25} \mathrm{D}_{0} \mathrm{~cm}^{2} / \mathrm{s}}, \\
\mathrm{t}_{100^{\circ} \mathrm{F}}=2.0 \times 10^{20} \mathrm{~s}=6.5 \times 10^{12} \text { years, }
\end{gathered}
$$

which is 6.5 trillion years. To be extremely conservative, we assume that the PV-4 pressure vessel may have experienced a temperature as high as $150^{\circ} \mathrm{F}$, and using the temperature of $150^{\circ} \mathrm{F}$ in Eq. 4.1 , the time required to produce diffusion equal to that in $12 \mathrm{~h}$ at $1120^{\circ} \mathrm{F}$ is decreased to 70 billion years.

There are two contributions that could lead to small decreases in these times. First, carbon atoms are smaller than iron atoms, and they occupy interstitial sites in the iron matrix; therefore, they can diffuse interstitially between iron atoms. As a result, the diffusion rates of carbon in iron are up to twice that of iron self-diffusion at high temperatures. Second, diffusion rates can be enhanced by residual or applied stresses (e.g., stress-enhanced diffusion), and there are significant residual stresses in the PV -4 pressure vessel. However, stress-enhanced diffusion occurs over a limited temperature range, which is usually $\sim 0.3$ 
to $0.4 \mathrm{~T}_{\mathrm{m}}\left(\mathrm{T}_{\mathrm{m}}\right.$ is melting temperature in Kelvin) and enhances diffusion by up to $20 \%$ to $30 \%$. If we are ultraconservative and include possible contributions of both carbon diffusion and stress-enhanced diffusion, the total decrease in the times shown above is less than one order of magnitude; and the approximate times required to produce measurable changes in the metallurgical structure are $\sim 0.6$ trillion and $\sim 7$ billion years at temperatures of $100^{\circ} \mathrm{F}$ and $150^{\circ} \mathrm{F}$, respectively. Therefore, we conclude that since PV-4 has always been operated at ambient (room) temperature, or slightly above room temperature, there is no known physical mechanism by which the existing microstructure could be altered; and therefore, no mechanism to produce a change in the metallurgical structure or the shrink-fit pressure. We use operated at room temperature or slightly above room temperature because the room in which PV-4 is located is an unairconditioned room, and the temperature in the room is heated to a few degrees Fahrenheit above room temperature to prevent condensation of moisture and concomitant rusting of the low alloy steels of the press and its components.

\subsection{Residual Stresses}

Strain gauges are bonded to structures in order to evaluate the effects of subsequently imposed loadings. They are set to read zero strain (at no imposed load), and their further responses then track the imposed loads. They do not account for fabrication stresses, and for most structural applications these are quite low in comparison with the operating stresses. However, for the shrink-fitted cylinders that make up the pressure vessel of the PV-4 press, these residual stresses are significant, since their function is to place the inner surfaces in (circumferential) compression in order to limit subsequent tensile loadings imposed by press operation.

The highest measured increment of operating stress at the design maximum operating pressure of PV-4 is 60,000 psi (Fig. 4.2.8). An interference fit of 0.001 in./in. between the sleeve and the liner (as per E. W. Bliss drawing 155A-2272) would compress the liner to about 15,000 psi (and give a residual tensile stress of the same value on the sleeve). A similar shrink fit for the outer ring would result in an even higher tensile hoop stress, while adding a smaller increment of compressive stress to the inner surface of the chamber liner.

The residual tensile stress on the surface of the outer ring is added to the $(60,000 \mathrm{psi})$ tensile stress developed in the press operating cycle and the combination is a major part of the specified $125 \mathrm{ksi}$ 
minimum yield strength for the pressure vessel materials (Table C-2). This factor will be considered in greater detail in Y/QS-0007, "Stress Analyses for the PV-4 Pressure Vessel" (Ref. 2), and in Y/QS-0008, "Estimates of the Fatigue Life for the PV-4 Pressure Vessel" (Ref. 3), to be published. 



\section{FURTHER WORK}

In addition to the analyses being conducted for stresses on the pressure vessel and for the fatigue life of the pressure vessel, it is recommended that monitoring of stresses on the PV-4 frame and pressure vessel with precision strain gauges be continued. Continued monitoring of strains is required to detect development of possible defects, cracks, or flaws in the vessel and to make certain that there is no relaxation of the original shrink-fit pressure.

Since the zero values recorded prior to the off-normal operation of the press on July 9,1996 , are no longer valid, from that date forward we do not have the data necessary to verify that no flaws have developed in the pressure vessel and that there has been no relaxation of the shrink-fit pressure. Therefore, highest priority should be given to establishing a new set of zero values and slopes of strain as a function of operating pressure for the gauges on the pressure vessel. Zero and slope readings should be taken at frequent intervals (e.g., three to four times a year) for the next three to five years to reestablish a documented data base as extensive as that developed from December 4, 1984, to January 17, 1996. Development of this new data base should begin immediately.

The highest stresses in the entire press system are at and adjacent to the circumferential groove at the axial midplane of the pressure vessel; and the groove itself can be considered as a notch or stress riser. Because of this, the most sensitive indicator of the integrity of the press is knowledge of the stresses near this groove. Therefore, it is recommended that high priority be given to placing precision strain gauges as close as is technically feasible to the midplane groove; and that a schedule be established and adhered to for monitoring zero strain readings and slopes of strain as a function of operating pressure for these gauges. To maximize the value of the information obtained from these gauges, unstrained reference gauges should be placed at strategic locations on or near the press and monitored on the same schedule as the gauges near the groove.

Also, serious consideration should be given to mounting strain gauges on the frame and vessel at the same locations at which Sturm \& Krouse mounted gauges in September 1960. Gauges at the same locations as those used by Sturm \& Krouse would provide for much better quantitative comparisons of the current strain readings with those obtained in 1960 , prior to operation of the press.

Addition of a thermocouple on the pressure vessel would provide temperature history and eliminate the need to speculate and/or estimate the temperature history of the press. 



\section{SUMMARY}

The PV-4 isostatic press has a very large working volume $\left(98 \mathrm{ft}^{3}\right)$ that was designed for routine operations at internal pressures up to $30 \mathrm{ksi}$ and is, therefore, a unique and valuable component of the U.S. DOE Y-12 manufacturing capability. More than 13,000 pressing operations have been conducted since initiation of operations in September 1960. The pressure vessel portion consists of three concentric cylinders of high-strength steel with the outer two cylinders shrink-fitted on the innermost cylinder to minimize tensile stresses on the inner surface of the vessel. The third, outermost cylinder consists of two sections; each section is one-half the length of the pressure vessel. The vessel is contained within a large frame which is made of T-1 steel.

PV-4 was built in 1959 and 1960, with the design methodology, materials technology, and ASME Code criteria in existence in the late 1950s. Since the press was constructed, several new regulatory agencies, and associated regulations, dealing with pressure vessels have been created; and the ASME Code has adopted new criteria and guidelines for operations and maintenance of pressure vessels. Although PV-4 was "grandfathered" from the new criteria and guidelines, it has been our intent to employ the best available evaluations and analysis methods to ensure continued long-term operation of the press with maximum safety. In addition, there has been some concern that after long-term operation of the press at working pressures of $\sim 15 \mathrm{ksi}$ to $30 \mathrm{ksi}$, a flaw or crack may have been initiated in the vessel, or there may have been a relaxation of the original shrink-fit pressures.

To address the above concerns, in 1982 and 1983 precision strain gauges were mounted at selected locations on the frame and the outer surface of the pressure vessel to monitor the operating stresses. Where possible, locations of the gauges mounted in 1982 and 1983 were at or near the same locations as the strain gauges mounted in 1960 to monitor stresses on the frame and vessel during preoperational testing and design verification of the press. This report presents the information obtained with these strain gauges for tests conducted in September 1960 prior to any operation of the press and for the period July 1983 to August 1997.

On September 8 and 9, 1960, Sturm \& Krouse used 120 strain gauges on the frame and 20 strain gauges on the outer surface of the pressure vessel to measure strains in PV-4 as a function of operating pressure from 0 to $33 \mathrm{ksi}$. Although the design maximum operating pressure of the press was $30 \mathrm{ksi}$, to provide a safety factor for operations at $30 \mathrm{ksi}$ and to assure totally elastic behavior of the steel components 
of the frame and pressure vessel at pressures above the design pressure, strains were also measured at operating pressures of 32 and $33 \mathrm{ksi}$.

Sturm \& Krouse observed that the stresses on the frame and vessel were a linear function of operating pressure over the test range from 0 to $33 \mathrm{ksi}$. They verified the design performance and parameters of the press and linear elastic behavior to at least $10 \%$ higher than the design operating pressure.

Stresses calculated from strain gauge measurements taken between July 29, 1983, and August 5 , 1997, at an operating pressure of $30 \mathrm{ksi}$ are in good to excellent agreement with those obtained in September 1960 on the frame and are in excellent agreement with those obtained on the pressure vessel. In addition, slopes of the measured strain as a function of internal pressure have remained the same from preoperational testing on September 8 and 9, 1960, through August 5, 1997, the last date on which strain measurements were conducted. Also, there have been no systematic changes in the zero strain values for measurements taken with the same data acquisition system.

The excellent agreement of the stresses and slopes measured from 1983 to 1997 with those measured in 1960 indicates that no cracks, defects, or other flaws have developed in the pressure vessel that could affect the integrity of the pressure vessel. Also, this excellent agreement indicates that there has not been any relaxation of the original shrink-fit pressures that were employed in fabrication of the vessel. Therefore, the original shrink-fit pressures may be used for stress analysis of the pressure vessel and for estimating the fatigue life of the vessel.

The excellent agreement of the stresses and slopes of strain as a function of internal pressure obtained for the period 1983 to 1997 with those obtained in 1960 are exactly as expected for the metallurgical structure of the steels of which the press frame and pressure vessel were constructed.

To assure long-term integrity of the pressure vessel and that the shrink-fit pressures are not relaxed, continued monitoring of the vessel with precision strain gauges is required. 


\section{ACKNOWLEDGMENTS}

We express our appreciation to M. S. Hayden who prepared the manuscript. We extend our special thanks to K. T. Ziehlke for helpful discussions, careful review and editing of this manuscript, and for recommendations that greatly improved the quality and value of this report. 



\section{REFERENCES}

1. E. W. Bliss Co., Drawing 55-W-1805, March 10, 1959.

2. C. K. Chung, J. A. Horak, and J. L. Frazier, "Stress Analysis for the PV-4 Pressure Vessel," Y/QS0007 , to be published.

3. J. A. Horak, C. K. Chung, and J. L. Frazier, "Estimates of the Fatigue Life for the PV-4 Pressure Vessel," Y/QS-0008, to be published.

4. Aerospace Structural Metals Handbook 1989 Publication, Code 1103, pp. 1-15, Battelle Columbus Division, Columbus, $\mathrm{OH}$.

5. George E. Dieter, Jr., Mechanical Metallurgy, pp. 240, 242-243, McGraw-Hill Book Co., New York, NY, 1961.

6. "Test of the 60 Inch Isostatic Press at Union Carbide Nuclear Company," Union Carbide Corporation Nuclear Division Subcontract Number 2040, Sturm \& Krouse, Inc., Auburn, AL, December 15, 1960.

7. J. L. Frazier, "Y-12 Isostatic Press Interim Report," Ḳ/PS-1131, Martin Marietta Energy Systems, Inc., Oak Ridge, TN, March 31, 1986.

8. C. C. Perry and H. R. Lissner, The Strain Gauge Primer, second edition, McGraw-Hill Book Company, New York, NY.

9. “Type C Investigation of Isostatic Press 4 Malfunction July 9, 1996," Y/AD-634, December 17, 1996.

10. See for example P. G. Shewmon, Diffusion in Solids, McGraw-Hill Book Co., New York, NY, or W. Jost, Diffusion in Solids, Liquids, Gases, Academic Press, Inc., New York, NY, or any current textbook on Materials Science, Physical Metallurgy, or Solid State Physics. 

APPENDIX A

PROCEDURES USED TO APPLY STRAIN GAUGE ROSETTES TO PV-4 IN 1982 AND 1983 

Mineral oil is used as a pressure transfer medium in PV-4; and as a result of filling and pressing operations conducted between 1960 and 1982, the surfaces of the frame and pressure vessel were coated with a thick layer of mineral oil. All strain gauge adhesives available in 1982 deteriorate upon exposure to mineral oil. Deterioration of the adhesive results in partial or total debonding of the strain gauge, resulting in erroneous data or loss of function. To avoid this problem, laboratory tests and analyses were conducted which resulted in the following procedures for bonding the strain gauges to the frame and pressure vessel of PV-4 and protecting the adhesive and gauge from contact with mineral oil.

1. In the area where a strain gauge is to be mounted, degrease an area $\sim 12 \mathrm{in.} \times 12$ in. with Chlorothene $\mathrm{Nu}^{\mathrm{a}}$.

2. Remove all paint and pitting to produce a bright, metallic, smooth surface.

3. Select the exact location where the gauge is to be bonded and outline this area with a scribe.

4. Degrease again with Chlorothene $\mathrm{Nu}$.

5. Wet-sand the gauge area with $320 \mathrm{G}$ and Conditioner $\mathrm{A}^{\mathrm{a}}$.

6. Neutralize the sanded area with M-Prep Neutralizer $5 A^{b}$. Note, follow the specific instructions provided by the manufacturer of neutralizer $5 \mathrm{~A}$.

7. Mount rosettes using M-bond AE-10 adhesive and an electrically heated Vacuum Application Pad

8. Visually inspect the gauge for voids and/or uneveness in the adhesive.

9. Conduct an electrical test of the gauge for any defects, short circuits, or open circuits.

10. Install $\sim 6$ in. length of neoprene-insulated wire pigtail.

11. Coat strain gauge and wires with $M-C o a t D^{a}$ and allow to dry thoroughly.

12. Overcoat the area coated with $M$-Coat $D$ with $M$-Coat $G^{a}$, allowing the overcoat to extend at least $2 \mathrm{in}$. beyond the area coated with M-Coat D. Use the M-Coat G for anchoring the lead wires to the surface.

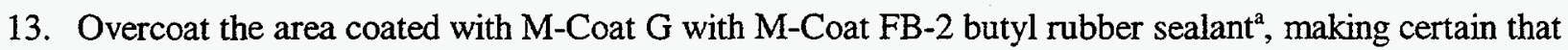
the M-Coat FB-2 is firmly adhered to the surface.

14. Cover the entire gauge area with adhesive-backed aluminum foil. Firmly press the aluminum foil to the clean base metal substrate, making certain that there are no air gaps, seams, or paths for mineral oil to come in contact with the strain gauge. 
All wiring was \#18 gauge, Teflon-insulated with a woven copper braid and a Teflon overjacket. A three-wire circuit was used for each individual gauge. A 100-channel Vishay 4000 System $^{\mathrm{a}}$ was used for all data signal conditioning and acquisition.

The supplier's names and their generic counterparts are:

Measurements

\section{Group Proprietary Name}

(1 Chlorothene $\mathrm{Nu}$

(2) Conditioner A

(3) Neutralizer 5A

(4 M-Bond AE-10

(5) M-Coat D

(6) M-Coat G

(7 M-Coat FB-2 butyl rubber sealant

${ }^{2}$ Measurements Group, Inc., Raleigh, NC.

${ }^{\mathrm{b}}$ Applications Technology, Inc., Hampton, VA

\section{Generic}

1-1-1 Trichloroethene

Mild Phosphoric Acid Compound

Ammonium Hydroxide Compound

Proprietary $100 \%$ Solids Epoxy System

Toluene-Thinned Acrylic Lacquer

Polysulfide Epoxy

Proprietary butyl rubber compound 
APPENDIX B

STRESSES ON THE PV-4 FRAME AND PRESSURE VESSEL AT AN INTERNAL PRESSURE OF 33 ksi ON SEPTEMBER 9, 1960

Table B-1 Calculated maximum stresses (ksi) for single- and two-gauge rosettes on the PV-4 frame and pressure vessel at an internal pressure of $33 \mathrm{ksi}$ on September 9, 1960.

Table B-2 Calculated maximum principal stresses for three-gauge rosettes on the PV-4 frame at an internal pressure of $33 \mathrm{ksi}$ on September 9, 1960. 

Table B-1. Calculated maximum stresses (ksi) for single- and two-gauge rosettes on the PV-4 frame and pressure vessel at an internal pressure of $33 \mathrm{ksi}$ on September 9, 1960

\begin{tabular}{|c|c|c|c|c|c|}
\hline Gauge & Stress (ksi) & Gauge & Stress (ksi) & Gauge & Stress (ksi) \\
\hline 1 & 56.9 & 33 & 41.1 & 65 & 23.8 \\
\hline 2 & 55.4 & 34 & 41.6 & 66 & 22.8 \\
\hline 3 & 52.0 & 35 & 43.6 & 67 & 26.2 \\
\hline 4 & 54.9 & 36 & 43.6 & 68 & 26.2 \\
\hline 5 & 54.5 & 37 & 22.8 & 69 & 27.2 \\
\hline 6 & 56.9 & 38 & 23.8 & 70 & 33.7 \\
\hline 7 & 51.5 & 39 & 23.8 & 71 & 34.2 \\
\hline 8 & 51.0 & 40 & 25.2 & 72 & 32.7 \\
\hline 9 & 54.9 & 41 & 23.3 & 73 & -15.0 \\
\hline 10 & 54.9 & 42 & 23.3 & 74 & -7.0 \\
\hline 11 & 54.0 & 43 & 24.8 & 75 & -18.9 \\
\hline 12 & 55.4 & 44 & 25.2 & 76 & -8.7 \\
\hline 13 & 25.7 & 45 & 40.6 & 121 & 46.8 \\
\hline 14 & 26.7 & 46 & 30.7 & 122 & 7.4 \\
\hline 15 & 27.2 & 47 & 26.7 & 123 & 46.7 \\
\hline 16 & 27.2 & 48 & 33.7 & 124 & 7.1 \\
\hline 17 & 27.2 & 49 & 59.4 & 125 & 59.8 \\
\hline 18 & 26.7 & 50 & 57.9 & 126 & 9.6 \\
\hline 19 & 27.7 & 51 & 57.4 & 127 & 60.8 \\
\hline 20 & 28.7 & 52 & 58.9 & 128 & 9.4 \\
\hline 21 & 25.7 & 53 & 61.4 & 129 & 62.1 \\
\hline 22 & 33.7 & 54 & 56.4 & 130 & 2.3 \\
\hline 23 & 32.7 & 55 & 55.4 & 131 & 63.6 \\
\hline
\end{tabular}


Table B-1. Calculated maximum stresses (ksi) for single- and two-gauge rosettes on the PV-4 frame and pressure vessel at an internal pressure of $33 \mathrm{ksi}$ on September 9, 1960 (continued)

\begin{tabular}{llllll}
\hline Gauge & Stress (ksi) & Gauge & Stress (ksi) & Gauge & Stress (ksi) \\
\hline 24 & 33.7 & 56 & 56.4 & 132 & 5.8 \\
25 & -20.2 & 57 & 57.9 & 133 & 58.4 \\
26 & -1.1 & 58 & 59.4 & 134 & 13.1 \\
27 & -14.9 & 59 & 60.4 & 135 & 56.8 \\
28 & 0.0 & 60 & 57.9 & 136 & 10.4 \\
29 & 41.6 & 61 & 25.2 & 137 & 38.4 \\
30 & 41.1 & 62 & 24.8 & 138 & 6.1 \\
31 & 42.6 & 63 & 24.3 & 139 & 38.7 \\
32 & 42.6 & 64 & 25.7 & 140 & 6.6 \\
\hline
\end{tabular}


Table B.2. Calculated maximum principal stresses for three-gauge rosettes on the PV-4 frame at an internal pressure of $33 \mathrm{ksi}$ on September 9, 1960.

\begin{tabular}{lc}
\hline Gauge & Maximum Stress (ksi) \\
\hline $77-79$ & 23.5 \\
$80-82$ & 43.0 \\
$83-85$ & 43.4 \\
$86-88$ & 40.8 \\
$89-91$ & 12.3 \\
$92-94$ & 41.0 \\
$95-97$ & 42.4 \\
$98-100$ & 41.1 \\
$101-103$ & gauge failed \\
$104-106$ & 16.2 \\
$107-109$ & 15.3 \\
$110-112$ & 7.3 \\
\hline
\end{tabular}




\section{APPENDIX C}

MANUFACTURER'S CERTIFIED CHEMICAL COMPOSITION AND MECHANICAL PROPERTIES OF STEEL HEATS USED IN CONSTRUCTION OF THE PV-4 ISOSTATIC PRESS

Table C-1 Chemical composition of the heats of T-1 steel used as the plates for the frame of the PV-4 press.

Table C-2 Tensile and Charpy impact properties of the heats of T-1 steel used as the plates for the frame of the PV-4 press.

Table C-3 Tensile and Charpy impact properties of the heats of steel used in the pressure vessel of the PV-4 press.

Table C-4 Tensile and Charpy impact properties of the heats of steel used in other components of the PV-4 press. 



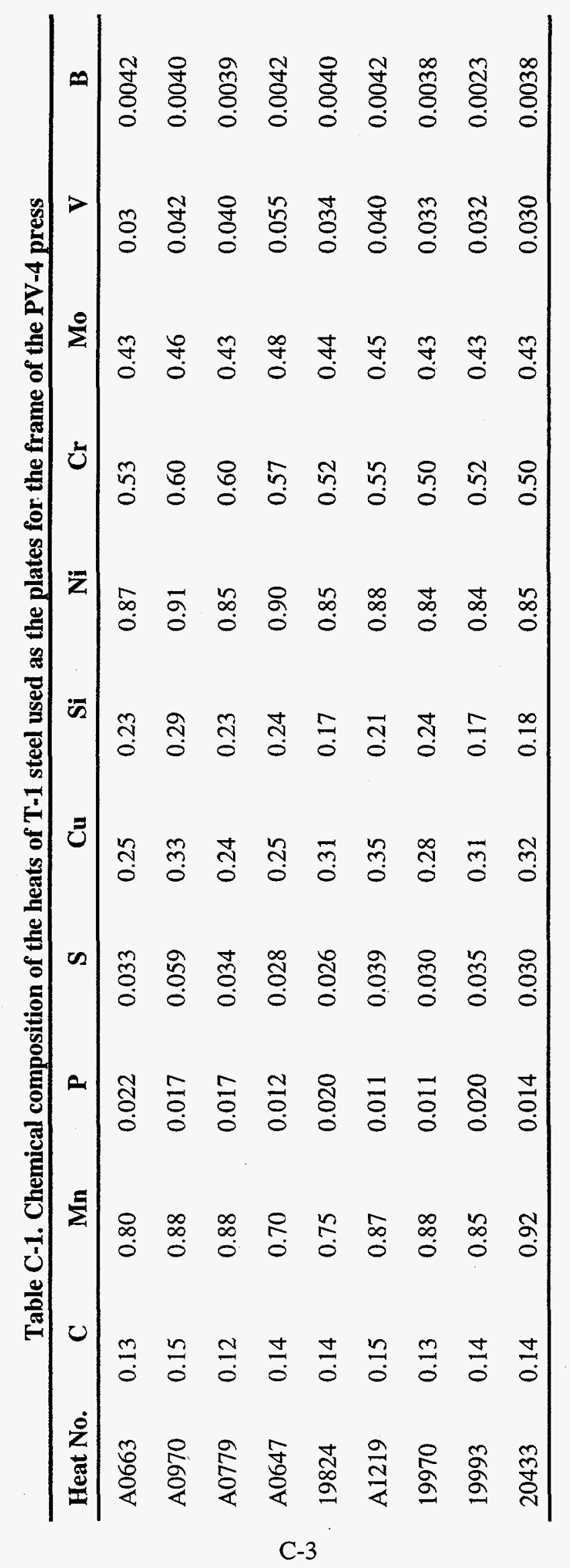




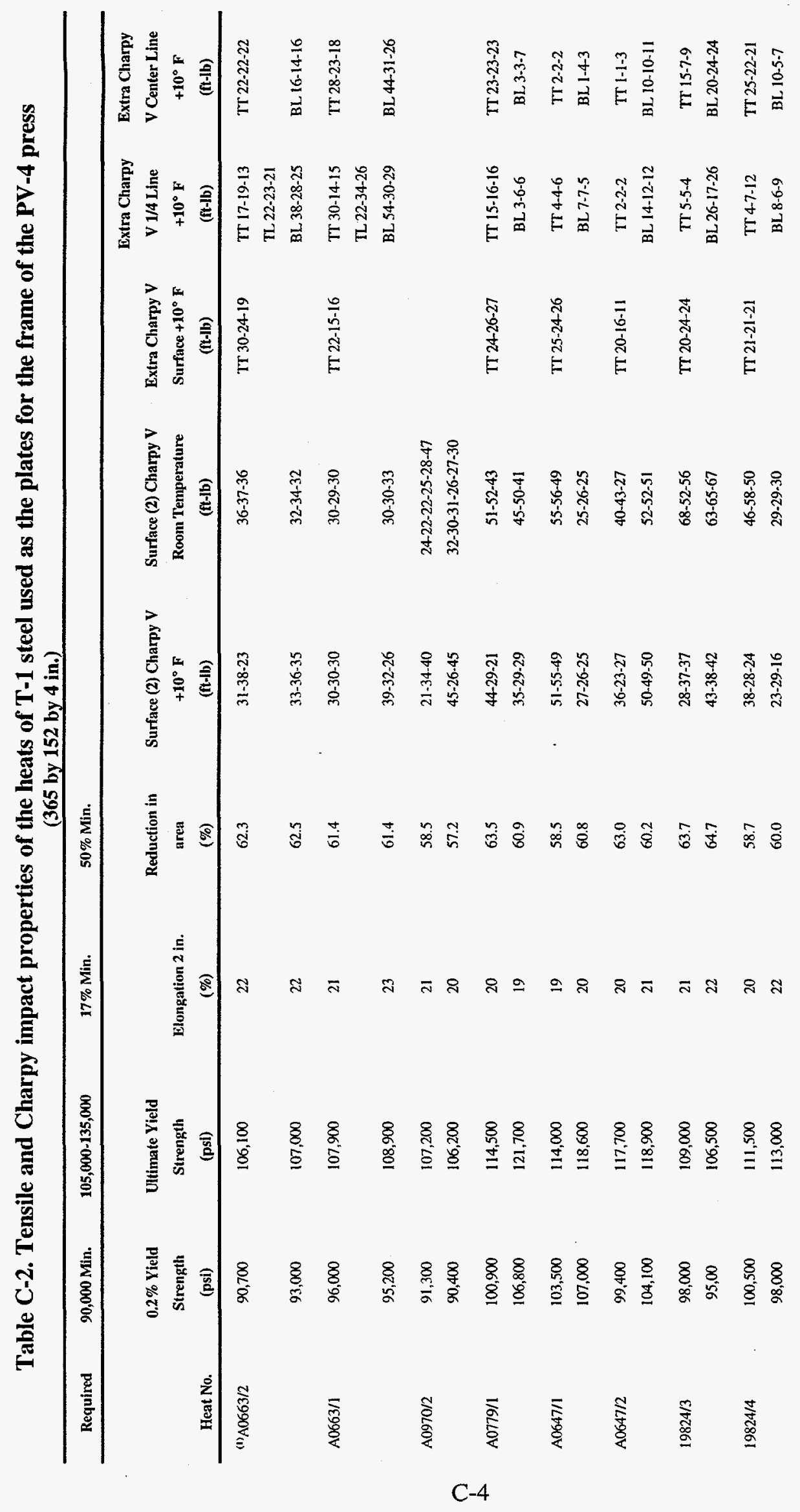




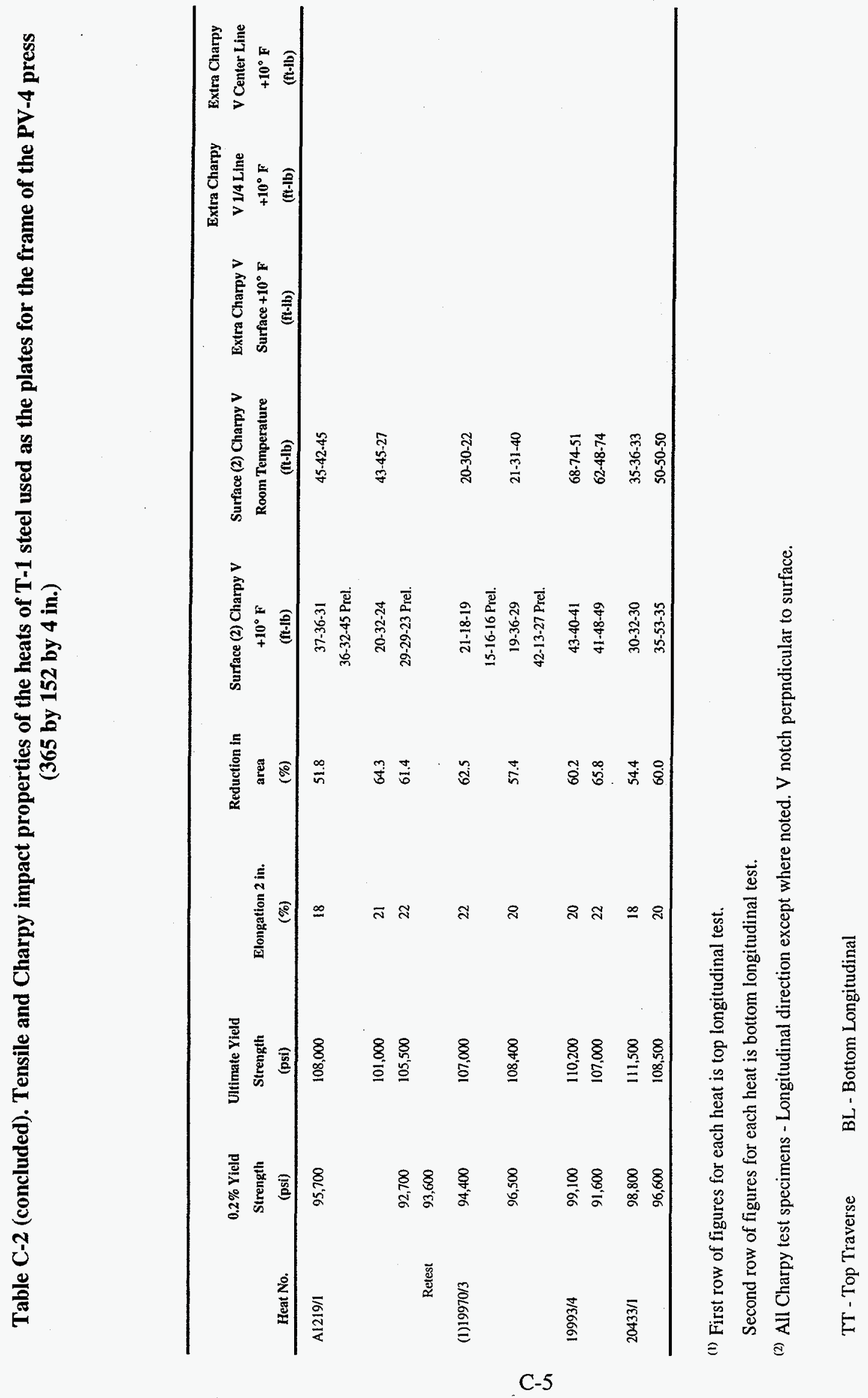




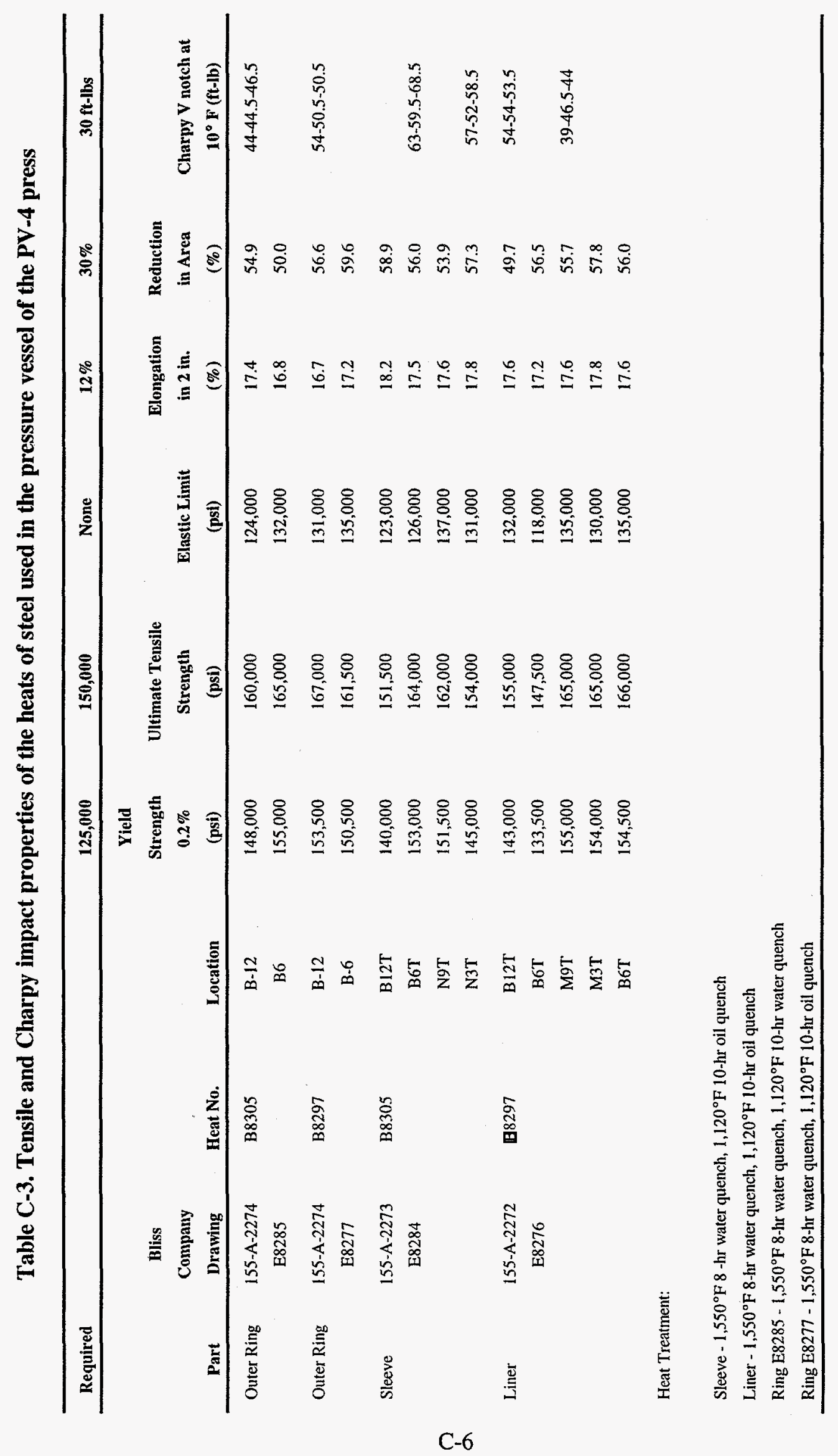




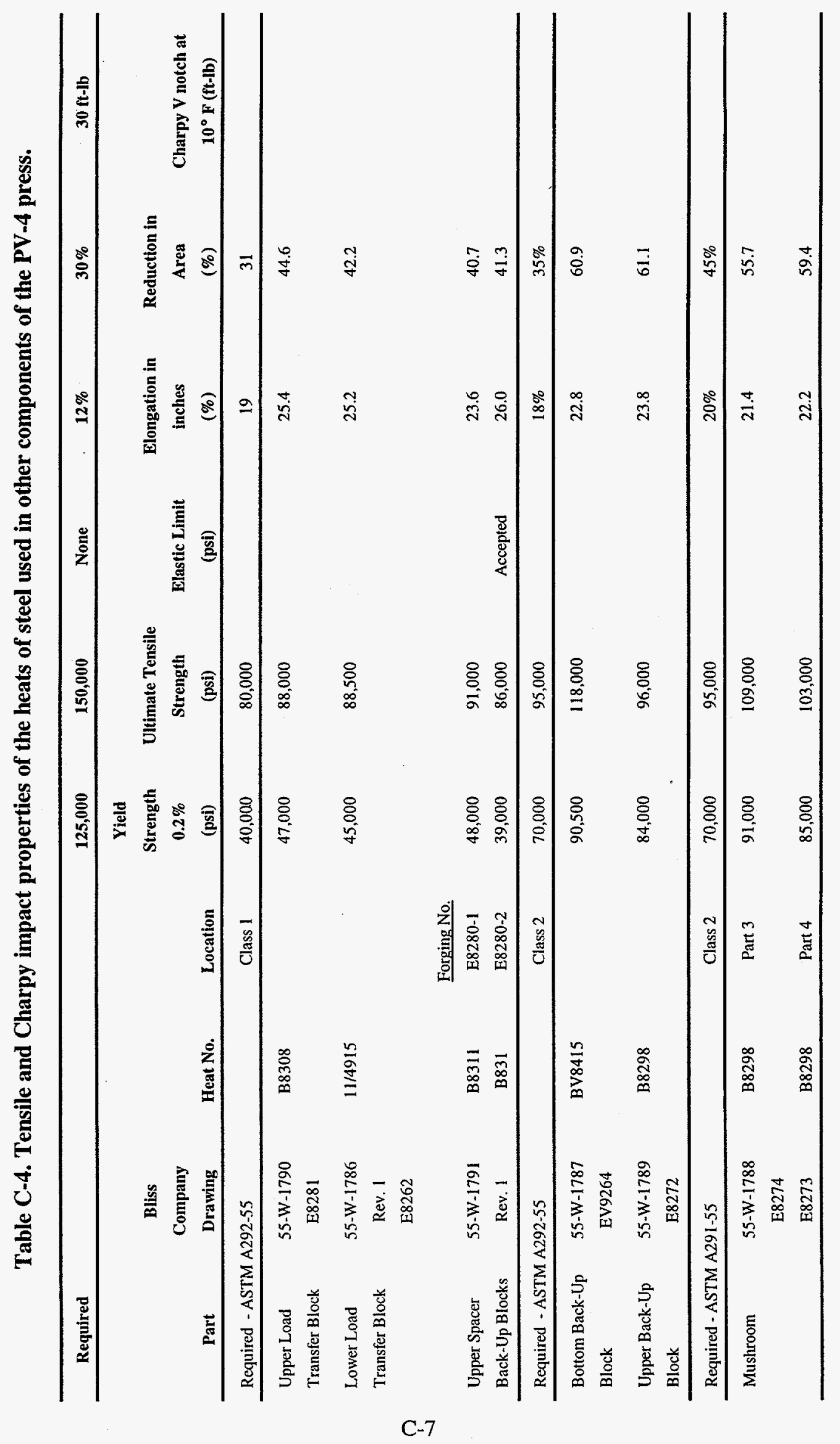





\section{APPENDIX D}

\section{PLOTS OF STRAIN AS A FUNCTION OF INTERNAL PRESSURE FOR THE SEVEN STRAIN GAUGES AND LOCATIONS LISTED IN TABLE 4.2.4 AND THE COMPENSATOR GAUGES FOR MEASUREMENTS CONDUCTED ON SEPTEMBER 8 AND 9, 1960. PAGES WERE MADE FROM THE BEST AVAILABLE COPY OF THE STURM \& KROUSE REPORT}

Fig. D-1. Plot of strain as a function of internal pressure for gauge 37 located on the left outside midplane of Plate \#1.

Fig. D-2. Plot of strain as a function of internal pressure for gauge 40 located on the left outside midplane of Plate \#12.

Fig. D-3. Plot of strain as a function of internal pressure for gauge 121 located on the pressure vessel at $0^{\circ}$ and 4 in. from the top of the vessel.

Fig. D-4. Plot of strain as a function of internal pressure for gauge 123 located on the pressure vessel at $180^{\circ}$ and 4 in. from the top of the vessel.

Fig. D-5. Plot of strain as a function of internal pressure for gauge 125 located on the pressure vessel at $0^{\circ}$ and 22 in. from the top of the vessel.

Fig. D-6. Plot of strain as a function of internal pressure for gauge 135 located on the pressure vessel at $180^{\circ}$ and 26 in. from the bottom of the vessel.

Fig. D-7. Plot of strain as a function of internal pressure for compensator gauge 115 .

Fig. D-8. Plot of strain as a function of internal pressure for compensator gauge 116.

Fig. D-9. Plot of strain as a function of internal pressure for compensator gauge 117. 



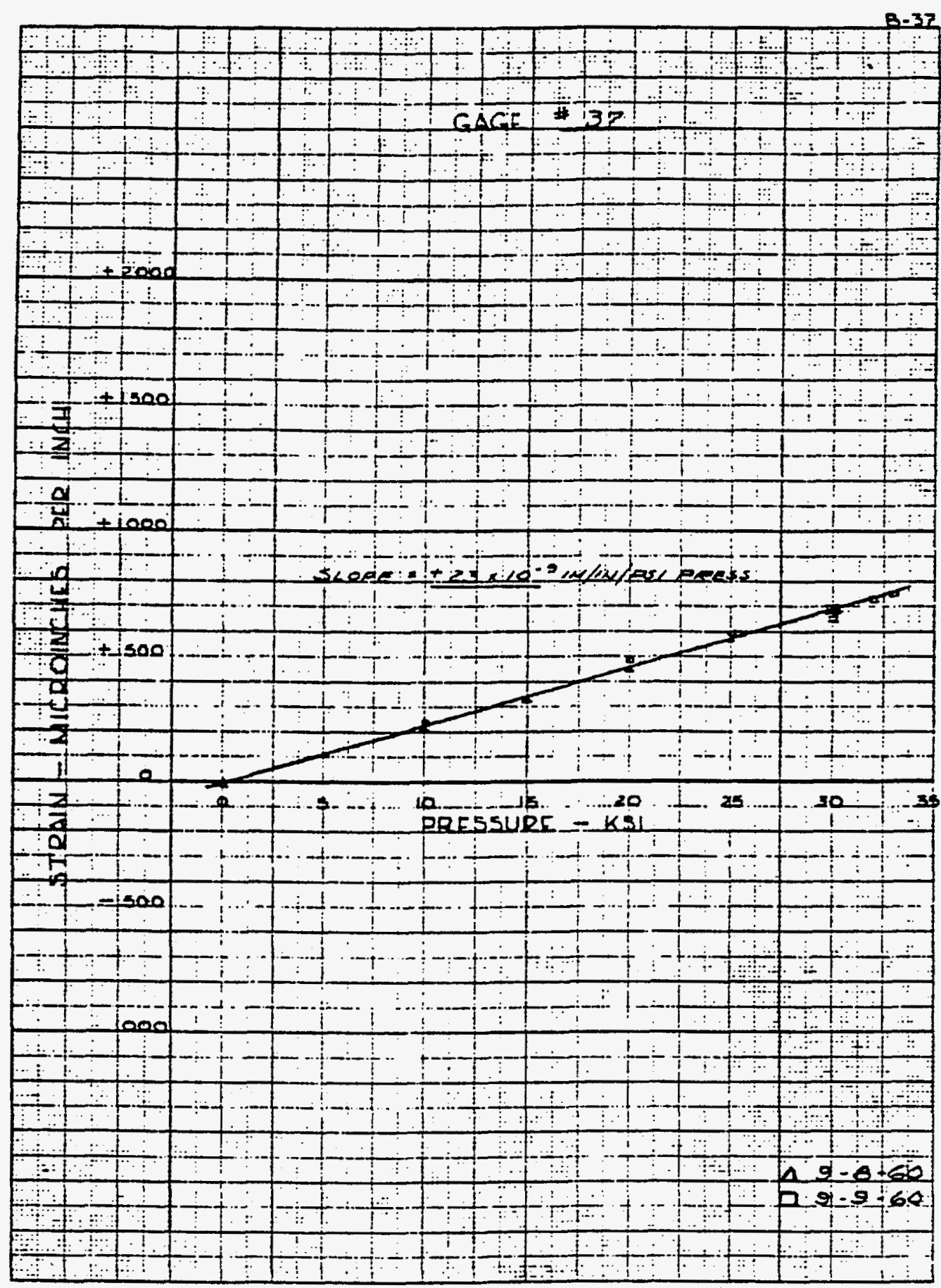

Fig. D-1. Plot of strain as a function of internal pressure for gauge 37 located on the left outside midplane of Plate \#1. 


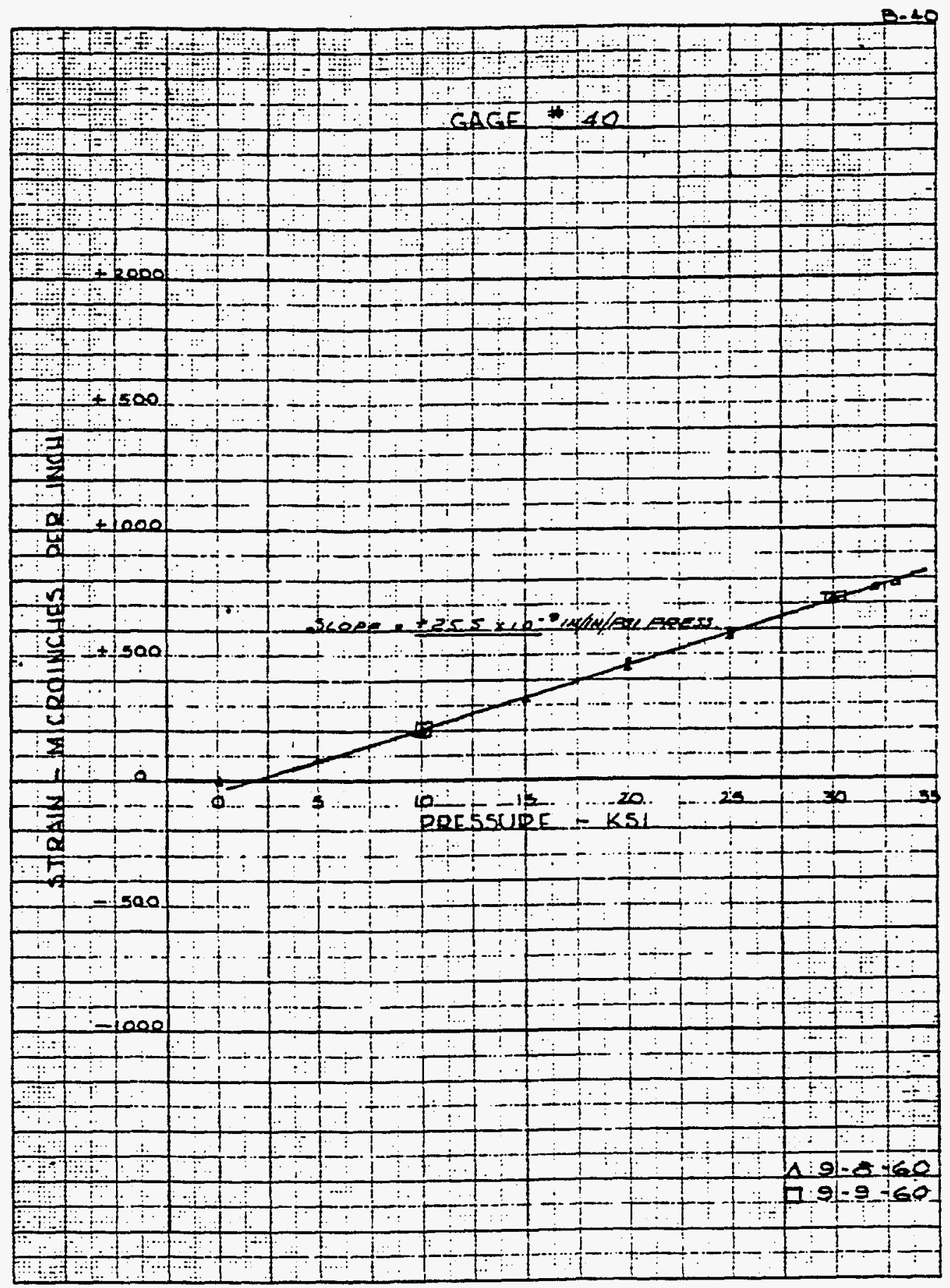

Fig. D-2. Plot of strain as a function of internal pressure for gauge $\mathbf{4 0}$ located on the left outside midplane of Plate \#12. 


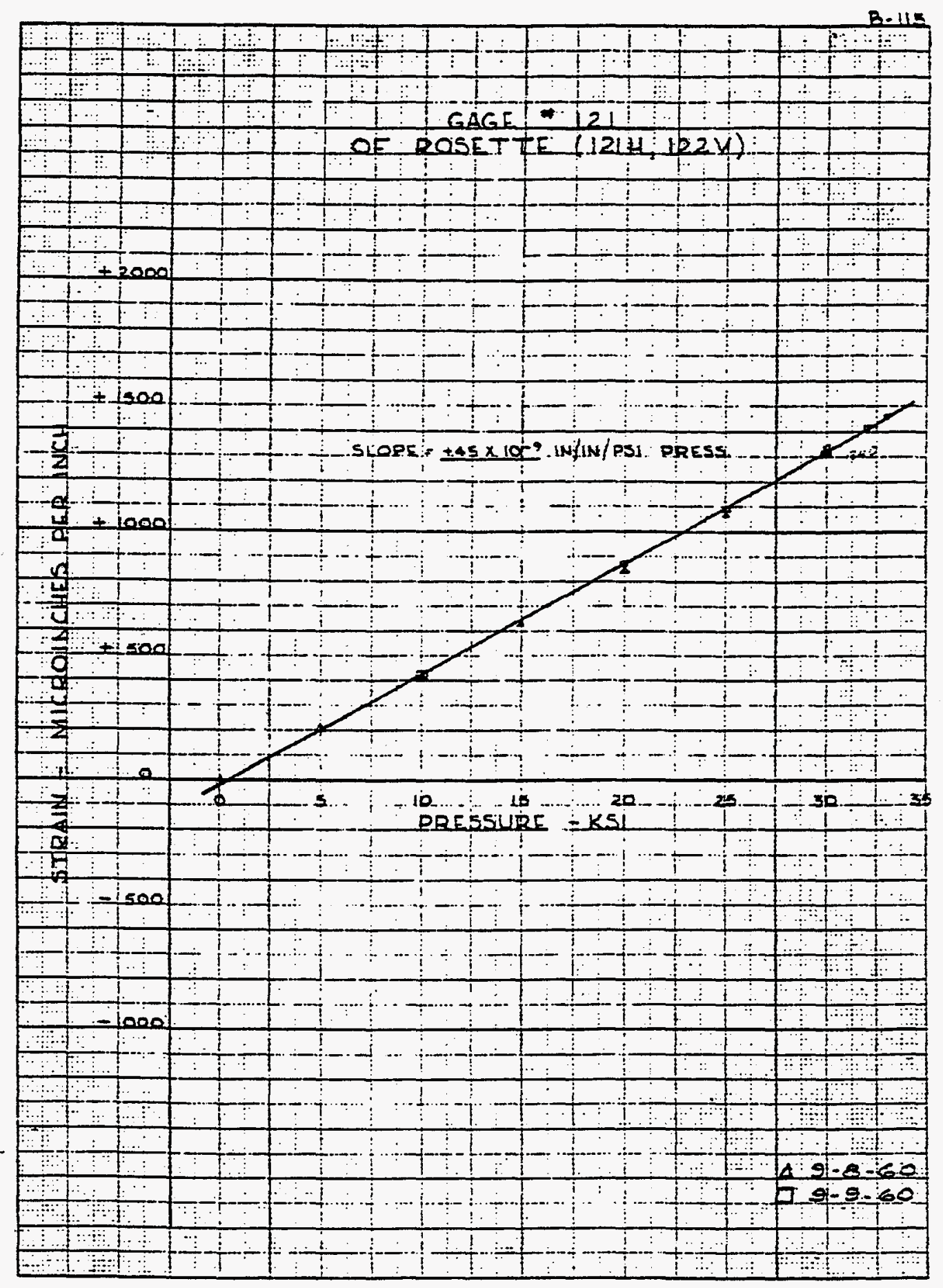

Fig. D-3. Plot of strain as a function of internal pressure for gauge 121 located on the pressure vessel at $0^{\circ}$ and $4 \mathrm{in}$. from the top of the vessel. 


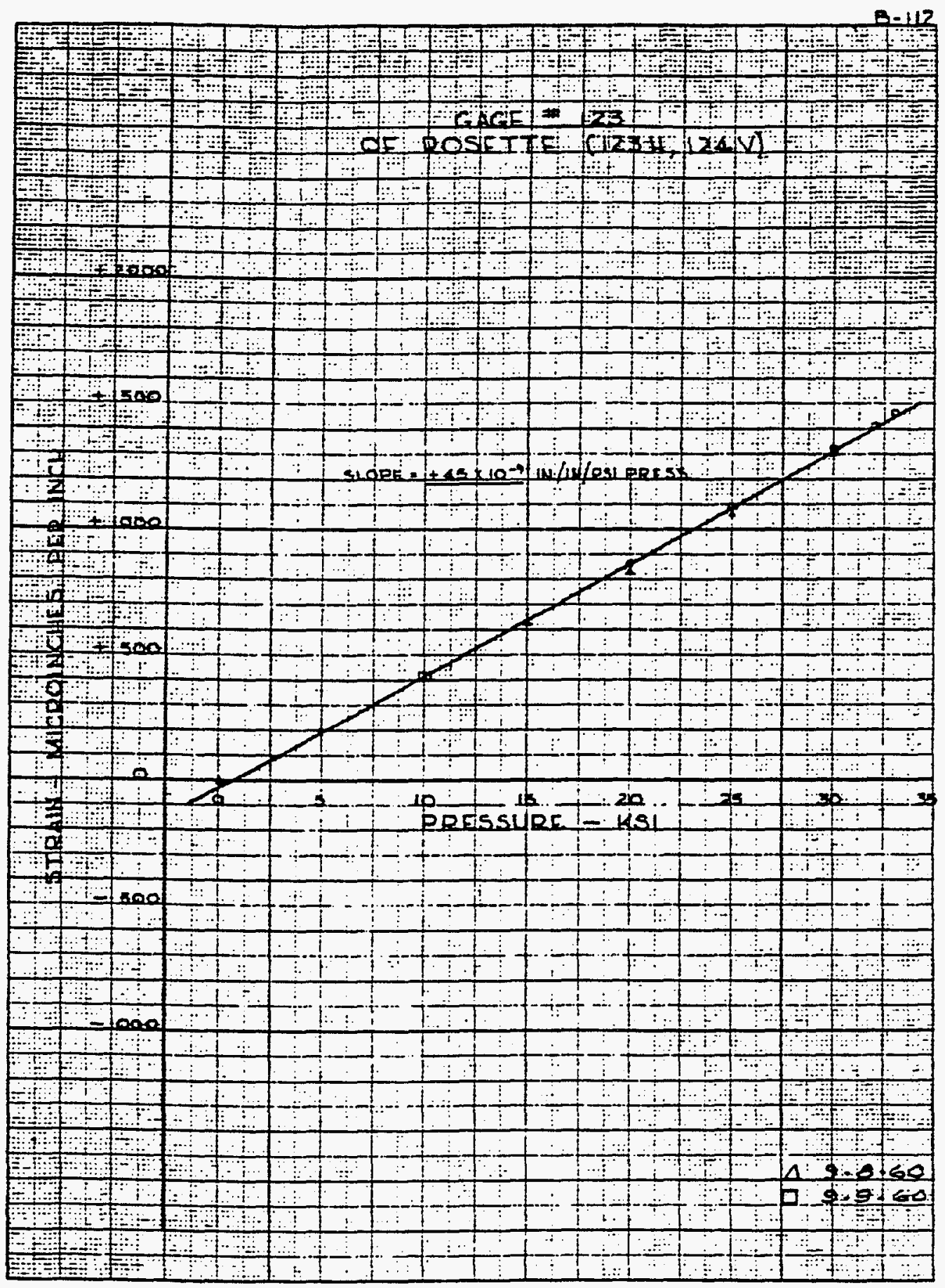

Fig. D-4. Plot of strain as a function of internal pressure for gauge 123 located on the pressure vessel at $180^{\circ}$ and 4 in. from the top of the vessel. 


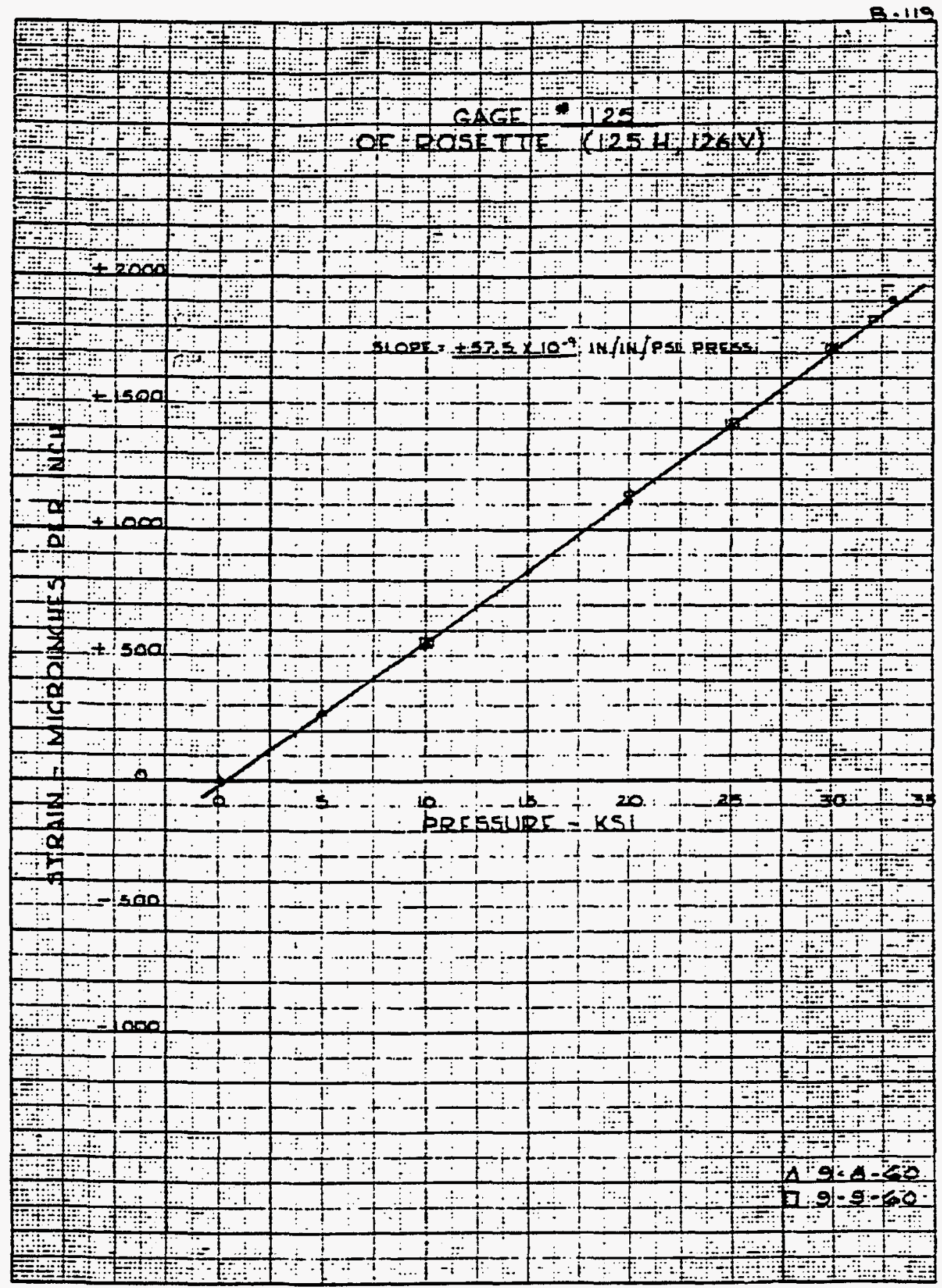

Fig. D-5. Plot of strain as a function of internal pressure for gauge 125 located on the pressure vessel at $0^{\circ}$ and 22 in. from the top of the vessel. 


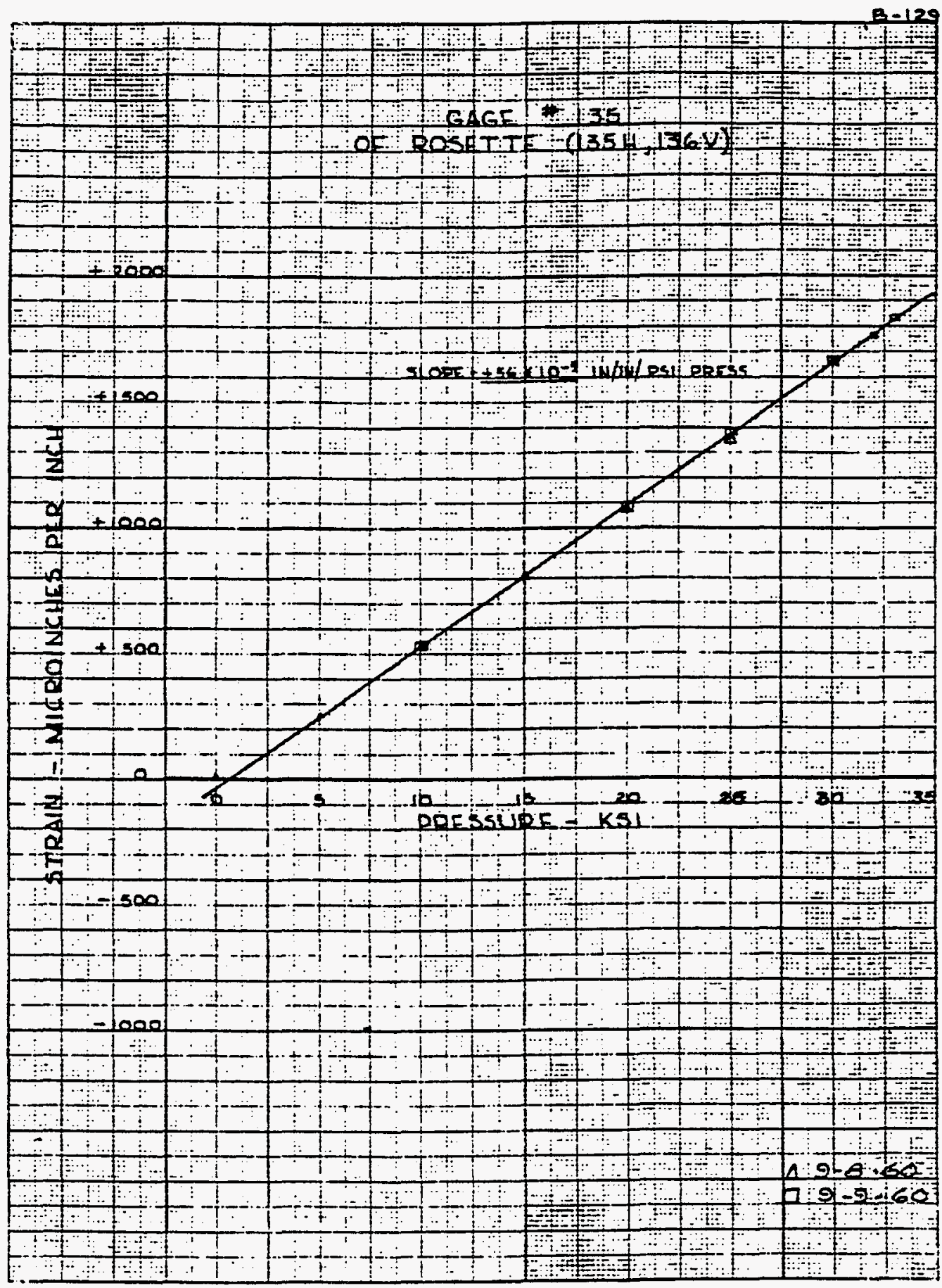

Fig. D-6. Plot of strain as a function of internal pressure for gauge 135 located on the pressure vessel at $180^{\circ}$ and $26 \mathrm{in}$. from the bottom of the vessel. 


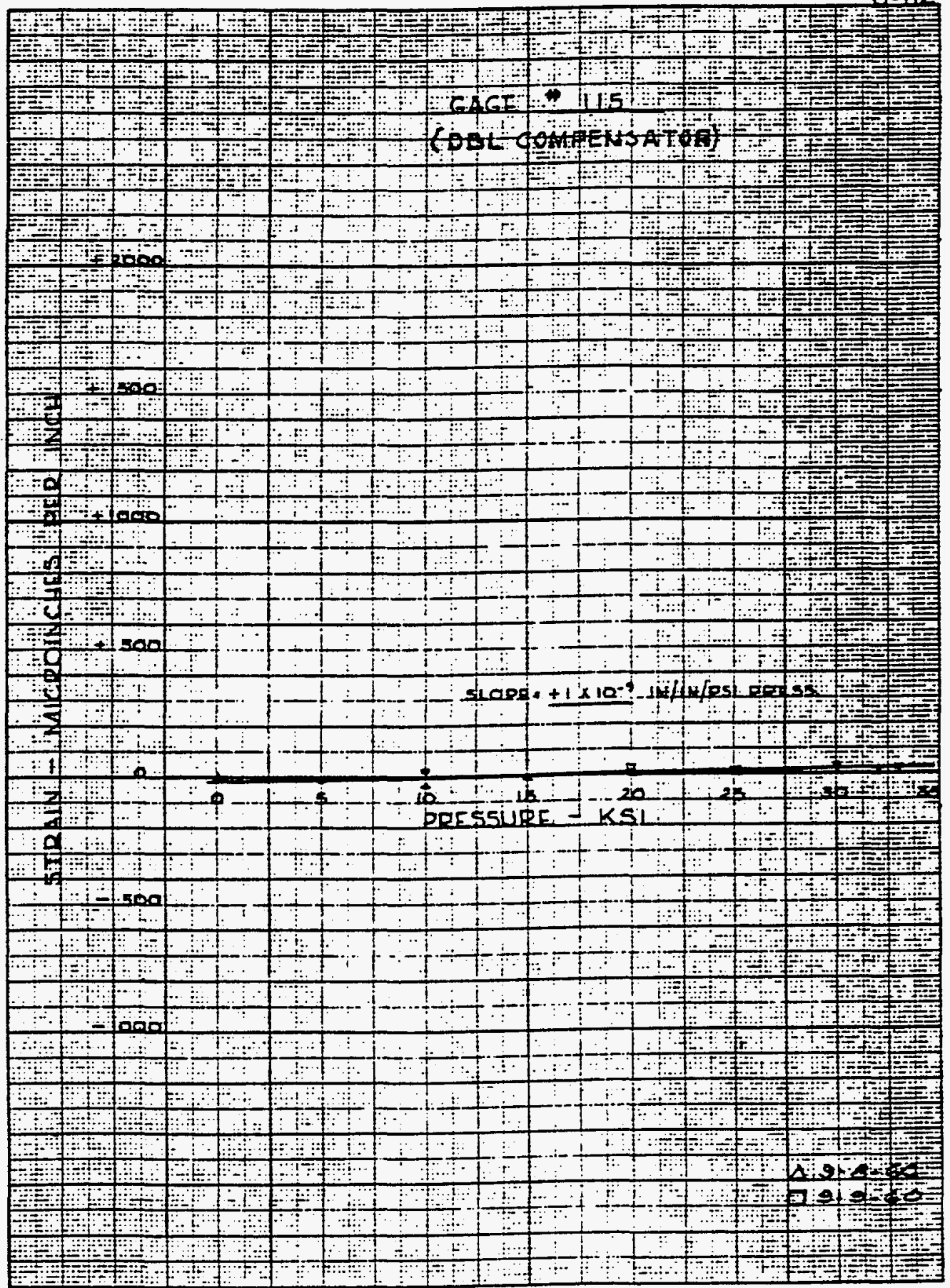

Fig. D-7. Plot of strain as a function of internal pressure for compensator gauge 115. 


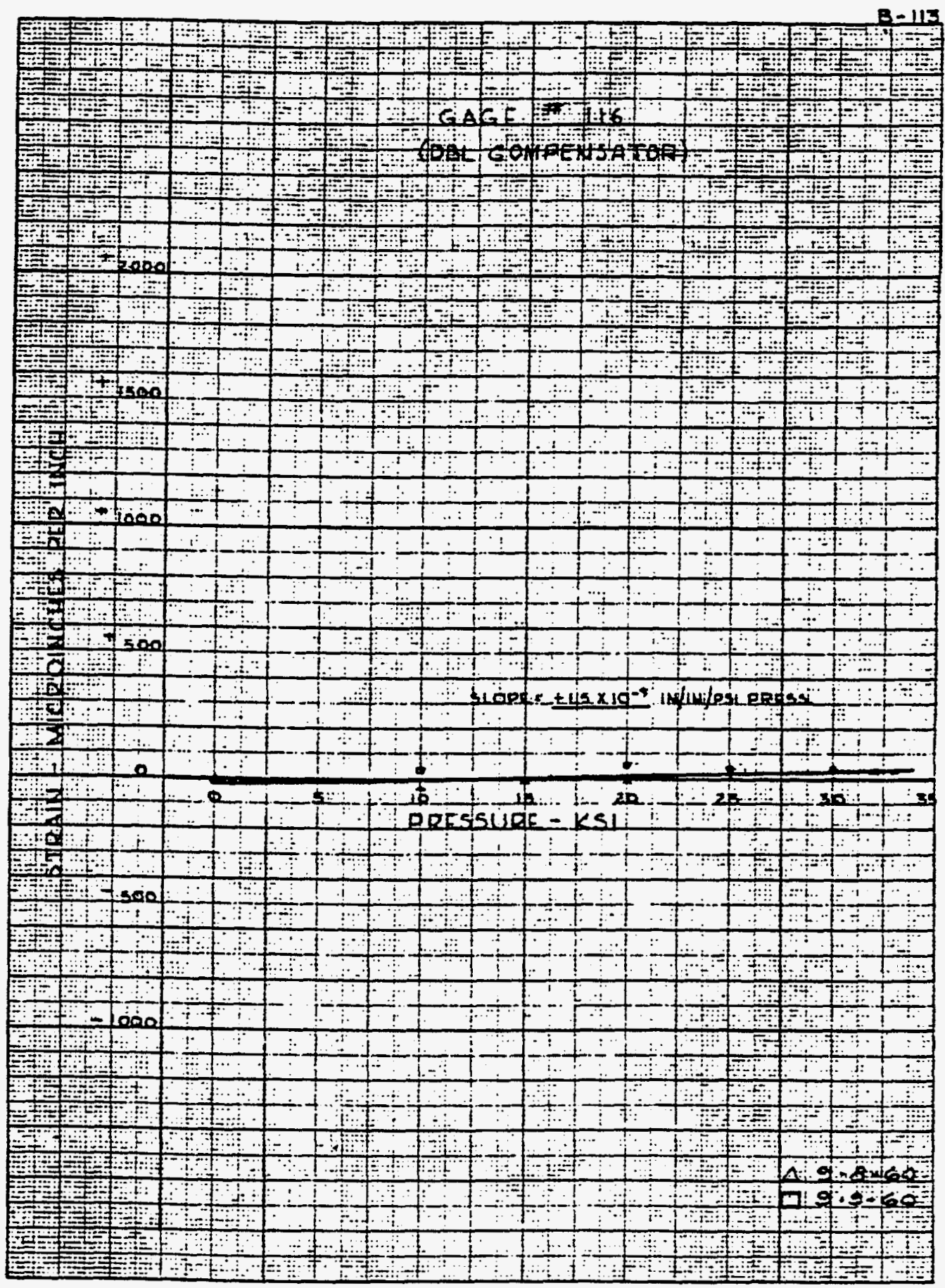

Fig. D-8. Plot of strain as a function of internal pressure for compensator gauge 116. 


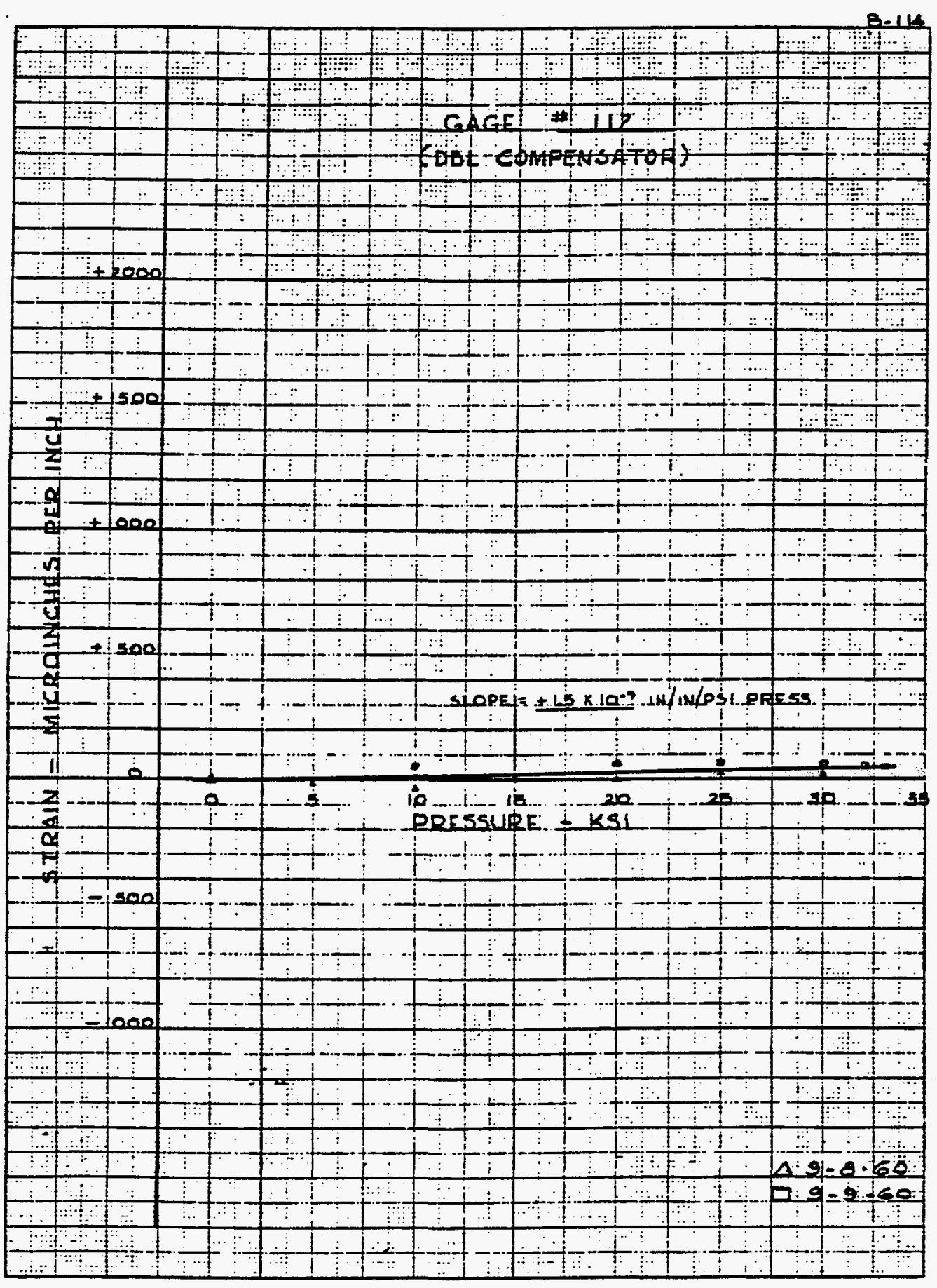

Fig. D-9. Plot of strain as a function of internal pressure for compensator gauge 117. 

Distribution

1-2. R. E. Adamski (2)

3. J. R. Brewster

4. T. R. Butz

5. G. R. Childress

6. C. K. Chung

7. B. G. Davis

8. R. E. Fenstermaker

9-10. J. L. Frazier (2)

11. R. B. Jones III

12-16. J. A. Horak (5)

17-18. D. C. Howard (2)

19-20. D. K. Kelley (2)

21. D. J. Merkel

22. M. K. Morrow

23. W. A. Muenzer

24. B. J. Owens

25. J. P. Stanley

26. Quality Division, Records

27-29. Y-12 Central Files (3) 